\title{
Impact of Backbone Tether Length and Structure on the Electro-chemical Performance of Viologen Redox Active Polymers
}

Mark Burgess, ${ }^{\dagger,+}$, Etienne Chenard, $^{\dagger,+, \diamond}$ Kenneth Hernández-Burgos, ${ }^{\dagger,+, \diamond}$ Gavvalapalli Nagarjuna, ${ }^{\dagger, \dagger}$ Rajeev S. Assary, ${ }^{\text {o, }}{ }^{\dagger}$ Jingshu Hui, ${ }^{\dagger, \varphi}$ Jeffrey S. Moore, ${ }^{\dagger,+, \ll, *}$ and Joaquín Rodríguez-López ${ }^{\dagger, \ddagger}, *$

$\dagger$ Joint Center for Energy Storage Research

$\$$ Department of Chemistry, University of Illinois at Urbana-Champaign, 600 South Mathews Avenue, Urbana, IL 61801

$\varphi$ Department of Materials Science and Engineering, University of Illinois at Urbana-Champaign, $1304 \mathrm{~W}$ Green St, Urbana, IL 61801

${ }^{\circ}$ Argonne National Laboratory, Materials Science Division, Argonne, IL 60439

«Beckman Institute for Advanced Science and Technology, University of Illinois at Urbana-Champaign

\section{Supporting Information}




\section{Table of contents}

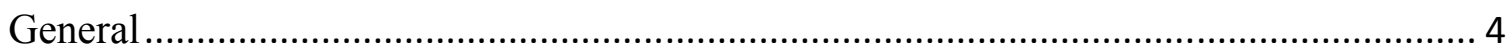

$N$-Ethyl-4,4'-bipyridinium (MonoEtVPF6) ............................................................. 5

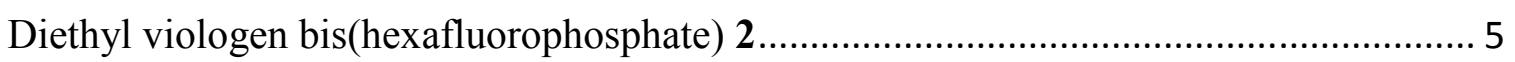

General protocol for the preparation of tethered viologens ........................................ 6

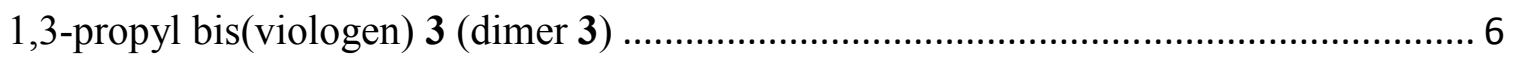

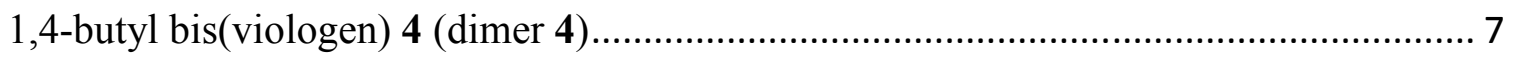

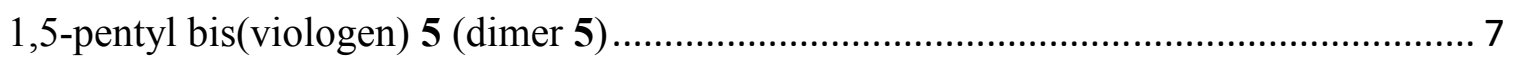

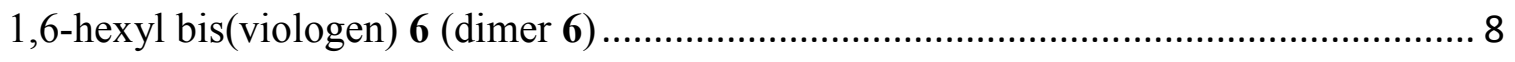

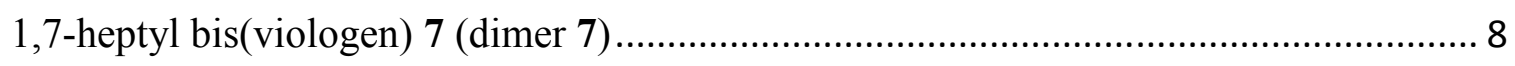

ortho-xylyl bis(viologen) tetra(hexafluorophoshate) 8 (o-Benzene dimer 8).................. 9

meta-xylyl bis(viologen) tetra(hexafluorophoshate) 9 ( $m$-Benzene dimer 9)................. 10

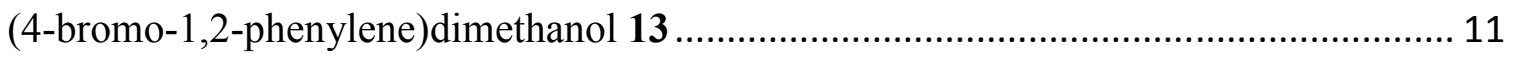

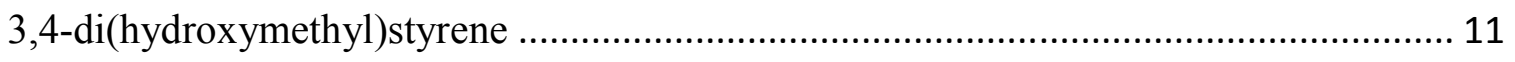

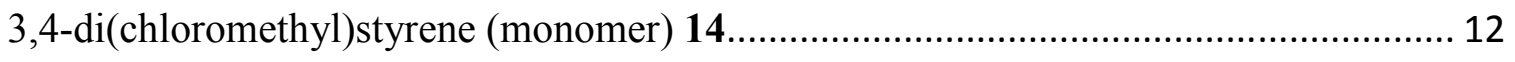

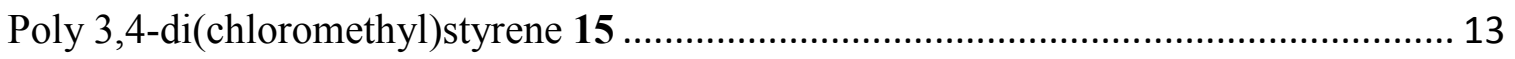

Poly 3,4-di(methylene(1-ethylviologen)styrene tetra hexafluorophosphate $\mathbf{1 0}$ (o-Benzene

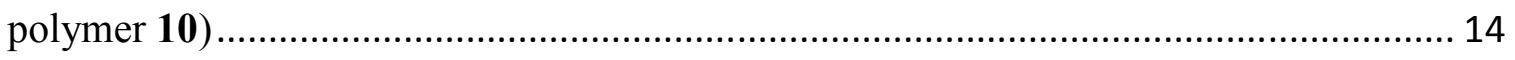

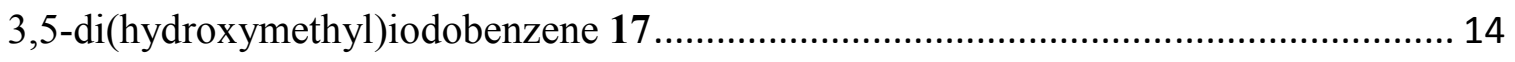

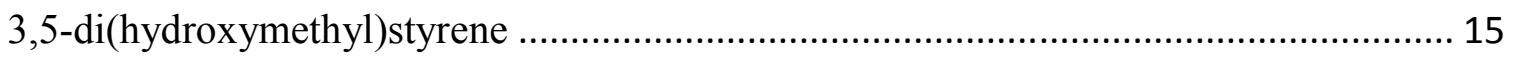

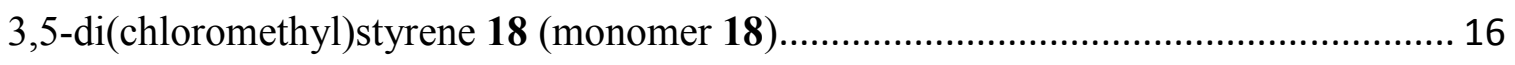

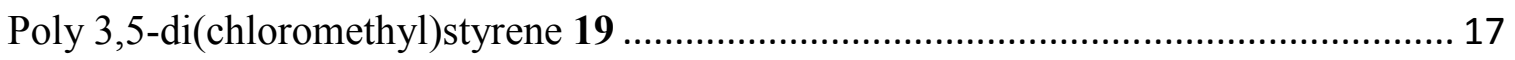

Poly 3,5-di(methylene(1-ethylviologen)styrene tetra hexafluorophosphate 11 ( $m$-Benzene

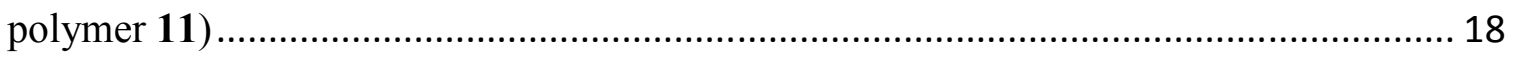

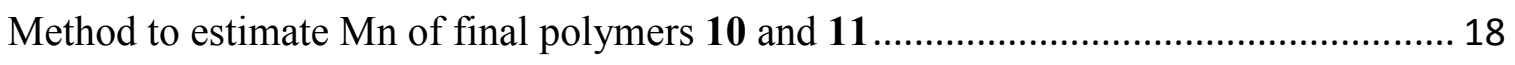

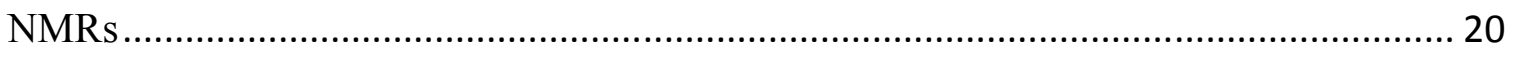

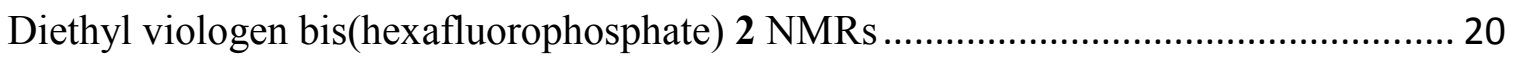

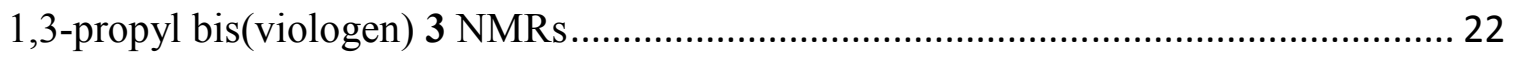

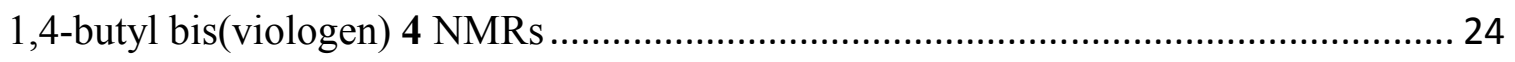




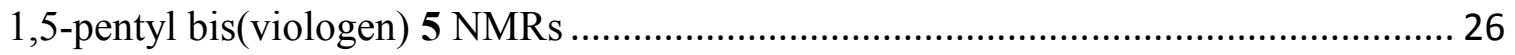

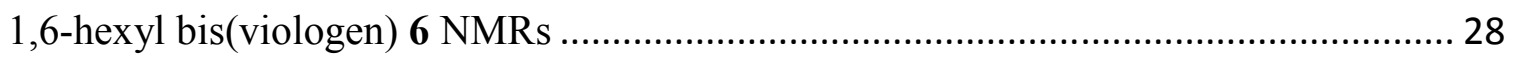

1,7-heptyl bis(viologen) 7 NMRs .......................................................................... 30

ortho-xylyl bis(viologen) tetra(hexafluorophoshate) 8 NMRs ........................................ 32

meta-xylyl bis(viologen) tetra(hexafluorophoshate)9 NMRs ........................................... 34

Poly 3,4-di[(1-ethylviologen)methyl] styrene tetra hexafluorophosphate 10 NMRs ........ 36

Poly 3,5-di[(1-ethylviologen)methyl]styrene tetra hexafluorophosphate 11 NMRs ........ 38

3,4-di(chloromethyl)styrene 14 (monomer) NMRs ......................................................... 40

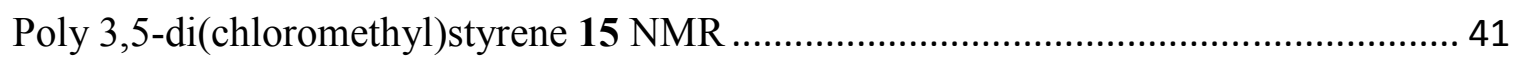

3,5-di(chloromethyl)styrene 18 (monomer) NMRs ....................................................... 42

Poly 3,5-di(chloromethyl)styrene 19 NMR …………................................................ 43

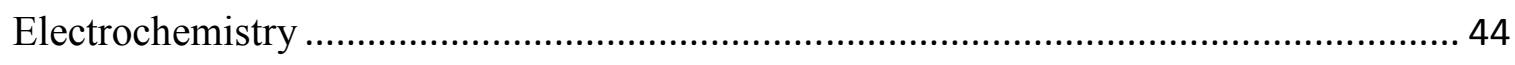

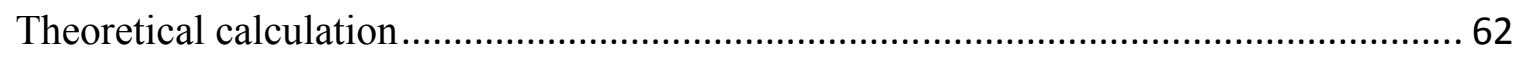

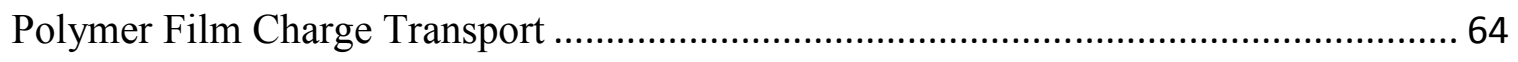

Nanoelectrode Voltammetry for Charge Tranfer Kinetics Determination ........................ 64 


\section{General}

5-bromophtalide was purchased from Alfa Aeser. Halide alkyl, 1,2-Bis(bromomethyl)benzene , 1,3-Bis(bromomethyl)benzene, $\mathrm{PPh}_{3}, \mathrm{PdCl}_{2}$, and ethyl 2-(phenylcarbonothioylthio)-2-

phenylacetate (CIA) were purchased from Aldrich. Potassium vinyltrifluoroborate and $\mathrm{Cs}_{2} \mathrm{CO}_{3}$ were purchased from AK Scientific. AIBN was recrystallized.

Unless otherwise noted, all manipulations were conducted under a nitrogen atmosphere in the absence of oxygen and water. Dry dichloromethane $\left(\mathrm{CH}_{2} \mathrm{Cl}_{2}\right)$ and dimethylformamide (DMF) were obtained from SDS. Visualization of the TLC was performed by ultraviolet light $254 \mathrm{~nm}$, by staining with potassium permanganate solution as developing agents. Flash columns chromatographies were performed using Isolera ${ }^{\mathrm{TM}}$ Prime, from Biotage ${ }^{\circledR}$. FTIR spectra were acquired on a Nicolet Nexus 670 FT-IR spectrometer and are reported in reciprocal centimeters $\left(\mathrm{cm}^{-1}\right)$. Nuclear magnetic resonance spectra $\left({ }^{1} \mathrm{H},{ }^{13} \mathrm{C},{ }^{19} \mathrm{~F}\right.$, and $\left.{ }^{31} \mathrm{P}\right)$ were recorded either on a Varian Unity 400, 500, VXR 500 and Inova 400 or 600 spectrometers. Chemical shifts for ${ }^{1} \mathrm{H}$ NMR spectra are recorded in parts per million with the solvent resonance central peak as the internal standard $\left(\mathrm{CDCl}_{3}, 7.26 \mathrm{ppm} ; \mathrm{CD}_{3} \mathrm{CN}, \delta 1.94 \mathrm{ppm}\right){ }^{1}$ Data are reported as follows: chemical shift, multiplicity $(\mathrm{s}=$ singlet, $\mathrm{d}=$ doublet, $\mathrm{t}=$ triplet, $\mathrm{q}=$ quartet, and $\mathrm{m}=$ multiplet), coupling constant in Hertz $(\mathrm{Hz})$, integration $(\mathrm{xH})$. Chemical shifts for ${ }^{13} \mathrm{C}$ NMR spectra are recorded in parts per million using the central peak of $\mathrm{CDCl}_{3}(77.16 \mathrm{ppm})$ and $\mathrm{CD}_{3} \mathrm{CN}(118.26$ ppm) as the internal standard. All ${ }^{13} \mathrm{C}$ NMR spectra were obtained with complete proton decoupling. ${ }^{31} \mathrm{P}$ NMR were calibrated with a solution of $80 \% \mathrm{H}_{3} \mathrm{PO}_{3}(\delta 0.0 \mathrm{ppm})$ in water as external standard. ${ }^{19} \mathrm{~F}$ NMR were recorded after calibration using a solution of $\mathrm{BF}_{3} \cdot \mathrm{Et}_{2} \mathrm{O}(\delta$ $-153.0 \mathrm{ppm}$ ) in $\mathrm{CDCl}_{3}$ as external standard. High resolution mass ESI spectra were performed on a Waters Synapt G2-Si and EI spectra were performed on a Waters 70-VSE, by the Mass Spectrometry Laboratory of the School of Chemical Science at UIUC. CHN analyses were performed by the Microanalysis Laboratory of the School of Chemical Science of UIUC, using Exeter Analytical CE 440 and Perkin Elmer 2440, Series II. Melting points (MP) are uncorrected. 


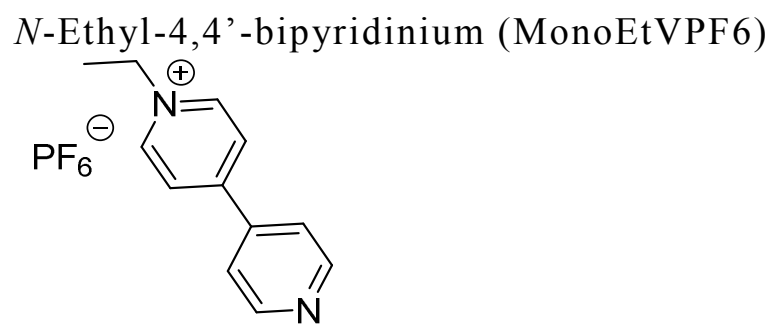

EtI (5.12 mL, 64.0, 1.00 equiv) was added to a solution of 4,4-bipyridine (10.0 g, $64.0 \mathrm{mmol}$, 1.00 equiv) in $\mathrm{CH}_{2} \mathrm{Cl}_{2}(50 \mathrm{~mL})$. As the reaction progress, an orange solid precipitated out. The mixture was stirred for $24 \mathrm{~h}$ at room temperature. An orange solid was precipitated out from the solution by adding $\mathrm{Et}_{2} \mathrm{O}$ and rinsed with a solution of $\mathrm{CH}_{2} \mathrm{Cl}_{2} / \mathrm{Et}_{2} \mathrm{O}(1: 1, \mathrm{v} / \mathrm{v})$. The solid was then dissolved in a minimal amount of $\mathrm{H}_{2} \mathrm{O}$ and $\mathrm{NH}_{4} \mathrm{PF}_{6}(53.0 \mathrm{~g}, 325 \mathrm{mmol}, 5.08$ equiv) was added portion wise. $\mathrm{As}_{\mathrm{NH}_{4}} \mathrm{PF}_{6}$ was added, a beige solid precipitated out. The resulting mixture was stirred for $24 \mathrm{~h}$. The solid was filtered out and rinsed with $\mathrm{H}_{2} \mathrm{O}, \mathrm{MeOH}$, and then $\mathrm{Et}_{2} \mathrm{O}$. The resulting solid was dried under vacuum for $24 \mathrm{~h}$ to yield $N$-Ethyl-4,4'-bipyridinium hexafluorophosphate $(6.27 \mathrm{~g}, 30 \%, 2$ steps $)$ as a beige solid. ${ }^{2}$

Diethyl viologen bis(hexafluorophosphate) 2

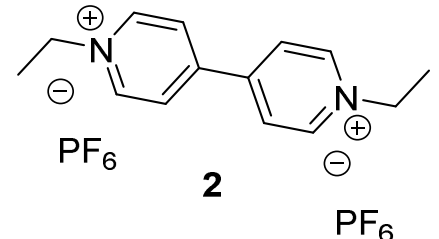

EtI (2.1 mL, 26. mmol, 3.7 equiv) was added to a solution of 4,4'-bipyridine ( $1.1 \mathrm{~g}, 7.0 \mathrm{mmol}, 1.0$ equiv) in DMF $(3 \mathrm{~mL})$. The solution was then allowed to reach $60{ }^{\circ} \mathrm{C}$ and stirred at this temperature for 3 days. As the reaction progress, an orange solid precipitated out. The solid was further precipitated with $\mathrm{Et}_{2} \mathrm{O}$, and the solid was filtered out and rinsed with a solution of $\mathrm{CH}_{2} \mathrm{Cl}_{2} / \mathrm{Et}_{2} \mathrm{O}(1: 1, \mathrm{v} / \mathrm{v})$. The solid was then dissolved in a minimal amount of $\mathrm{H}_{2} \mathrm{O}$ and $\mathrm{NH}_{4} \mathrm{PF}_{6}$ (7.0 g, 43. mmol, 6.7 equiv) was added portion wise. The resulting mixture was stirred for $24 \mathrm{~h}$. The solid was filtered out and rinsed with $\mathrm{H}_{2} \mathrm{O}, \mathrm{MeOH}$, and then $\mathrm{Et}_{2} \mathrm{O}$. The resulting solid was dried under vacuum for $24 \mathrm{~h}$ to yield diethyl viologen bis-hexafluorophosphate $2(3.4 \mathrm{~g}, 97 \%)$ as beige solid.

M.P. $274{ }^{\circ} \mathrm{C}$ (deg.)

${ }^{1}$ H NMR $\left(499 \mathrm{MHz}, \mathrm{CD}_{3} \mathrm{CN}\right) \delta 8.93(\mathrm{~d}, J=6.5 \mathrm{~Hz}, 4 \mathrm{H}), 8.40(\mathrm{~d}, J=5.4 \mathrm{~Hz}, 4 \mathrm{H}), 4.68(\mathrm{q}, J=$ $7.3 \mathrm{~Hz}, 4 \mathrm{H}), 1.65(\mathrm{t}, J=7.2 \mathrm{~Hz}, 6 \mathrm{H})$;

${ }^{13}$ C NMR (126 MHz, CD $\left.{ }_{3} \mathrm{CN}\right) \delta 150.8,146.4-145.9(\mathrm{~m}), 128.1,128.0,58.6(\mathrm{t}, J=13.6 \mathrm{~Hz})$, $16.6-16.0(\mathrm{~m})$;

${ }^{19}$ F NMR $\left(470 \mathrm{MHz}, \mathrm{CD}_{3} \mathrm{CN}\right) \delta-72.9(\mathrm{~d}, J=707.3 \mathrm{~Hz})$;

${ }^{31} \mathbf{P}$ NMR $\left(202 \mathrm{MHz}, \mathrm{CD}_{3} \mathrm{CN}\right) \delta-143.50$ (hept, $J=707.3 \mathrm{~Hz}$ );

HRMS (ESI-TOF): $m / z$ for $\mathrm{C}_{14} \mathrm{H}_{18} \mathrm{~N}_{2}{ }^{2+}$ calcd 214.1470, found 214.1469. 
General protocol for the preparation of tethered viologens:

Dihalide linker (1 equiv) was added to a solution of $N$-Ethyl-4,4'-bipyridinium hexafluorophsphate (2.1 equiv) in DMF or DMSO ([bipyridinium] $\sim 1-3 \mathrm{M}$ ). The solution was then allowed to reach $60{ }^{\circ} \mathrm{C}$ and stirred at this temperature for 3 days. As the reaction progress, a solid precipitated out. The mixture was added of $\mathrm{Et}_{2} \mathrm{O}$, and the solid was filtered out and rinsed with a solution of $\mathrm{Et}_{2} \mathrm{O}$. The solid was then dissolved in a minimal amount of $\mathrm{MeCN} / \mathrm{H}_{2} \mathrm{O}(1: 4$, $\mathrm{v} / \mathrm{v}$ ) and $\mathrm{NH}_{4} \mathrm{PF}_{6}$ (10 equiv) in a minimal amount of $\mathrm{H}_{2} \mathrm{O}$ was added portion wise. The resulting mixture was stirred for $24 \mathrm{~h}$. MeCN was removed in vacuo with a rotary evaporator and $\mathrm{H}_{2} \mathrm{O}$ was added to the mixture to further precipitate out the solid. The solid was filtered out and rinsed with $\mathrm{H}_{2} \mathrm{O}, \mathrm{MeOH}$, and then $\mathrm{Et}_{2} \mathrm{O}$. The solid was dried under vacuum for $24 \mathrm{~h}$ to yield tethered viologen as a solid.

\section{1,3-propyl bis(viologen) 3 (dimer $\mathbf{3}$ )}

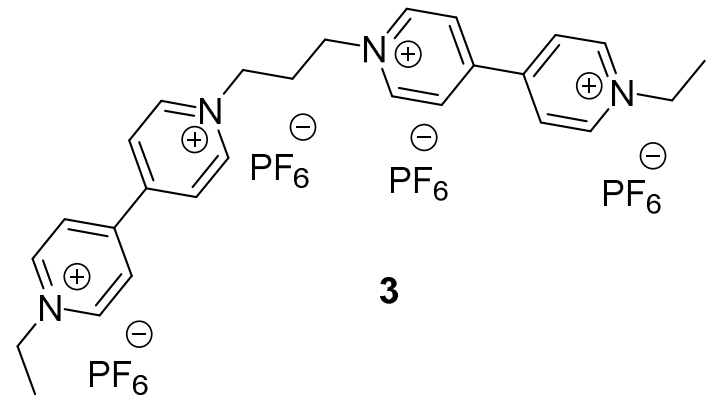

Following the general protocol, 1,3-dibromopropane ( $0.83 \mathrm{~g}, 4.1 \mathrm{mmol}, 1.0$ equiv) was reacted with $N$-Ethyl-4,4'-bipyridinium hexafluorophosphate (3.0 g, $9.1 \mathrm{mmol}, 2.2$ equiv) in DMSO (10 $\mathrm{mL}) . \mathrm{NH}_{4} \mathrm{PF}_{6}(4.0 \mathrm{~g}, 25 \mathrm{mmol}, 6.1$ equiv) was used for the anionic exchange to yield the bis(viologen) $3(0.50 \mathrm{~g}, 12 \%)$ as an off-white solid.

M.P. $259^{\circ} \mathrm{C}($ deg. $)$

${ }^{1}$ H NMR $\left(500 \mathrm{MHz}, \mathrm{CD}_{3} \mathrm{CN}\right) \delta 8.98-8.90(\mathrm{~m}, 8 \mathrm{H}), 8.49-8.38(\mathrm{~m}, 8 \mathrm{H}), 4.82-4.75(\mathrm{~m}, 4 \mathrm{H})$, $4.68(\mathrm{q}, J=7.3 \mathrm{~Hz}, 4 \mathrm{H}), 2.81-2.70(\mathrm{~m}, 2 \mathrm{H}), 1.66(\mathrm{t}, J=7.3 \mathrm{~Hz}, 6 \mathrm{H})$;

${ }^{13}$ C NMR (126 MHz, $\left.\mathrm{CD}_{3} \mathrm{CN}\right) \delta 151.5,150.6,146.7,146.4$ - 146.1 (m), 128.4, 128.1, 59.14, 58.6, 32.6, 16.4;

${ }^{19}$ F NMR $\left(470 \mathrm{MHz}, \mathrm{CD}_{3} \mathrm{CN}\right) \delta-73.0(\mathrm{~d}, J=707.2 \mathrm{~Hz})$;

${ }^{31} \mathbf{P}$ NMR $\left(202 \mathrm{MHz}, \mathrm{CD}_{3} \mathrm{CN}\right) \delta-143.6$ (hept, $J=707.2 \mathrm{~Hz}$ );

IR (neat) 3145, 3083, 2945, 2869, 1643, 1566, 1511, 1472, 1453 1394, 1355, 1223, 1181, 826 $\mathrm{cm}^{-1}$;

HRMS (ESI-TOF): $m / z$ for $\mathrm{C}_{27} \mathrm{H}_{32} \mathrm{~N}_{4} \mathrm{~F}_{18} \mathrm{P}_{3}{ }^{+}$calcd 847.1552, found 847.1535. 
1,4-butyl bis(viologen) 4 (dimer 4)

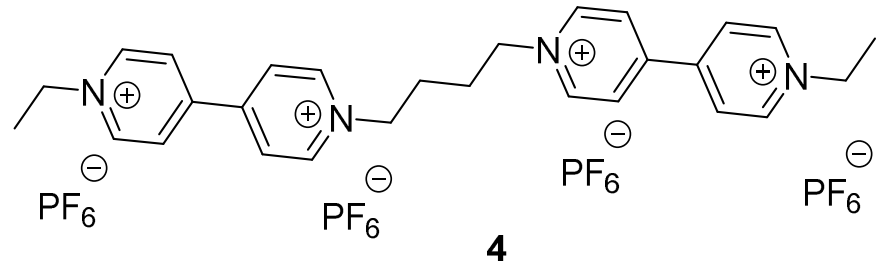

Following the general protocol, 1,4-diodobutane $(0.19 \mathrm{~mL}, 1.4 \mathrm{mmol}, 1.0$ equiv) was reacted with $N$-Ethyl-4,4'-bipyridinium hexafluorophosphate ( $1.1 \mathrm{~g}, 3.3 \mathrm{mmol}, 2.3$ equiv) in DMF (1 mL).

$\mathrm{NH}_{4} \mathrm{PF}_{6}(3.4 \mathrm{~g}, 21 \mathrm{mmol}, 15$ equiv) was used for the anionic exchange to yield the bis(viologen) 4 $(0.94 \mathrm{~g}, 67 \%)$ as a beige solid.

M.P. $304^{\circ} \mathrm{C}$ (deg.)

${ }^{1}$ H NMR $\left(499 \mathrm{MHz}, \mathrm{CD}_{3} \mathrm{CN}\right) \delta 8.93(\mathrm{~d}, J=6.7 \mathrm{~Hz}, 4 \mathrm{H}), 8.89(\mathrm{~d}, J=6.9 \mathrm{~Hz}, 4 \mathrm{H}), 8.43-8.36(\mathrm{~m}$, $8 \mathrm{H}), 4.71-4.65(\mathrm{~m}, 8 \mathrm{H}), 2.16-2.10(\mathrm{~m}, 4 \mathrm{H}), 1.65(\mathrm{t}, J=7.3 \mathrm{~Hz}, 6 \mathrm{H})$;

${ }^{13}$ C NMR (126 MHz, $\left.\mathrm{CD}_{3} \mathrm{CN}\right) \delta 151.2,150.8,146.51$ (br s), 146.30 (br s), $128.4-128.0$ (m), $62.0,58.7,28.1,16.5(\mathrm{t}, J=11.0 \mathrm{~Hz})$;

${ }^{19}$ F NMR $\left(470 \mathrm{MHz}, \mathrm{CD}_{3} \mathrm{CN}\right) \delta-72.9(\mathrm{~d}, J=707.4 \mathrm{~Hz})$;

${ }^{31}$ P NMR $\left(202 \mathrm{MHz}, \mathrm{CD}_{3} \mathrm{CN}\right) \delta-143.5$ (hept, $\left.J=707.4 \mathrm{~Hz}\right)$

IR (neat) $3149,3069,3002,2955,1643,1567,1509,1457,1393,1353,1226,1181,826 \mathrm{~cm}^{-1}$;

HRMS (ESI-TOF): $m / z$ for $\mathrm{C}_{28} \mathrm{H}_{34} \mathrm{~F}_{18} \mathrm{~N}_{4} \mathrm{P}_{3}{ }^{+}$calcd 861.1709, found 861.1688.

1,5-pentyl bis(viologen) 5 (dimer 5)

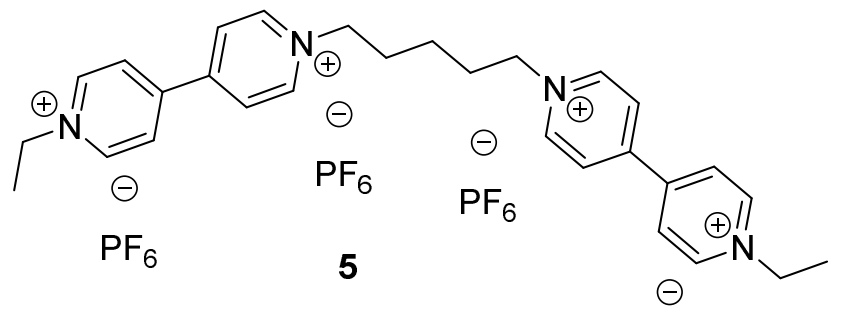

$\mathrm{PF}_{6}$

Following the general protocol, 1,5-diodopentane $(0.21 \mathrm{~mL}, 1.4 \mathrm{mmol}, 1.0$ equiv) was reacted with $N$-Ethyl-4,4'-bipyridinium hexafluorophosphate ( $1.0 \mathrm{~g}, 3.0 \mathrm{mmol}, 2.2$ equiv) in DMF (1 $\mathrm{mL}) . \mathrm{NH}_{4} \mathrm{PF}_{6}(2.4 \mathrm{~g}, 15 \mathrm{mmol}, 11$ equiv) was used for the anionic exchange to yield the bis(viologen) $5(0.92 \mathrm{~g}, 66 \%)$ as a light yellow solid.

M.P. $297^{\circ} \mathrm{C}$ (deg.)

${ }^{1}$ H NMR $\left(499 \mathrm{MHz}, \mathrm{CD}_{3} \mathrm{CN}\right) \delta 8.92(\mathrm{~d}, J=6.7 \mathrm{~Hz}, 4 \mathrm{H}), 8.90(\mathrm{~d}, J=6.9 \mathrm{~Hz}, 4 \mathrm{H}), 8.43-8.35(\mathrm{~m}$, $8 \mathrm{H}), 4.68(\mathrm{q}, J=7.3 \mathrm{~Hz}, 4 \mathrm{H}), 4.62(\mathrm{t}, J=7.6 \mathrm{~Hz}, 4 \mathrm{H}), 2.13-2.04(\mathrm{~m}, 4 \mathrm{H}), 1.66(\mathrm{t}, J=7.3 \mathrm{~Hz}$, $6 \mathrm{H}), 1.56-1.48(\mathrm{~m}, 2 \mathrm{H})$;

${ }^{13}$ C NMR $\left(126 \mathrm{MHz}, \mathrm{CD}_{3} \mathrm{CN}\right) \delta 150.9,150.7,146.5-145.9(\mathrm{~m}), 128.2-127.8(\mathrm{~m}), 62.43(\mathrm{t}, J=$ $15.4 \mathrm{~Hz}), 58.5(\mathrm{t}, J=14.5 \mathrm{~Hz}), 30.8(\mathrm{t}, J=12.6 \mathrm{~Hz}), 22.8(\mathrm{t}, J=14.2 \mathrm{~Hz}), 16.5-15.9(\mathrm{~m}) ;{ }^{19} \mathbf{F}$

NMR $\left(470 \mathrm{MHz}, \mathrm{CD}_{3} \mathrm{CN}\right) \delta-72.8(\mathrm{~d}, J=707.9 \mathrm{~Hz})$;

${ }^{31} \mathbf{P}$ NMR $\left(202 \mathrm{MHz}, \mathrm{CD}_{3} \mathrm{CN}\right) \delta-143.5$ (hept, $J=707.9 \mathrm{~Hz}$ );

IR (neat) 3141, 3081, 2996, 2947, 1644, 1569, 1512, 1451, 1391, 1353, 1224, 1185, 1173, 822 $\mathrm{cm}^{-1}$;

HRMS (ESI-TOF): $m / z$ for $\mathrm{C}_{29} \mathrm{H}_{36} \mathrm{~F}_{18} \mathrm{~N}_{4} \mathrm{P}_{3}{ }^{+}$calcd 875.1865, found 875.1837. 
<smiles>CC[n+]1ccc(-c2cc[n+](CCCCCC[n+]3ccc(-c4cc[n+](CC)cc4)cc3)cc2)cc1</smiles>

$\mathrm{PF}_{6}$

Following the general protocol, 1,6-diodohexane $(0.24 \mathrm{~mL}, 1.4 \mathrm{mmol}, 1.0$ equiv) was reacted with $N$-Ethyl-4,4'-bipyridinium hexafluorophosphate (1.0 g, $3.0 \mathrm{mmol}, 2.2$ equiv) in DMF (2 $\mathrm{mL}) . \mathrm{NH}_{4} \mathrm{PF}_{6}(3.4 \mathrm{~g}, 21 \mathrm{mmol}, 15$ equiv) was used for the anionic exchange to yield the bis(viologen) $6(1.0 \mathrm{~g}, 71 \%)$ as a beige solid.

M.P. $240^{\circ} \mathrm{C}$ (deg.)

${ }^{1}$ H NMR $\left(499 \mathrm{MHz}, \mathrm{CD}_{3} \mathrm{CN}\right) \delta 9.15-8.73(\mathrm{~m}, 8 \mathrm{H}), 8.39(\mathrm{~d}, J=5.9 \mathrm{~Hz}, 8 \mathrm{H}), 4.68(\mathrm{q}, J=7.2 \mathrm{~Hz}$, $4 \mathrm{H}), 4.61(\mathrm{t}, J=7.6 \mathrm{~Hz}, 4 \mathrm{H}), 2.11-1.97(\mathrm{~m}, 4 \mathrm{H}), 1.66(\mathrm{t}, J=7.4 \mathrm{~Hz}, 6 \mathrm{H}), 1.54-1.42(\mathrm{~m}, 4 \mathrm{H})$;

${ }^{13}$ C NMR $\left(126 \mathrm{MHz}, \mathrm{CD}_{3} \mathrm{CN}\right) \delta 150.8,150.7,146.7-145.8(\mathrm{~m}), 128.00,127.96,62.7,58.5$, $31.3,25.6,16.4$;

${ }^{19}$ F NMR $\left(470 \mathrm{MHz}, \mathrm{CD}_{3} \mathrm{CN}\right) \delta-73.2(\mathrm{~d}, \mathrm{~J}=706.8 \mathrm{~Hz})$;

${ }^{31} \mathbf{P}$ NMR $\left(243 \mathrm{MHz}, \mathrm{CD}_{3} \mathrm{CN}\right) \delta-144.7$ (hept, $J=706.8 \mathrm{~Hz}$ );

IR (neat) $3142,3083,2945,2869,1643,1566,1507,1465,1394,1357,1224,1178,826 \mathrm{~cm}^{-1}$;

HRMS (ESI-TOF): $m / z$ for $\mathrm{C}_{30} \mathrm{H}_{38} \mathrm{~F}_{18} \mathrm{~N}_{4} \mathrm{P}_{3}{ }^{+}$calcd 889.2022, found 889.1995.

1,7-heptyl bis(viologen) 7 (dimer 7)

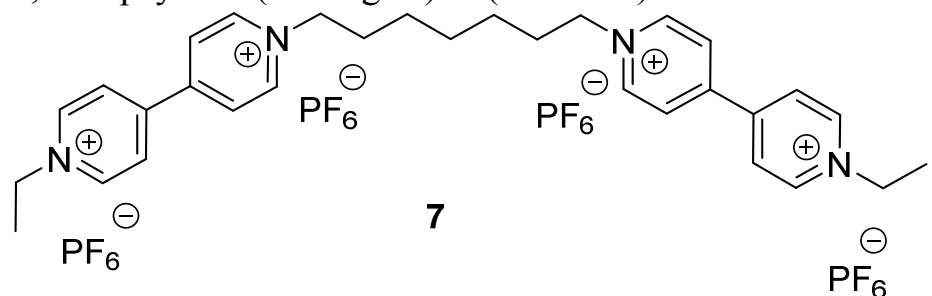

Following the general protocol, 1,7-dibromoheptane ( $2.0 \mathrm{~g}, 7.8 \mathrm{mmol}, 1.0$ equiv) was reacted with $N$-Ethyl-4,4'-bipyridinium hexafluorophosphate (6.0 g, $18 \mathrm{mmol}, 2.3$ equiv) in DMSO:DMF $(1: 1,40 \mathrm{~mL}) . \mathrm{NH}_{4} \mathrm{PF}_{6}(6.0 \mathrm{~g}, 37 \mathrm{mmol}, 4.7$ equiv) was used for the anionic exchange to yield the bis(viologen) 7 (2.6 g, 32\%) as an off-white solid.

M.P. $268^{\circ} \mathrm{C}$ (deg.)

${ }^{1}$ H NMR $\left(500 \mathrm{MHz}, \mathrm{CD}_{3} \mathrm{CN}\right) \delta 8.94-8.91(\mathrm{~m}, 4 \mathrm{H}), 8.91-8.87(\mathrm{~m}, 4 \mathrm{H}), 8.39(\mathrm{~d}, J=6.2 \mathrm{~Hz}$, $8 \mathrm{H}), 4.68(\mathrm{q}, J=7.3 \mathrm{~Hz}, 4 \mathrm{H}), 4.61(\mathrm{t}, J=7.6 \mathrm{~Hz}, 4 \mathrm{H}), 2.08-1.98(\mathrm{~m}, 4 \mathrm{H}), 1.65(\mathrm{t}, J=7.4 \mathrm{~Hz}$, $6 \mathrm{H}), 1.48-1.36(\mathrm{~m}, 6 \mathrm{H})$;

${ }^{13}$ C NMR $\left(126 \mathrm{MHz}, \mathrm{CD}_{3} \mathrm{CN}\right) \delta 150.85,150.81,146.4,146.3-146.1(\mathrm{~m}), 128.01,62.9,58.6$, 31.6, 28.8, 26.1, 16.4;

${ }^{19}$ F NMR $\left(470 \mathrm{MHz}, \mathrm{CD}_{3} \mathrm{CN}\right) \delta-73.0(\mathrm{~d}, J=707.0 \mathrm{~Hz}$;

${ }^{31} \mathbf{P}$ NMR $\left(202 \mathrm{MHz}, \mathrm{CD}_{3} \mathrm{CN}\right) \delta-143.5$ (hept, $J=707.0 \mathrm{~Hz}$ );

IR (neat) 3143, 3080, 2945, 2867, 1642, 1566, 1508, 1465, 1395, 1356, 1221, 1177, $827 \mathrm{~cm}^{-1}$;

HRMS (ESI-TOF): $m / z$ for $\mathrm{C}_{31} \mathrm{H}_{40} \mathrm{~N}_{4} \mathrm{~F}_{18} \mathrm{P}_{3}{ }^{+}$calcd 903.2178 , found 903.2156. 
ortho-xylyl bis(viologen) tetra(hexafluorophoshate) 8 (o-Benzene dimer $\mathbf{8}$ )

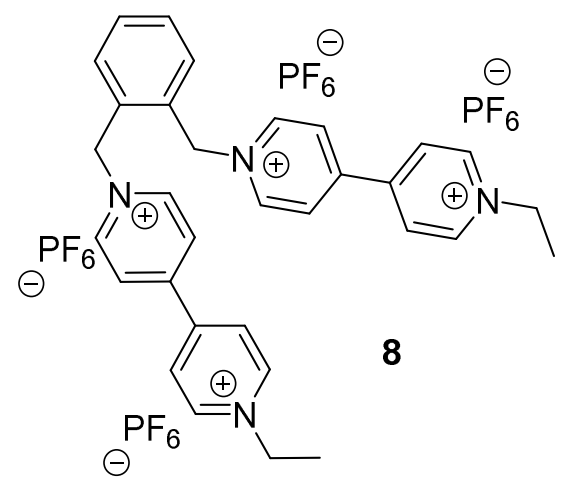

Following the general protocol, 1,2-di(bromomethyl)benzene $(0.11 \mathrm{~g}, 0.41 \mathrm{mmol}, 1.0$ equiv) was reacted with $N$-Ethyl-4,4'-bipyridinium hexafluorophosphate $(0.29 \mathrm{~g}, 0.87 \mathrm{mmol}, 2.1$ equiv $)$ in DMF (1 mL). $\mathrm{NH}_{4} \mathrm{PF}_{6}(2.8 \mathrm{~g}, 11 \mathrm{mmol}, 11$ equiv) was used for the anionic exchange to yield the expected $o$-Benzene dimer $\mathbf{8}(0.28 \mathrm{~g}, 65 \%, 2$ steps $)$ as a beige solid.

M.P. $258^{\circ} \mathrm{C}$ (deg.)

${ }^{1}$ H NMR $\left(400 \mathrm{MHz}, \mathrm{CD}_{3} \mathrm{CN}\right) \delta 8.94(\mathrm{~d}, J=6.4 \mathrm{~Hz}, 4 \mathrm{H}), 8.89(\mathrm{~d}, J=6.9 \mathrm{~Hz}, 4 \mathrm{H}), 8.47-8.43(\mathrm{~m}$, $4 \mathrm{H}), 8.41(\mathrm{~d}, J=6.2 \mathrm{~Hz}, 4 \mathrm{H}), 7.65-7.59(\mathrm{~m}, 2 \mathrm{H}), 7.29(\mathrm{dd}, J=5.7,3.4 \mathrm{~Hz}, 2 \mathrm{H}), 5.94(\mathrm{~s}, 4 \mathrm{H})$, $4.69(\mathrm{q}, J=7.3 \mathrm{~Hz}, 4 \mathrm{H}), 1.66(\mathrm{t}, J=7.4 \mathrm{~Hz}, 6 \mathrm{H})$;

${ }^{13} \mathrm{C}$ NMR $\left(151 \mathrm{MHz}, \mathrm{CD}_{3} \mathrm{CN}\right) \delta 151.9,150.6,146.8,146.3(\mathrm{t}, J=8.8 \mathrm{~Hz}), 132.16,132.15,131.6$, 128.6, 128.2, 62.1, 58.7, 16.5;

${ }^{19} \mathrm{~F}$ NMR $\left(376 \mathrm{MHz}, \mathrm{CD}_{3} \mathrm{CN}\right) \delta-73.0(\mathrm{~d}, \mathrm{~J}=707.2 \mathrm{~Hz})$;

${ }^{31} \mathrm{P}$ NMR $\left(202 \mathrm{MHz}, \mathrm{CD}_{3} \mathrm{CN}\right) \delta-143.5$ (hept, $\mathrm{J}=707.2 \mathrm{~Hz}$ );

IR (neat) 3142, 3083, 2996, 1643, 1569, 1559, 1510, 1455, 1357, 1223, 1200, 1180, $826 \mathrm{~cm}^{-1}$;

HRMS (ESI-TOF): $m / z$ for $\mathrm{C}_{32} \mathrm{H}_{34} \mathrm{~F}_{18} \mathrm{~N}_{4} \mathrm{P}_{3}$ calcd 909.1709 , found 909.1695 . 
meta-xylyl bis(viologen) tetra(hexafluorophoshate) 9 ( $m$-Benzene dimer 9$)$<smiles></smiles>

Following the general protocol, 1,3-Bis(bromomethyl)benzene ( $0.51 \mathrm{~mL}, 1.9 \mathrm{mmol}, 1.0$ equiv) was reacted with $N$-Ethyl-4,4'-bipyridinium hexafluorophosphate (1.3 g, $3.9 \mathrm{mmol}, 2.1$ equiv) in DMF (5 mL). $\mathrm{NH}_{4} \mathrm{PF}_{6}(2.8 \mathrm{~g}, 11 \mathrm{mmol}, 5.8$ equiv) was used for the anionic exchange to yield the expected $m$-Benzene dimer 9 ( $0.54 \mathrm{~g}, 27 \%, 2$ steps $)$ as a beige solid.

M.P. $269^{\circ} \mathrm{C}($ deg. $)$

${ }^{1}$ H NMR $\left(400 \mathrm{MHz}, \mathrm{CD}_{3} \mathrm{CN}\right) \delta 8.97-8.89(\mathrm{~m}, 8 \mathrm{H}), 8.43-8.34(\mathrm{~m}, 8 \mathrm{H}), 7.66-7.54(\mathrm{~m}, 4 \mathrm{H})$, $5.83(\mathrm{~s}, 4 \mathrm{H}), 4.68(\mathrm{q}, J=7.4 \mathrm{~Hz}, 4 \mathrm{H}), 1.65(\mathrm{t}, J=7.4 \mathrm{~Hz}, 6 \mathrm{H})$;

${ }^{13}$ C NMR $\left(151 \mathrm{MHz}, \mathrm{CD}_{3} \mathrm{CN}\right) \delta 151.5,150.7,146.6,146.3(\mathrm{t}, J=8.5 \mathrm{~Hz}), 134.7,131.74,131.70$, 131.5, 65.0, 58.7, 16.5;

${ }^{19}$ F NMR $\left(470 \mathrm{MHz}, \mathrm{CD}_{3} \mathrm{CN}\right) \delta-73.1(\mathrm{~d}, J=706.9 \mathrm{~Hz})$;

${ }^{31} \mathbf{P}$ NMR $\left(202 \mathrm{MHz}, \mathrm{CD}_{3} \mathrm{CN}\right) \delta-143.5$ (hept, $\left.J=706.9 \mathrm{~Hz}\right)$;

IR (neat) 3144, 3082, 2996, 2950, 1643, 1569, 1560, 1509, 1456, 1357, 1223, 1201, 1180, 823 $\mathrm{cm}^{-1}$;

HRMS (ESI-TOF): $m / z$ for $\mathrm{C}_{32} \mathrm{H}_{34} \mathrm{~F}_{18} \mathrm{~N}_{4} \mathrm{P}_{3}$ calcd 909.1709 , found 909.1690 . 
<smiles>O=C1OCc2cc(Br)ccc21</smiles>

12

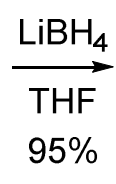

$5 \%$<smiles>OCc1ccc(Br)cc1CO</smiles>

13

A solution $2 \mathrm{M}$ solution of $\mathrm{LiBH}_{4}$ in THF ( $24 \mathrm{~mL}, 48 \mathrm{mmol}, 1.0$ equiv) was slowly added to a solution of 5-bromophtalide (10. g, $47 \mathrm{mmol}, 1.0$ equiv) in $\mathrm{THF}(0.15 \mathrm{~L})$, at $0{ }^{\circ} \mathrm{C}$. $\mathrm{MeOH}(0.30$ $\mathrm{mL}$ ) was added and the reaction was allowed to reach room temperature. The reaction was stirred $24 \mathrm{~h}$, even if TLC showed full conversion of starting material after 30 minutes. The solution was cooled to $0{ }^{\circ} \mathrm{C}$, and $\mathrm{MeOH}$ was slowly added until $\mathrm{H}_{2}$ evolution ceased. Water was then slowly added, followed by a $10 \% \mathrm{HCl}$ aqueous solution. Organic were removed under vacuo and aqueous was extracted with EtOAc. Aqueous layer were separated and extracted again with EtOAc. Organic were combined, dried over $\mathrm{Na}_{2} \mathrm{SO}_{4}$, and concentrated. The resulting residue was purified via flash chromatography $\left(80 \mathrm{~g}, \mathrm{SiO}_{2}, 2: 3 \mathrm{EtOAc}: \mathrm{Hex}\right)$ to yield the known diol 13 (9.7 g, $95 \%$ ) as a white solid. ${ }^{3}$

\section{3,4-di(hydroxymethyl)styrene}<smiles>OCc1ccc(Br)cc1CO</smiles>

13

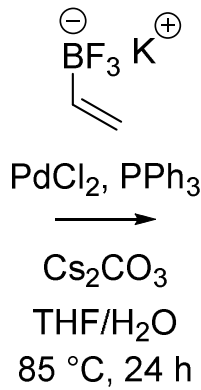
$85^{\circ} \mathrm{C}, 24 \mathrm{~h}$<smiles>C=Cc1ccc(CO)c(CO)c1</smiles>

3,4-di(hydroxymethyl)styrene

In a Schlenk flask, a mixture of diol 13 (1.0 g, $4.6 \mathrm{mmol}, 1.0$ equiv), potassium vinyltrifluoroborate ( $0.6 \mathrm{~g}, 4.5 \mathrm{mmol}, 1.0$ equiv), $\mathrm{PdCl}_{2}$ (16 mg, $0.090 \mathrm{mmol}, 0.020$ equiv), $\mathrm{PPh}_{3}$, (70. mg, 0.27 mmol, 0.060 equiv), $\mathrm{Cs}_{2} \mathrm{CO}_{3}$ (bis3.9 g, $12 \mathrm{mmol}, 2.7$ equiv), and THF: $\mathrm{H}_{2} \mathrm{O}$ solution ( $10 \mathrm{~mL}, 9: 1$ ) was degassed by freeze-pump thaw (3 cycles). The mixture was then stirred at 85 ${ }^{\circ} \mathrm{C}$ for $24 \mathrm{~h}$. Reaction mixture was cooled to room temperature, added of $\mathrm{H}_{2} \mathrm{O}$, and extracted with EtOAc. Aqueous layer was separated and extracted again with EtOAc. Organic were combined, dried over $\mathrm{Na}_{2} \mathrm{SO}_{4}$, and concentrated. Crude NMR confirmed the formation of the desired product. The residue was The resulting residue was purified via flash chromatography ( $40 \mathrm{~g}$, $\mathrm{SiO}_{2}, 1: 4$ to 3:7 EtOAc:Hex) to yield the corresponding unstable 3,4-di(hydroxymethyl)styrene, which was used in the next step immediately after isolation. 
<smiles>C=Cc1ccc(CO)c(CO)c1</smiles>

$\mathrm{PPh}_{3}$ (3.1 g, $12 \mathrm{mmol}, 2.7$ equiv) was slowly added to a vigorously stirred solution of NCS (1.5 g, $11 \mathrm{mmol}, 2.4$ equiv) at $0{ }^{\circ} \mathrm{C}$. Upon addition of $\mathrm{PPh}_{3}$, a precipitate was formed. The mixture was allowed to reach room temperature, and stirred for 30 minutes. A solution of the aforementioned 3,4-di(hydroxymethyl)styrene (theoretically $4.5 \mathrm{mmol}, 1.0$ equiv) was added to the freshly prepared phosphonium chloride mixture and stirred overnight at room temperature (monitored by TLC). Overtime, mixture turned to solution. Water was slowly added to the mixture and THF was removed under vacuo. Aqueous was extracted with EtOAc. Aqueous was separated and extracted again with EtOAc. Organic were combined, dried over $\mathrm{Na}_{2} \mathrm{SO}_{4}$, filtered and concentrated. The residue was purified via flash chromatography $\left(40 \mathrm{~g} \mathrm{SiO}_{2}\right.$, Hex $)$ to afford 3,4di(chloromethyl)styrene 14 ( $0.65 \mathrm{~g}, 72 \%$ over 2 steps) as a clear oil. The pure oil was immediately hidden from light and stored in the freezer.

${ }^{1}$ H NMR $\left(400 \mathrm{MHz}, \mathrm{CDCl}_{3}\right) \delta 7.43(\mathrm{~d}, J=1.7 \mathrm{~Hz}, 1 \mathrm{H}), 7.38(\mathrm{dd}, J=7.9,1.7 \mathrm{~Hz}, 1 \mathrm{H}), 7.35(\mathrm{~d}, J$ $=7.9 \mathrm{~Hz}, 1 \mathrm{H}), 6.70(\mathrm{dd}, J=17.6,10.9 \mathrm{~Hz}, 1 \mathrm{H}), 5.80(\mathrm{~d}, J=17.6 \mathrm{~Hz}, 1 \mathrm{H}), 5.33(\mathrm{~d}, J=10.9 \mathrm{~Hz}$, $1 \mathrm{H}), 4.75$ (s, 2H), $4.74(\mathrm{~s}, 2 \mathrm{H})$;

${ }^{13}$ C NMR $\left(101 \mathrm{MHz}, \mathrm{CDCl}_{3}\right) \delta 139.0,136.6,135.8,135.7,131.3,128.8,127.2,115.7,43.5,43.3$; IR (neat) 3090, 3007, 2974, 1445, 1262, 989, 914, 839, 758, 717, $681 \mathrm{~cm}^{-1}$;

HRMS (EI-TOF): $m / z$ for $\mathrm{C}_{10} \mathrm{H}_{10} \mathrm{Cl}_{2}$ calcd 200.0160, found 200.0150 . 
Poly 3,4-di(chloromethyl)styrene 15<smiles>C=Cc1ccc(CCl)c(CCl)c1</smiles>

In a schlenk flask, 3,4-di(chloromethyl)styrene 14 (0.59 g, 2.9 mmol, 1.0 equiv), CIA (0.90 mg, $5.5 \mu \mathrm{mol}, 0.0020$ equiv), and AIBN $(0.90 \mathrm{mg}, 2.8 \mu \mathrm{mol}, 0.0010$ equiv) were mixed with DMF $(0.1 \mathrm{~mL})$ and degassed with 3 cycles of freeze-pump thaw. The reaction mixture was then stirred at $80{ }^{\circ} \mathrm{C}$ for $24 \mathrm{~h}$. The reaction mixture was cooled to room temperature, precipitated out in $\mathrm{MeOH}$ (rinse with a minimal amount of THF). The precipitate was dissolved in THF and precipitated out again in $\mathrm{MeOH}$. Repeat precipitation. The solid was rinsed with $\mathrm{Et}_{2} \mathrm{O}$ and dried under vacuo to yield a Poly 3,4-di(chloromethyl)styrene 15 (0.34 mg, 58\%).

${ }^{1} \mathbf{H}$ NMR $\left(499 \mathrm{MHz}, \mathrm{CDCl}_{3}\right) \delta 7.21-6.91(\mathrm{~m}, 1 \mathrm{H}), 6.74-6.15(\mathrm{~m}, 2 \mathrm{H}), 4.78-3.88(\mathrm{~m}, 4 \mathrm{H})$, $2.19-1.30(\mathrm{~m}, 3 \mathrm{H})$;

IR (neat) 3014, 2923, 2853, 1612, 1502, 1445, 1426, 1262, 1236, 1166, 1104, 896, 834;

GPC:

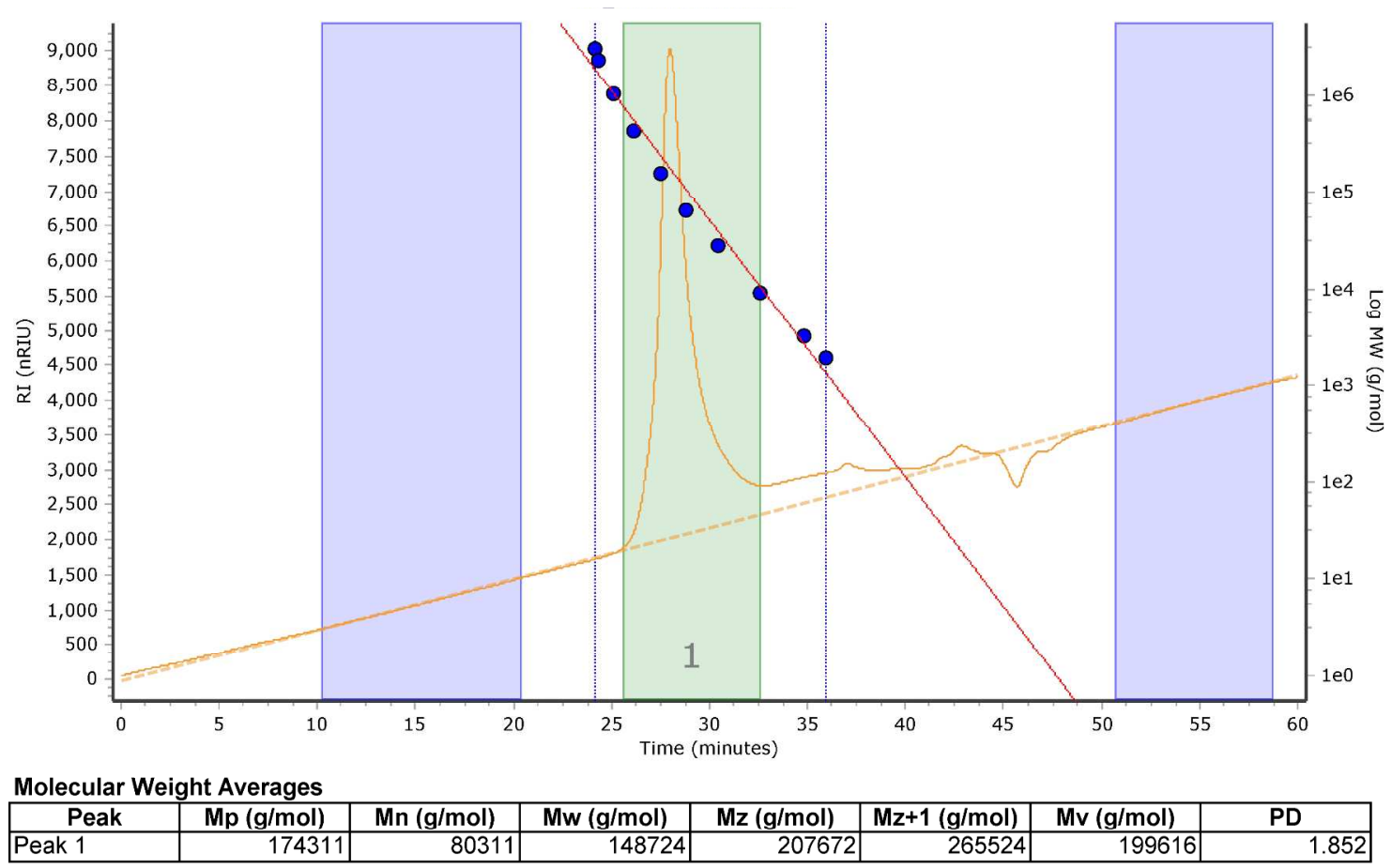


Poly 3,4-di(methylene(1-ethylviologen)styrene tetra hexafluorophosphate $\mathbf{1 0}$ (oBenzene polymer 10)

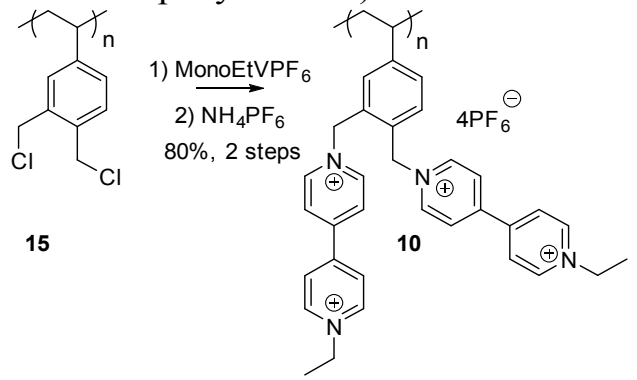

$\mathrm{N}$-Ethyl 4,4'-bipyridinium hexafluorophosphate (1.7 g, $5.1 \mathrm{mmol}, 5$.1 equiv) was added to a solution of polymer $15(0.21 \mathrm{~g}, 1.0 \mathrm{mmol}, 1.0$ equiv) in DMF $(1 \mathrm{~mL})$. The solution was heated at $60{ }^{\circ} \mathrm{C}$ for 5-6 days. The reaction solution was cooled to room temperature and polymer was precipitated out in $\mathrm{MeOH}$. The polymer was dissolved on a minimal amount of $\mathrm{MeCN}$, and precipitated out in $\mathrm{Et}_{2} \mathrm{O}$. Repeat. Polymer was dissolved in a solution of $\mathrm{MeCN}: \mathrm{H}_{2} \mathrm{O}(1: 1,20 \mathrm{~mL})$ and added of $\mathrm{NH}_{4} \mathrm{PF}_{6}(8.3 \mathrm{~g}, 51 \mathrm{mmol}, 10$ equiv). The mixture was stirred $24 \mathrm{~h}$ at room temperature. $\mathrm{MeCN}$ was removed under vacuum. Solid separated from water. The polymer was dissolved back in $\mathrm{MeCN}$ and stirred fresh distillated water was added. $\mathrm{MeCN}$ was removed under vacuo and the solid separated from water. Repeat. The solid was washed twice with $\mathrm{MeOH}$, followed by 2 cycles of dissolution/precipitation from $\mathrm{MeCN}$ and $\mathrm{Et}_{2} \mathrm{O}$. The solid was dried under vacuum to afford expected polymer $10(0.86 \mathrm{~g}, 80 \%, 2$ steps $)$, as an off-white solid.

${ }^{1} \mathbf{H}$ NMR $\left(600 \mathrm{MHz}, \mathrm{CD}_{3} \mathrm{CN}\right) \delta 9.26-8.50(\mathrm{~m}, 8 \mathrm{H}), 8.50-7.88(\mathrm{~m}, 8 \mathrm{H}), 7.81-6.35(\mathrm{~m}, 3 \mathrm{H})$, $6.32-4.99(\mathrm{~m}, 4 \mathrm{H}), 4.99-4.20(\mathrm{~m}, 4 \mathrm{H}), 1.85-0.96(\mathrm{~m}, 9 \mathrm{H})$;

${ }^{19}$ F NMR $\left(564 \mathrm{MHz}, \mathrm{CD}_{3} \mathrm{CN}\right) \delta-71.6(\mathrm{~d}, J=710.5 \mathrm{~Hz})$;

${ }^{31} \mathbf{P}$ NMR $\left(243 \mathrm{MHz}, \mathrm{CD}_{3} \mathrm{CN}\right) \delta-144.9$ (hept, $\left.J=710.5 \mathrm{~Hz}\right)$;

IR (neat) 3139, 3076, 2950, 1639, 1562, 1505, 1450, 1221, 1173, 1090, $825 \mathrm{~cm}^{-1}$;

Anal. Calcd for $\mathrm{C}_{34} \mathrm{H}_{36} \mathrm{~F}_{24} \mathrm{~N}_{4} \mathrm{P}_{4}$ : C, 37.79; H, 3.36; N, 5.19. Found: C, 37.68; H, 3.61; N, 5.06. Infrared spectral comparison of poly viologen $\mathbf{1 0}$ and polymer di(chloromethyl)styrene $\mathbf{1 5} .^{4,5}$

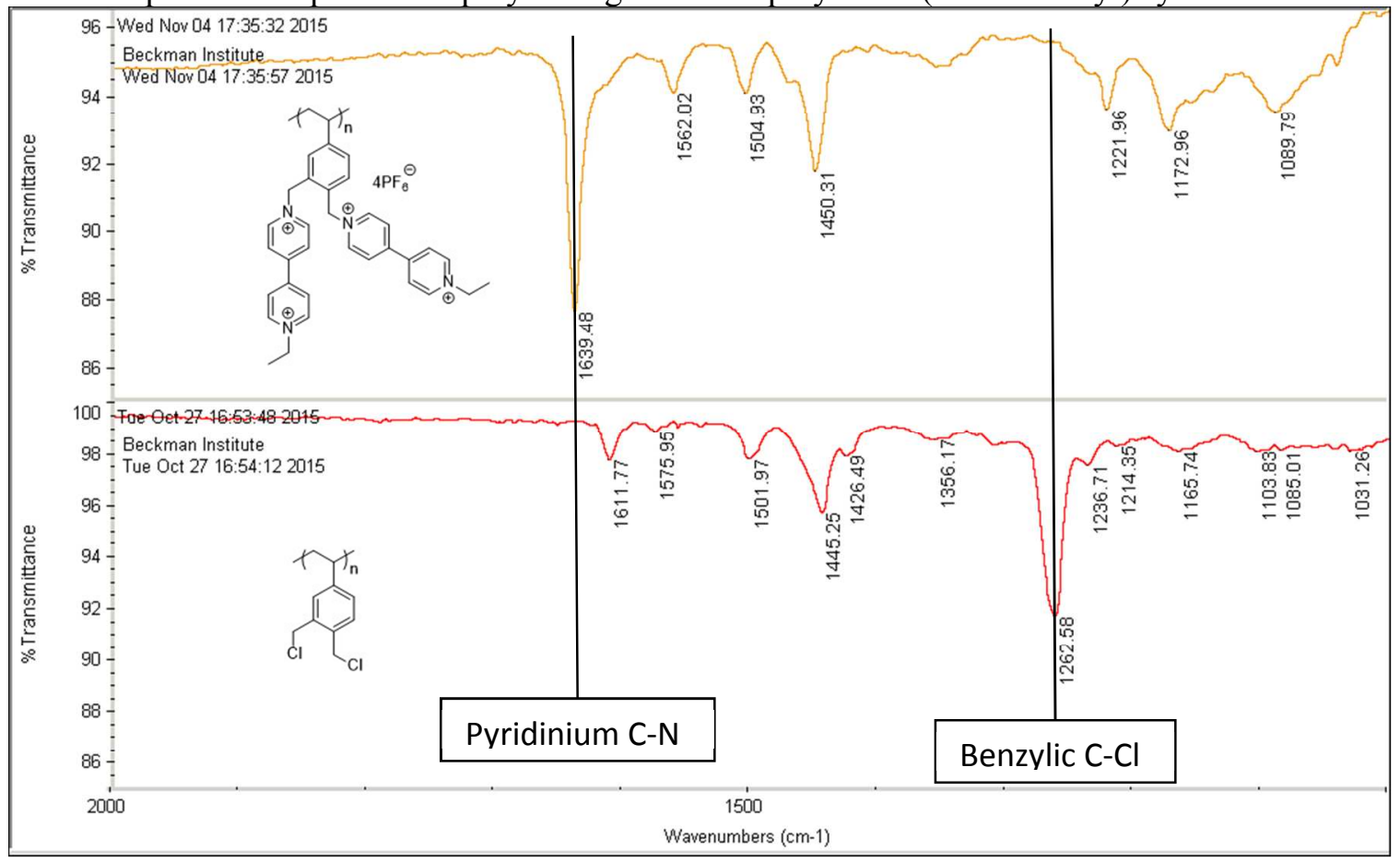

3,5-di(hydroxymethyl)iodobenzene $\mathbf{1 7}$ 
<smiles>COC(=O)c1cc(I)cc(C(=O)OC)c1</smiles>

16<smiles>OCc1cc(I)cc(CO)c1</smiles>

17

A solution $2 \mathrm{M}$ solution of $\mathrm{LiBH}_{4}$ in THF ( $3.0 \mathrm{~mL}, 6.0 \mathrm{mmol}, 1.0$ equiv) was slowly added to a solution of dimethyl 5-iodoisophtalate $16\left(1.9 \mathrm{~g}, 5.9 \mathrm{mmol}, 1.0\right.$ equiv) in THF $(20 \mathrm{~mL})$, at $0{ }^{\circ} \mathrm{C}$. $\mathrm{MeOH}(0.1 \mathrm{~mL})$ was added and the reaction was allowed to reach room temperature. The reaction was stirred $24 \mathrm{~h}$. The solution was cooled to $0{ }^{\circ} \mathrm{C}$, and $\mathrm{MeOH}$ was slowly added until $\mathrm{H}_{2}$ evolution ceased. Water was then slowly added, followed by a $10 \% \mathrm{HCl}$ aqueous solution. Organic were removed under vacuo and aqueous was extracted with EtOAc. Aqueous layer were separated and extracted again with EtOAc. Organic were combined, dried over $\mathrm{Na}_{2} \mathrm{SO}_{4}$, and concentrated. The resulting residue was purified via flash chromatography $\left(25 \mathrm{~g}, \mathrm{SiO}_{2}, 1: 19\right.$ $\left.\mathrm{MeOH}: \mathrm{CH}_{2} \mathrm{Cl}_{2}\right)$ to yield the known diol $17(1.2 \mathrm{~g}, 76 \%)$ as a white solid. ${ }^{6}$

3,5-di(hydroxymethyl)styrene

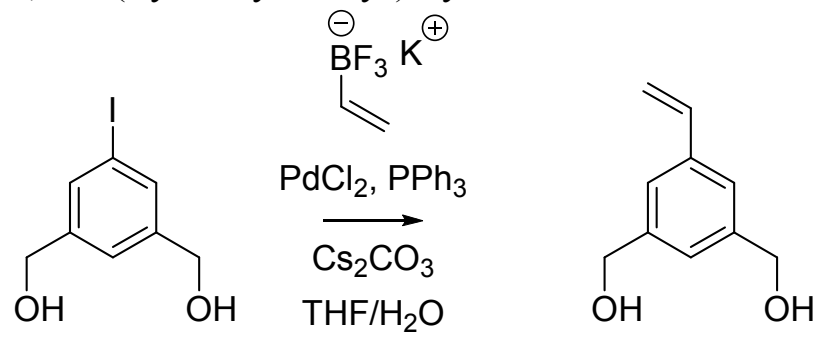

17

$85^{\circ} \mathrm{C}, 24 \mathrm{~h}$

3,5-di(hydroxymethyl)styrene

In a Schlenk flask, a mixture of diol 17 (1.0 g, $3.8 \mathrm{mmol}, 1.0$ equiv), potassium vinyltrifluoroborate $\left(0.51 \mathrm{~g}, 3.8 \mathrm{mmol}, 1.0\right.$ equiv), $\mathrm{PdCl}_{2}$ (13 $\mathrm{mg}, 0.073 \mathrm{mmol}, 0.019$ equiv), $\mathrm{PPh}_{3}$, (60. mg, 0.23 mmol, 0.061 equiv), $\mathrm{Cs}_{2} \mathrm{CO}_{3}$ (3.8 g, 12 mmol, 3.2 equiv), and THF: $\mathrm{H}_{2} \mathrm{O}$ solution ( $10 \mathrm{~mL}, 9: 1)$ was degassed by freeze-pump thaw ( 3 cycles). The mixture was then stirred at $85{ }^{\circ} \mathrm{C}$ for $24 \mathrm{~h}$. Reaction mixture was cooled to room temperature, added of $\mathrm{H}_{2} \mathrm{O}$, and extracted with EtOAc. Aqueous layer was separated and extracted again with EtOAc. Organic were combined, dried over $\mathrm{Na}_{2} \mathrm{SO}_{4}$, and concentrated. Crude NMR confirmed the formation of the desired product. The residue was The resulting residue was purified via flash chromatography ( $25 \mathrm{~g}, \mathrm{SiO}_{2}, \mathrm{CH}_{2} \mathrm{Cl}_{2}$ ) to yield the corresponding unstable 3,5-di(hydroxymethyl)styrene, which was used in the next step immediately after isolation. 


\section{3,5-di(chloromethyl)styrene $\mathbf{1 8}$ (monomer $\mathbf{1 8})$}

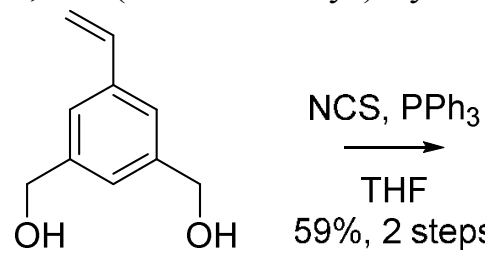<smiles>C=Cc1cc(CCl)cc(CCl)c1</smiles>

18

$\mathrm{PPh}_{3}$ (3.0 g, $11 \mathrm{mmol}, 2.9$ equiv) was slowly added to a vigorously stirred solution of NCS (1.5 g, $11 \mathrm{mmol}, 2.9$ equiv) at $0{ }^{\circ} \mathrm{C}$. Upon addition of $\mathrm{PPh}_{3}$, a precipitate was formed. The mixture was allowed to reach room temperature, and stirred for 30 minutes. A solution of the aforementioned 3,5-di(hydroxymethyl)styrene (theoretically $3.8 \mathrm{mmol}, 1.0$ equiv) was added to the freshly prepared phosphonium chloride mixture and stirred overnight at room temperature (monitored by TLC). Overtime, mixture turned to solution. Water was slowly added to the mixture and THF was removed under vacuo. Aqueous was extracted with EtOAc. Aqueous was separated and extracted again with EtOAc. Organic were combined, dried over $\mathrm{Na}_{2} \mathrm{SO}_{4}$, filtered and concentrated. The residue was purified via flash chromatography $\left(80 \mathrm{~g}, \mathrm{SiO}_{2}, \mathrm{Hex}\right)$ to afford 3,5-

di(chloromethyl)styrene 18 ( $0.45 \mathrm{~g}, 59 \%$ over 2 steps) as a clear oil. The pure oil was immediately hidden from light and stored in the freezer.

${ }^{1}$ H NMR (499 MHz, $\left.\mathrm{CDCl}_{3}\right) \delta 7.39(\mathrm{~s}, 2 \mathrm{H}), 7.32(\mathrm{~s}, 1 \mathrm{H}), 6.71(\mathrm{dd}, J=17.7,10.9 \mathrm{~Hz}, 1 \mathrm{H}), 5.81$ $(\mathrm{d}, J=17.7 \mathrm{~Hz}, 1 \mathrm{H}), 5.34(\mathrm{~d}, J=10.9 \mathrm{~Hz}, 1 \mathrm{H}), 4.58(\mathrm{~s}, 4 \mathrm{H})$;

${ }^{13}$ C NMR $\left(126 \mathrm{MHz}, \mathrm{CDCl}_{3}\right) \delta 138.8,138.4,135.8,128.0,126.5,115.4,45.8$; IR (neat) 3097, 2961. 2918, 2848, 1599, 1466, 1446, 1261, 989, 915, $710 \mathrm{~cm}^{-1}$; HRMS (EI-TOF): $\mathrm{m} / z$ for $\mathrm{C}_{10} \mathrm{H}_{10} \mathrm{Cl}_{2}$ calcd 200.0160, found 200.0159 . 
Poly 3,5-di(chloromethyl)styrene $\mathbf{1 9}$

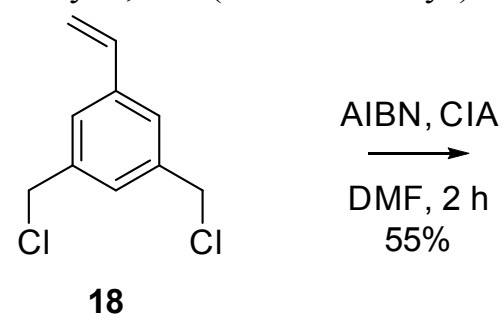<smiles>CCC(C)(C)c1cc(CCl)cc(CCl)c1</smiles>

In a schlenk flask, 3,5-di(chloromethyl)styrene 18 ( $0.40 \mathrm{~g}, 2.2 \mathrm{mmol}, 1.0$ equiv), CIA (1.0 mg, $3.2 \square \mathrm{mol}, 0.0014$ equiv), and AIBN (0.50 mg, $3.0 \square \mathrm{mol}, 0.0014$ equiv) were mixed with DMF $(0.1 \mathrm{~mL})$ and degassed with 3 cycles of freeze-pump thaw. The reaction mixture was then stirred at $80{ }^{\circ} \mathrm{C}$ for $2 \mathrm{~h}$. The reaction mixture was cooled to room temperature, precipitated out in $\mathrm{MeOH}$ (rinse with a minimal amount of THF). The precipitate was dissolved in THF and precipitated out again in $\mathrm{MeOH}$. Repeat precipitation. The solid was rinsed with $\mathrm{Et}_{2} \mathrm{O}$ and dried under vacuo to yield Poly 3,5-di(chloromethyl)styrene $19(0.22 \mathrm{~g}, 55 \%)$.

${ }^{1}$ H NMR $\left(499 \mathrm{MHz}, \mathrm{CDCl}_{3}\right) \delta 7.19-6.74(\mathrm{~m}, 1 \mathrm{H}), 6.73-6.04(\mathrm{~m}, 2 \mathrm{H}), 4.77-4.37(\mathrm{~m}, 4 \mathrm{H})$, $2.35-1.05(\mathrm{~m}, 3 \mathrm{H})$;

IR (neat) 3027, 2926, 2848, 1603, 1457, 1295, 1261, 1159, 1066, 972, 894, $855 \mathrm{~cm}^{-1}$;

GPC:

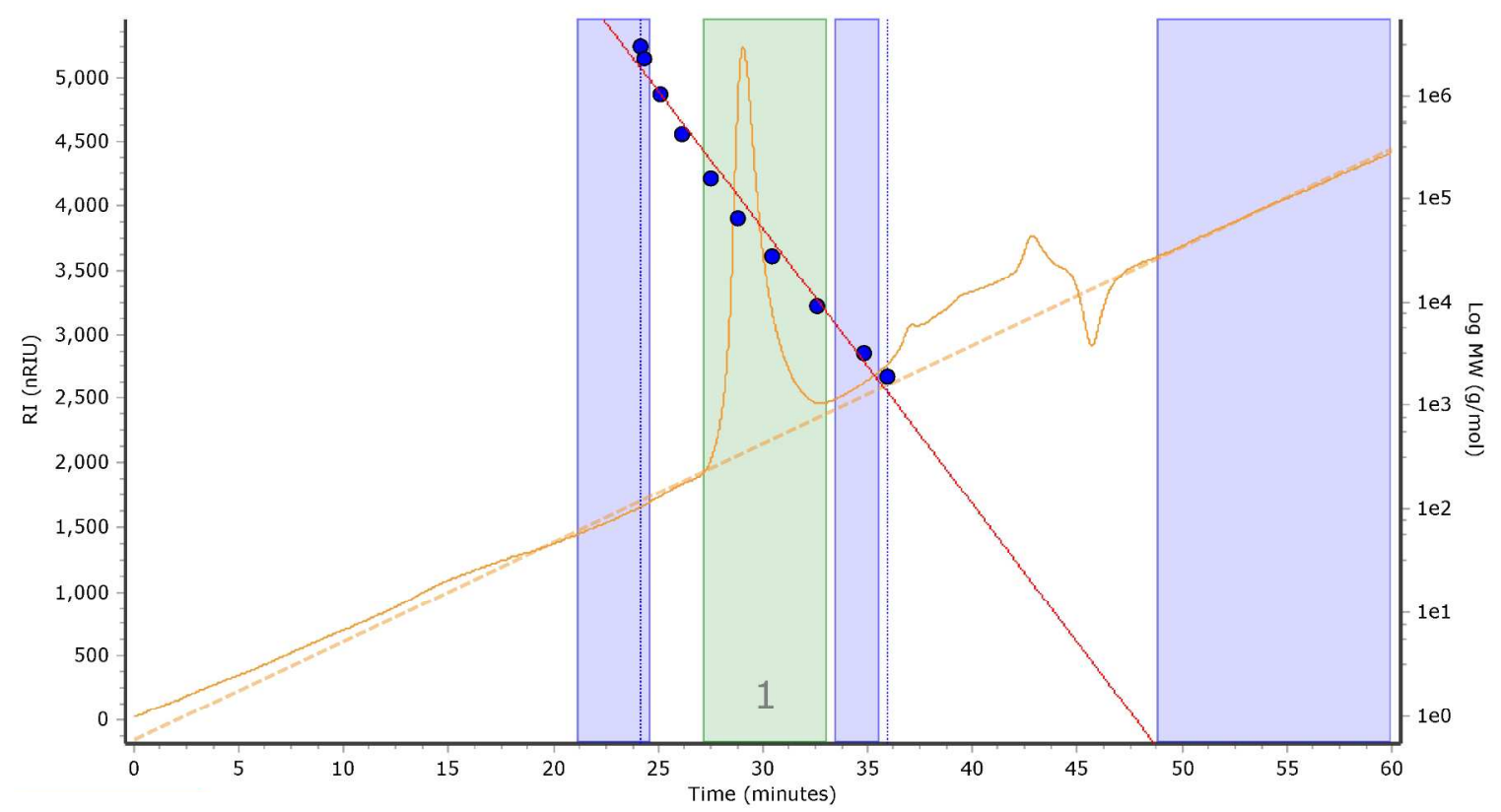

Molecular Weight Averages

\begin{tabular}{|c|r|r|r|r|r|r|r|}
\hline Peak & Mp (g/mol) & Mn (g/mol) & Mw (g/mol) & Mz (g/mol) & Mz+1 (g/mol) & Mv (g/mol) & PD \\
\hline Peak 1 & 91064 & 52959 & 76243 & 94949 & 111117 & 92503 & 1.44 \\
\hline
\end{tabular}


Poly 3,5-di(methylene(1-ethylviologen)styrene tetra hexafluorophosphate $11(\mathrm{~m}$ Benzene polymer 11)

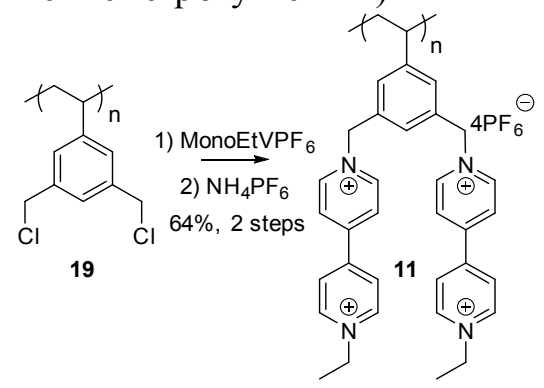

$\mathrm{N}$-Ethyl 4,4'-bipyridinium hexafluorophosphate ( $0.79 \mathrm{~g}, 2.4 \mathrm{mmol}, 5.0$ equiv) was added to a solution of polymer $19(96 \mathrm{mg}, 0.48 \mathrm{mmol}, 1.0$ equiv) in DMF $(1 \mathrm{~mL})$. The solution was heated at $60{ }^{\circ} \mathrm{C}$ for 5 days. The reaction solution was cooled to room temperature and polymer was precipitated out in $\mathrm{MeOH}$. The polymer was dissolved on a minimal amount of $\mathrm{MeCN}$, and precipitated out in $\mathrm{Et}_{2} \mathrm{O}$. Repeat. Polymer was dissolved in a solution of $\mathrm{MeCN}: \mathrm{H}_{2} \mathrm{O}(1: 1,10 \mathrm{~mL})$ and added of $\mathrm{NH}_{4} \mathrm{PF}_{6}(0.78 \mathrm{~g}, 4.8 \mathrm{mmol}, 10$. equiv). The mixture was stirred $24 \mathrm{~h}$ at room temperature. $\mathrm{MeCN}$ was removed under vacuum. Solid separated from water. The polymer was dissolved back in $\mathrm{MeCN}$ and stirred fresh distillated water was added. $\mathrm{MeCN}$ was removed under vacuo and the solid separated from water. Repeat. The solid was washed twice with $\mathrm{MeOH}$, followed by two cycles of dissolution/precipitation from $\mathrm{MeCN}$ and $\mathrm{Et}_{2} \mathrm{O}$. The solid was dried under vacuum to afford expected polymer $11(0.33 \mathrm{~g}, 64 \%, 2$ steps $)$ as a yellow solid.

${ }^{1} \mathbf{H}$ NMR $\left(600 \mathrm{MHz}, \mathrm{CD}_{3} \mathrm{CN}\right) \delta 9.22-8.53(\mathrm{~m}, 1 \mathrm{H}), 8.53-7.86(\mathrm{~m}, 1 \mathrm{H}), 7.80-6.27(\mathrm{~m}, 0 \mathrm{H})$, $6.29-4.96(\mathrm{~m}, 1 \mathrm{H}), 4.79-4.36(\mathrm{~m}, 1 \mathrm{H}), 1.82-1.05(\mathrm{~m}, 1 \mathrm{H})$;

${ }^{19}$ F NMR $\left(564 \mathrm{MHz}, \mathrm{CD}_{3} \mathrm{CN}\right) \delta-71.5(\mathrm{~d}, J=710.2 \mathrm{~Hz})$;

${ }^{31} \mathbf{P}$ NMR $\left(243 \mathrm{MHz}, \mathrm{CD}_{3} \mathrm{CN}\right) \delta-144.8$ (hept, $J=710.2 \mathrm{~Hz}$ );

IR (neat) 3137, 3080, 1640, 1564, 1507, 1451, 1220, 1174, 824;

Anal. Calcd for $\mathrm{C}_{34} \mathrm{H}_{36} \mathrm{~F}_{24} \mathrm{~N}_{4} \mathrm{P}_{4}$ : C, 37.79; H, 3.36; N, 5.19. Found: C, 38.43; H, 3.23; N, 4.89. Infrared spectral comparison of poly viologen 11 and poly di(chloromethyl)styrene 19. ${ }^{4,5}$

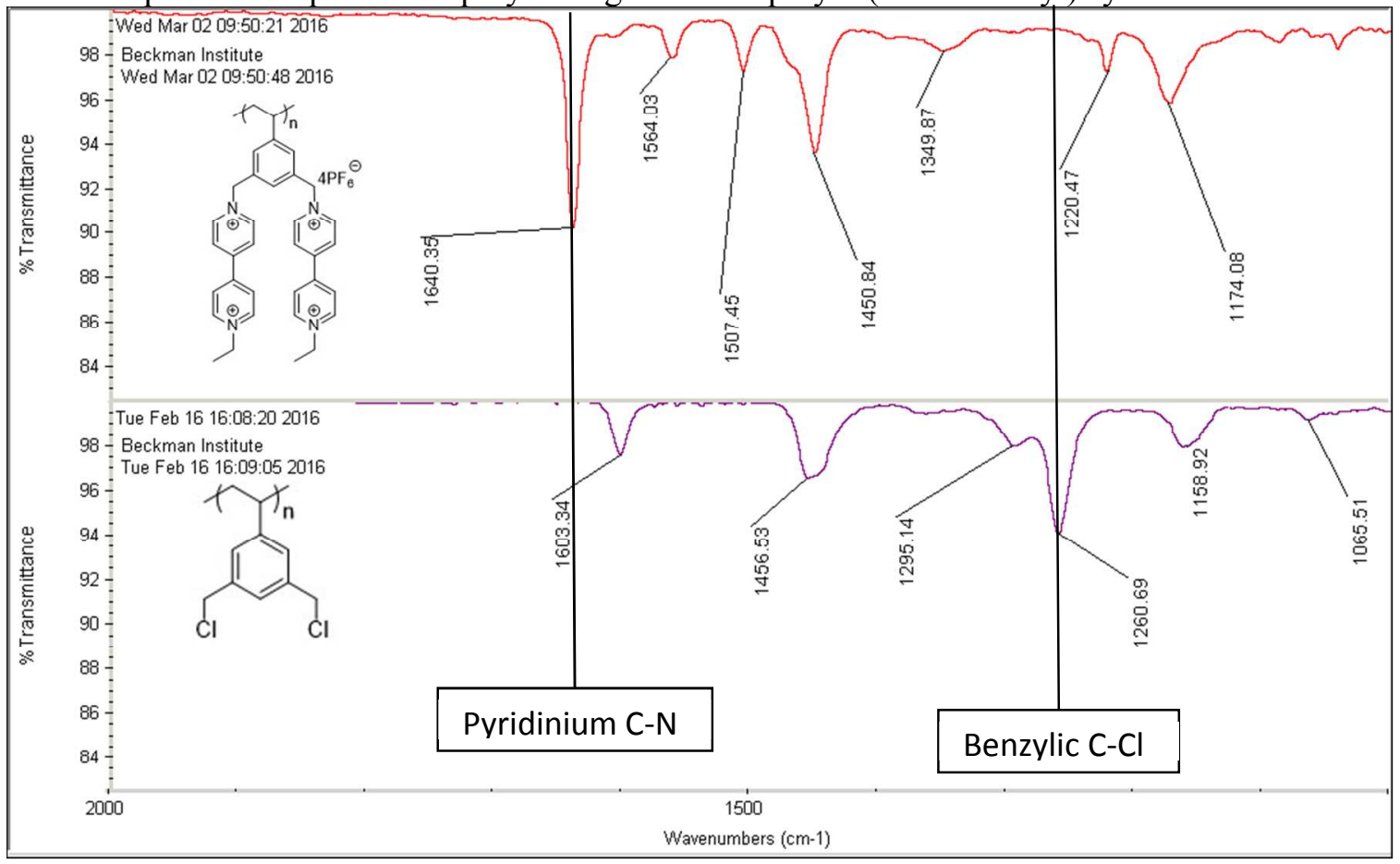

Method to estimate Mn of final polymers $\mathbf{1 0}$ and $\mathbf{1 1}$ 
We assumed that full conversions of polymer 15 and 19 to polymer 10 and $\mathbf{1 1}$, respectively, based on NMR, IR, and elemental analysis. For polymer 11, bulk electrolysis also exhibited $92 \%$ of the theoretical charge for this RAP solution assuming $100 \%$ functionalization.

Comparison between $\mathbf{1 5}$ or $\mathbf{1 9}$ and $\mathbf{1 0}$ of $\mathbf{1 1}$ suggests that polymers bearing two viologen units has a molecular weight which is 5.4 bigger than its precursor. With this molecular weight ratio, we could estimate that the polymer 15 with a Mn of $80 \mathrm{kDa}$ will convert to polymer 10 with a Mn of $432 \mathrm{kDa}(5.4 \times 80 \mathrm{kDa})$. The same approach is used for polymer 11, since is an isomer of 10 . 
NMRs:

Diethyl viologen bis(hexafluorophosphate) 2 NMRs $499 \mathrm{MHz}, \mathrm{CD}_{3} \mathrm{CN}$

$$
\underset{\substack{m \\ \infty}}{\substack{\infty_{\infty}^{\infty} \\ \infty}}
$$

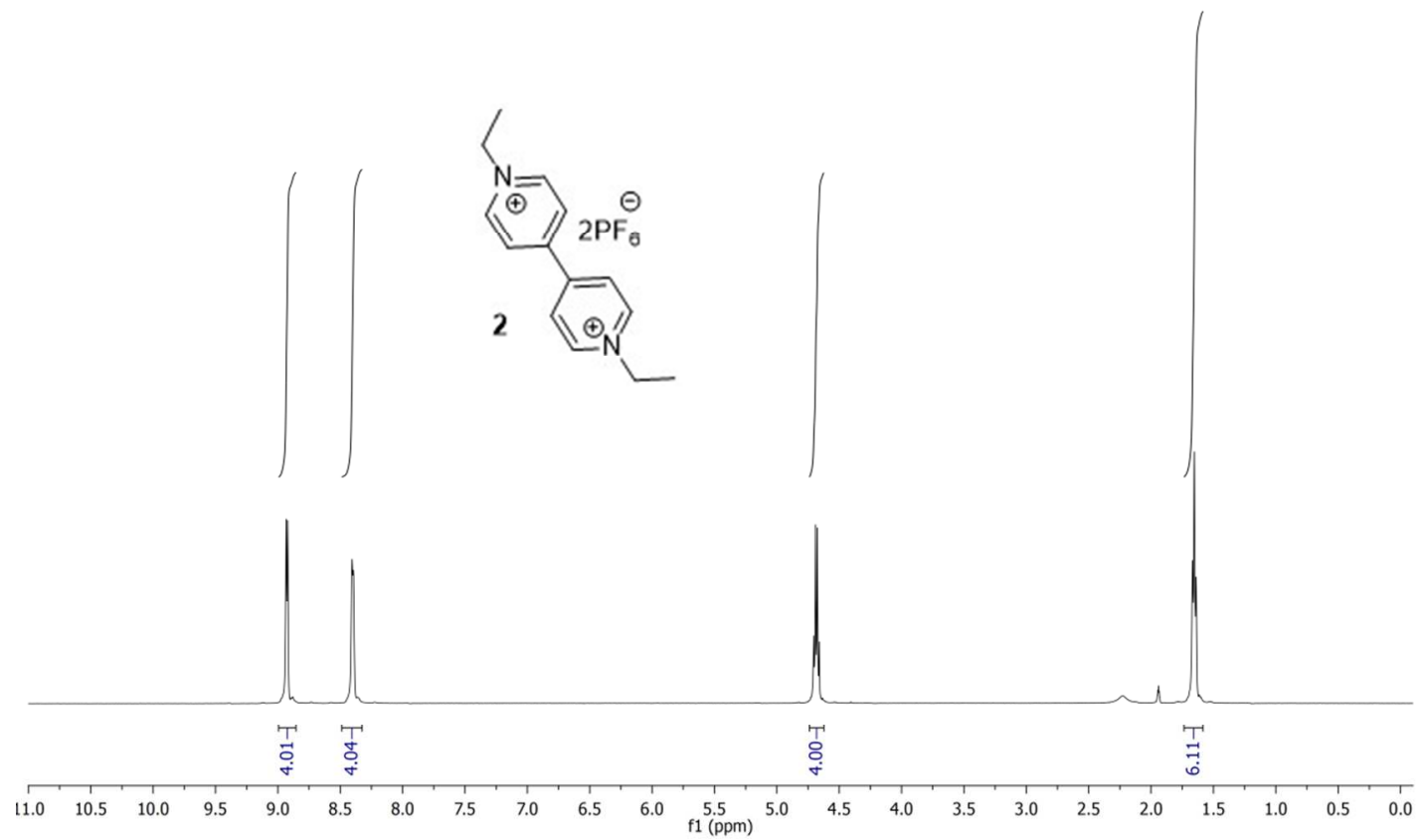

$126 \mathrm{MHz}, \mathrm{CD}_{3} \mathrm{CN}$

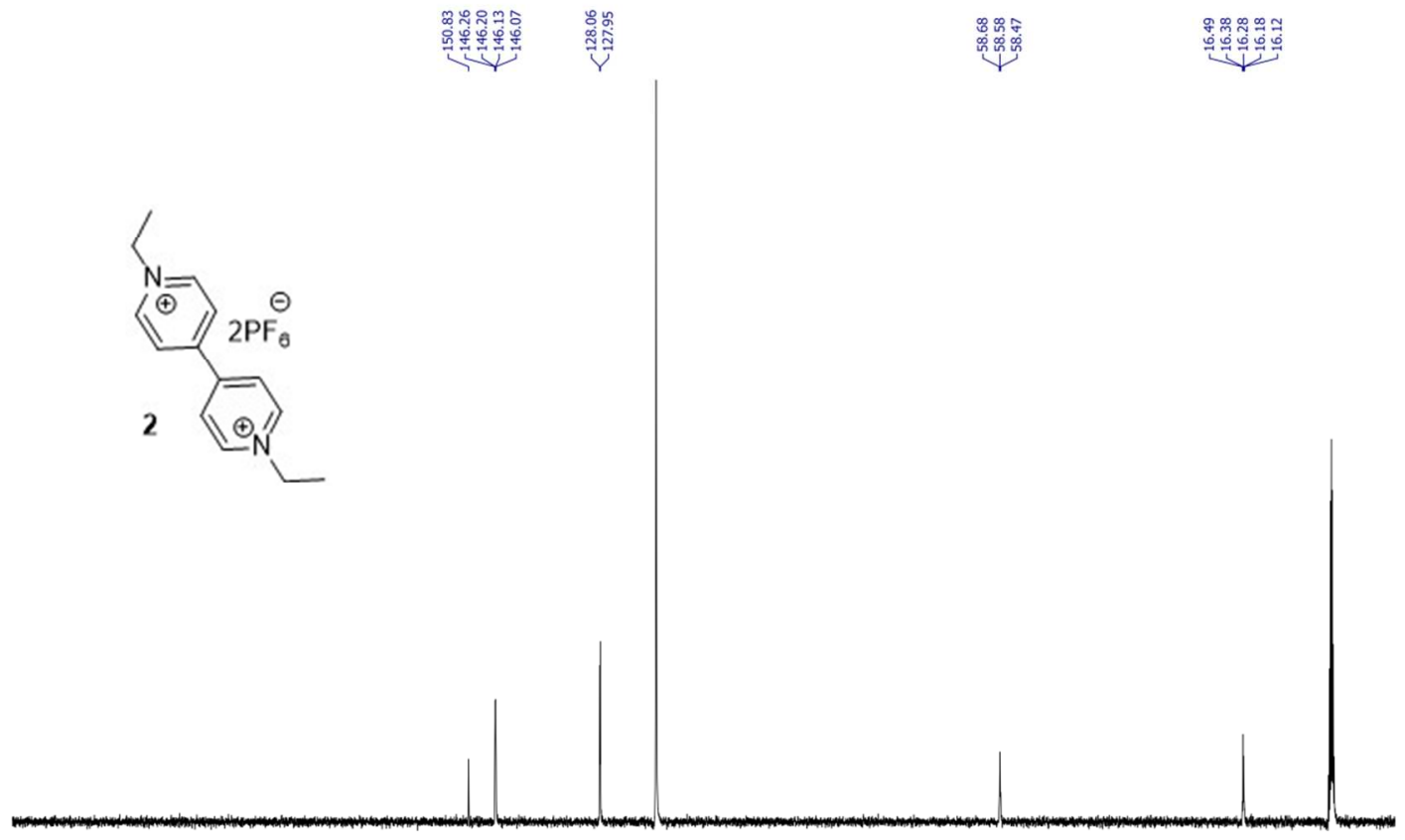

\begin{tabular}{rlllllllllllllllllllllllllllllllllll}
\hline 230 & 220 & 210 & 200 & 190 & 180 & 170 & 160 & 150 & 140 & 130 & 120 & 110 & 100 & 90 & 80 & 70 & 60 & 50 & 40 & 30 & 20 & 10 & 0 & -10
\end{tabular}

$470 \mathrm{MHz}, \mathrm{CD}_{3} \mathrm{CN}$ 

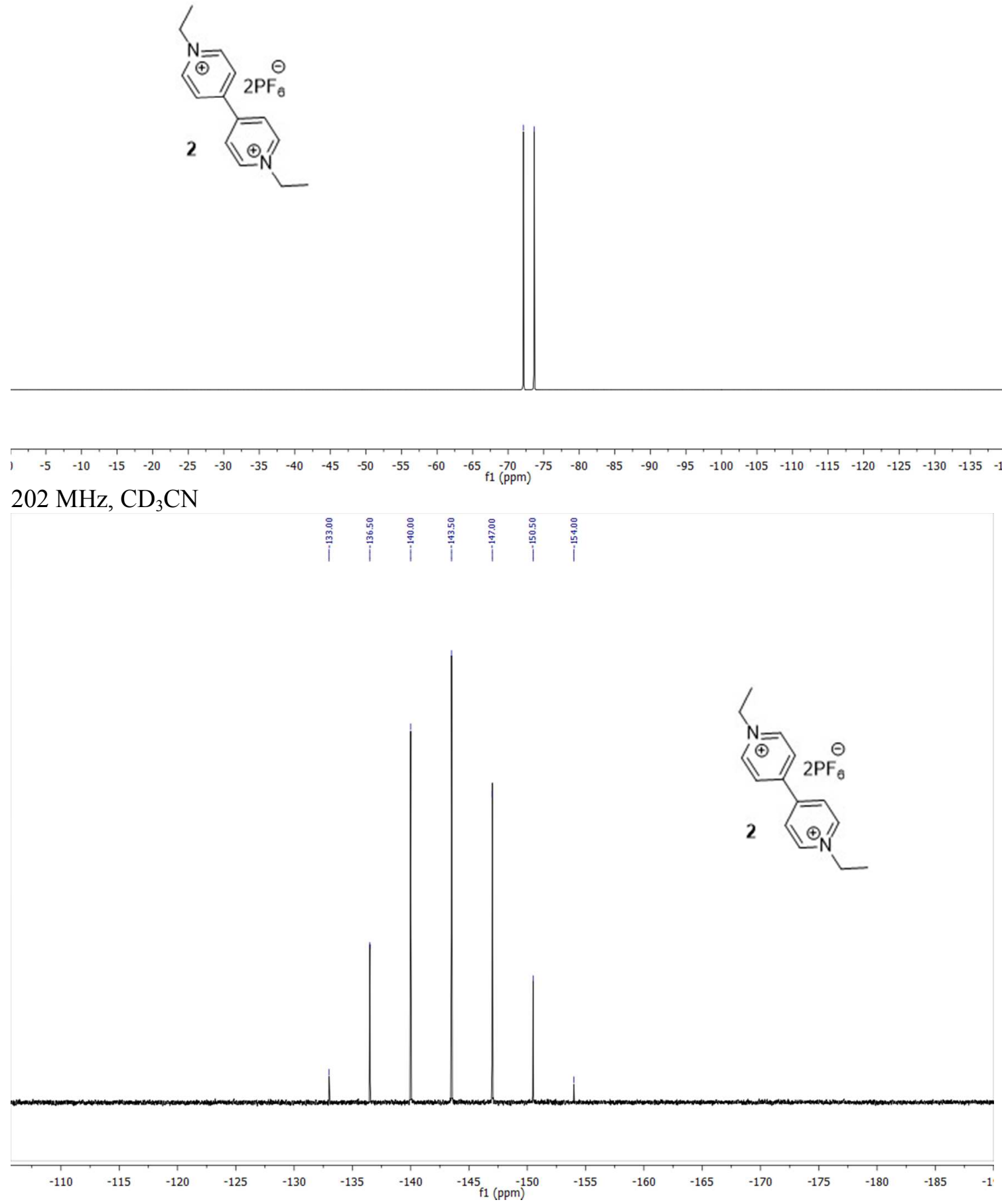
1,3-propyl bis(viologen) 3 NMRs

$500 \mathrm{MHz}, \mathrm{CD}_{3} \mathrm{CN}$

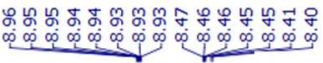

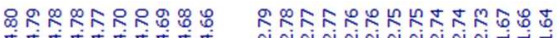

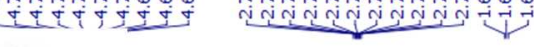
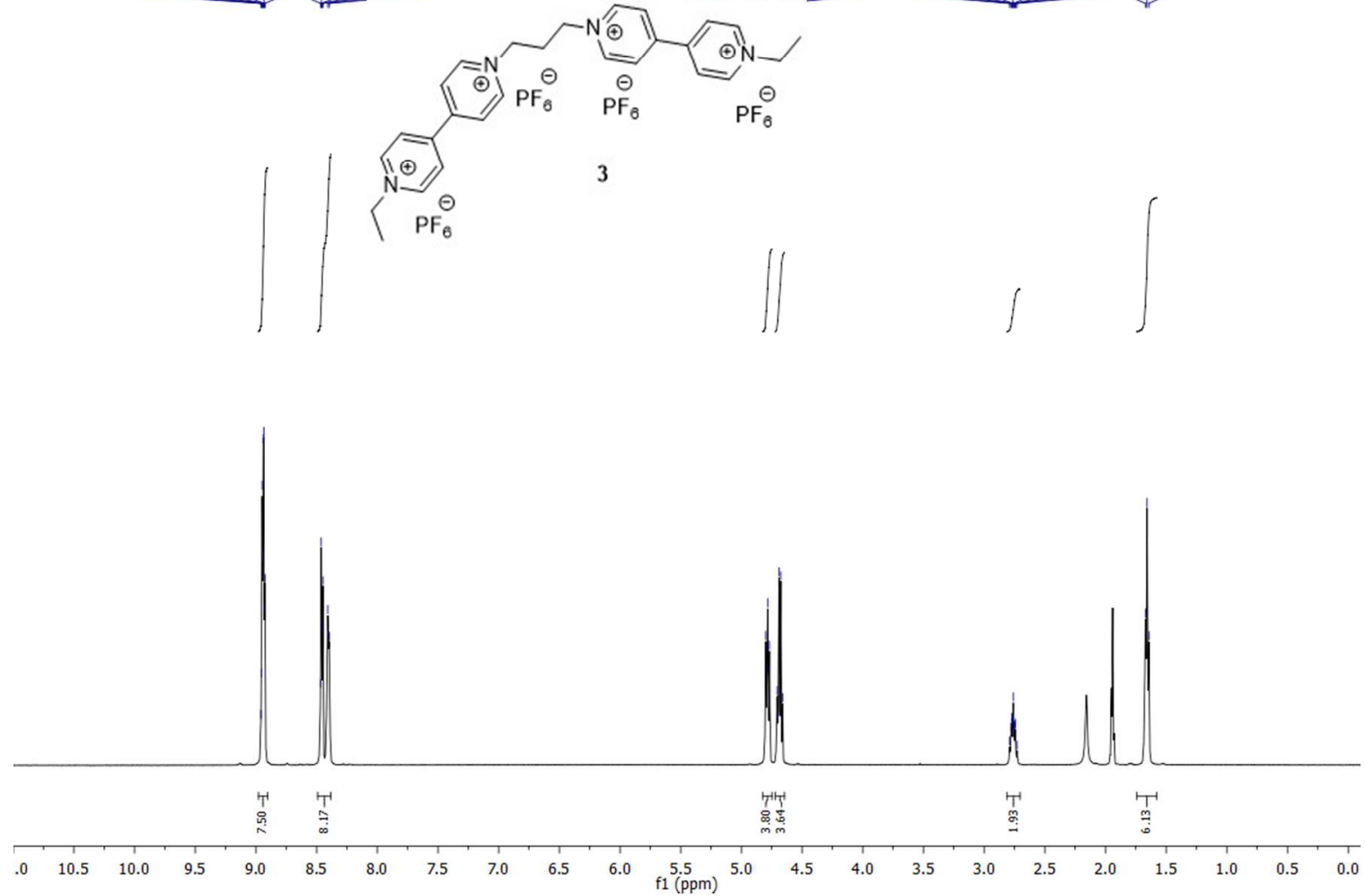
$126 \mathrm{MHz}, \mathrm{CD}_{3} \mathrm{CN}$

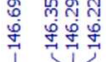

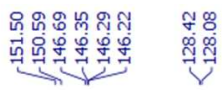

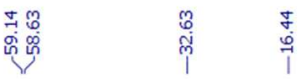
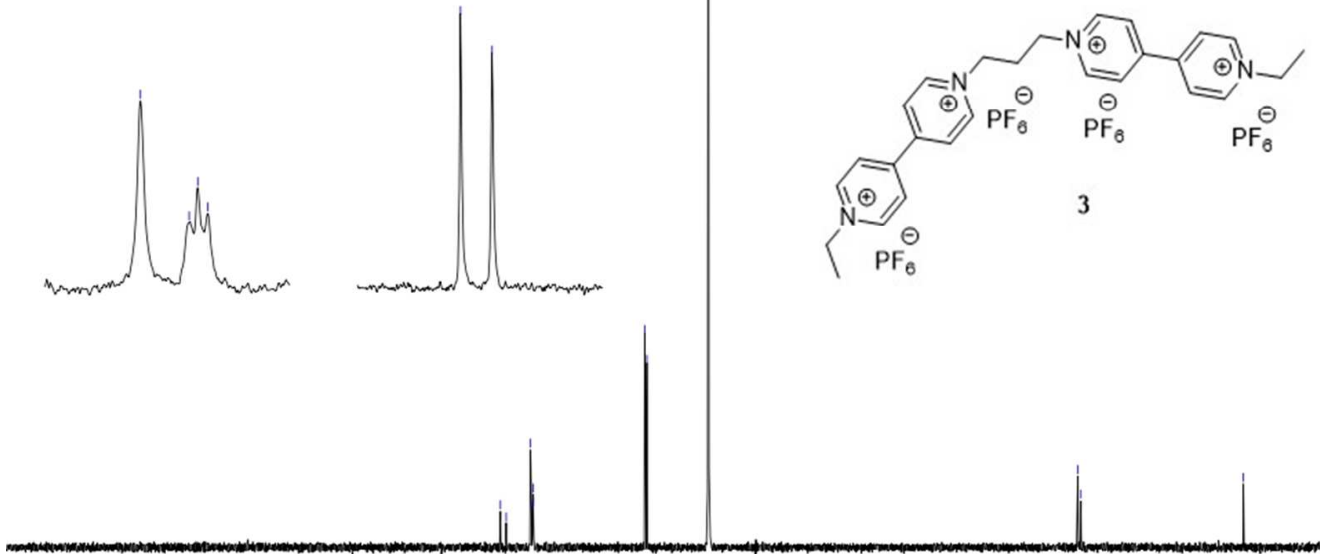


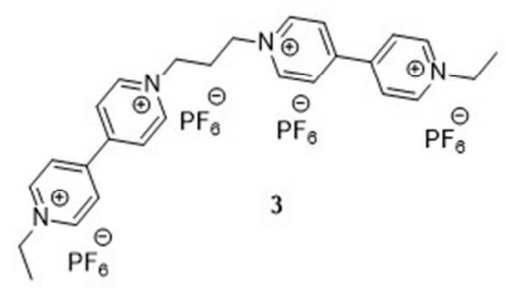

\begin{tabular}{|lccccccccccccccccccccccccccccccccc}
\hline & -5 & -10 & -15 & -20 & -25 & -30 & -35 & -40 & -45 & -50 & -55 & -60 & -65 & -70 & -75 & -80 & -85 & -90 & -95 & -100 & -105 & -110 & -115 & -120 & -125 & -130 & -135 & -1 & 1
\end{tabular} $202 \mathrm{MHz}, \mathrm{CD} 3 \mathrm{CN}$

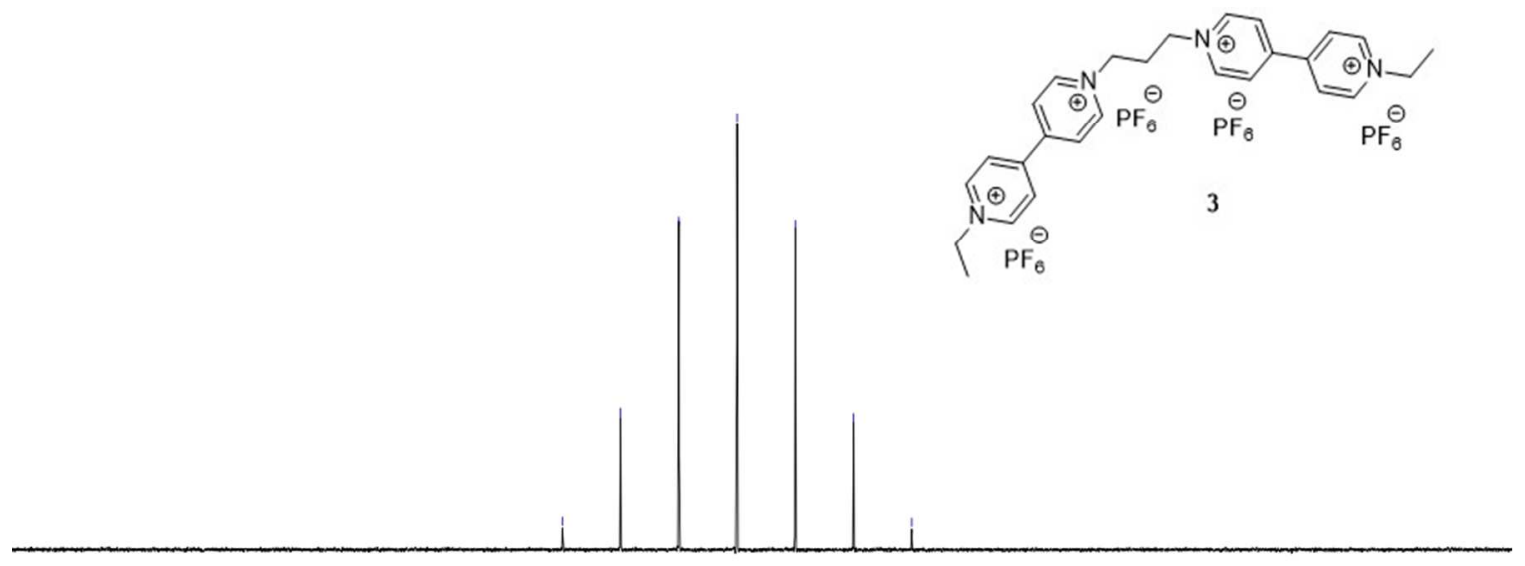


1,4-butyl bis(viologen) 4 NMRs

$499 \mathrm{MHz}, \mathrm{CD}_{3} \mathrm{CN}$

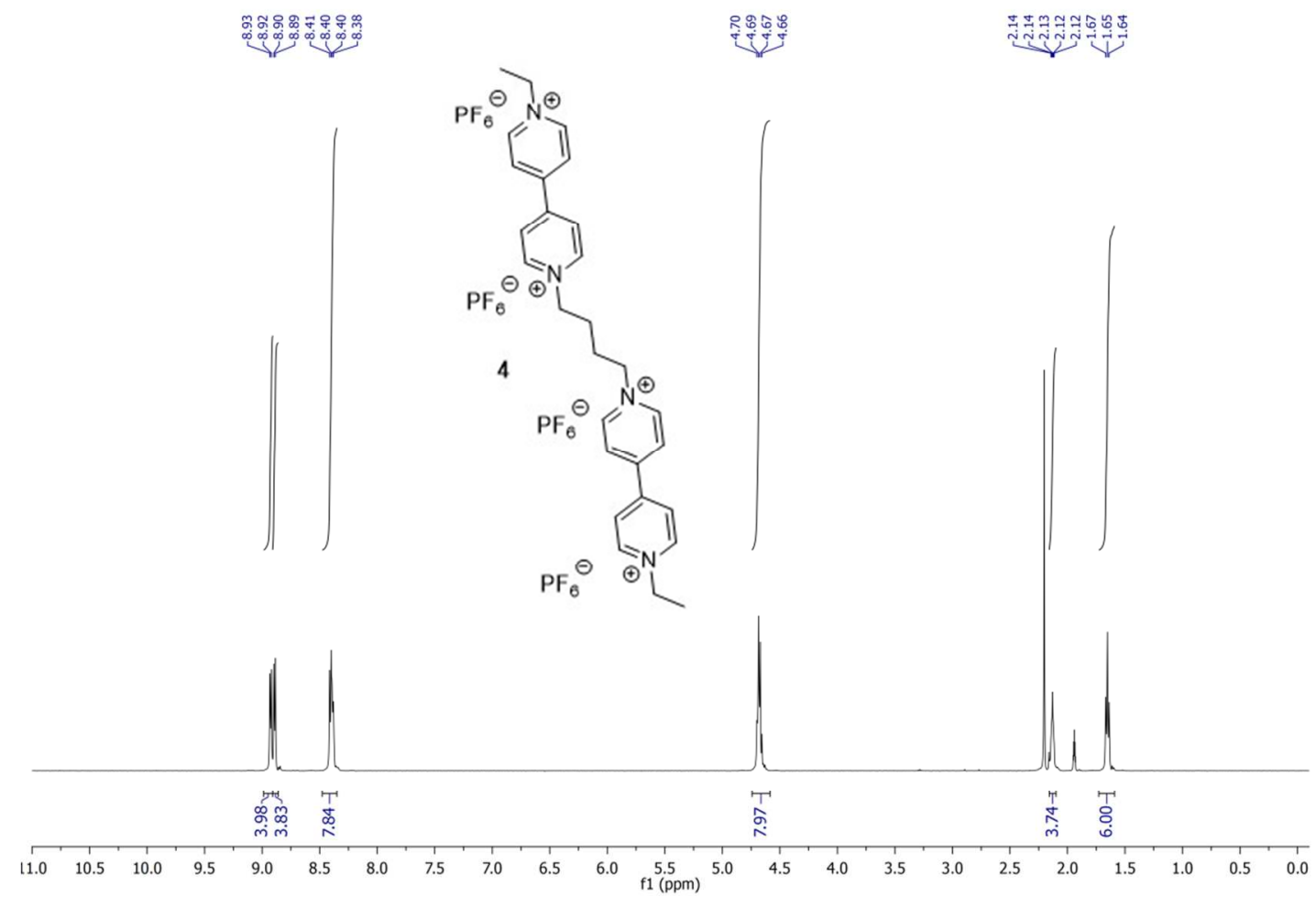

$126 \mathrm{MHz}, \mathrm{CD}_{3} \mathrm{CN}$

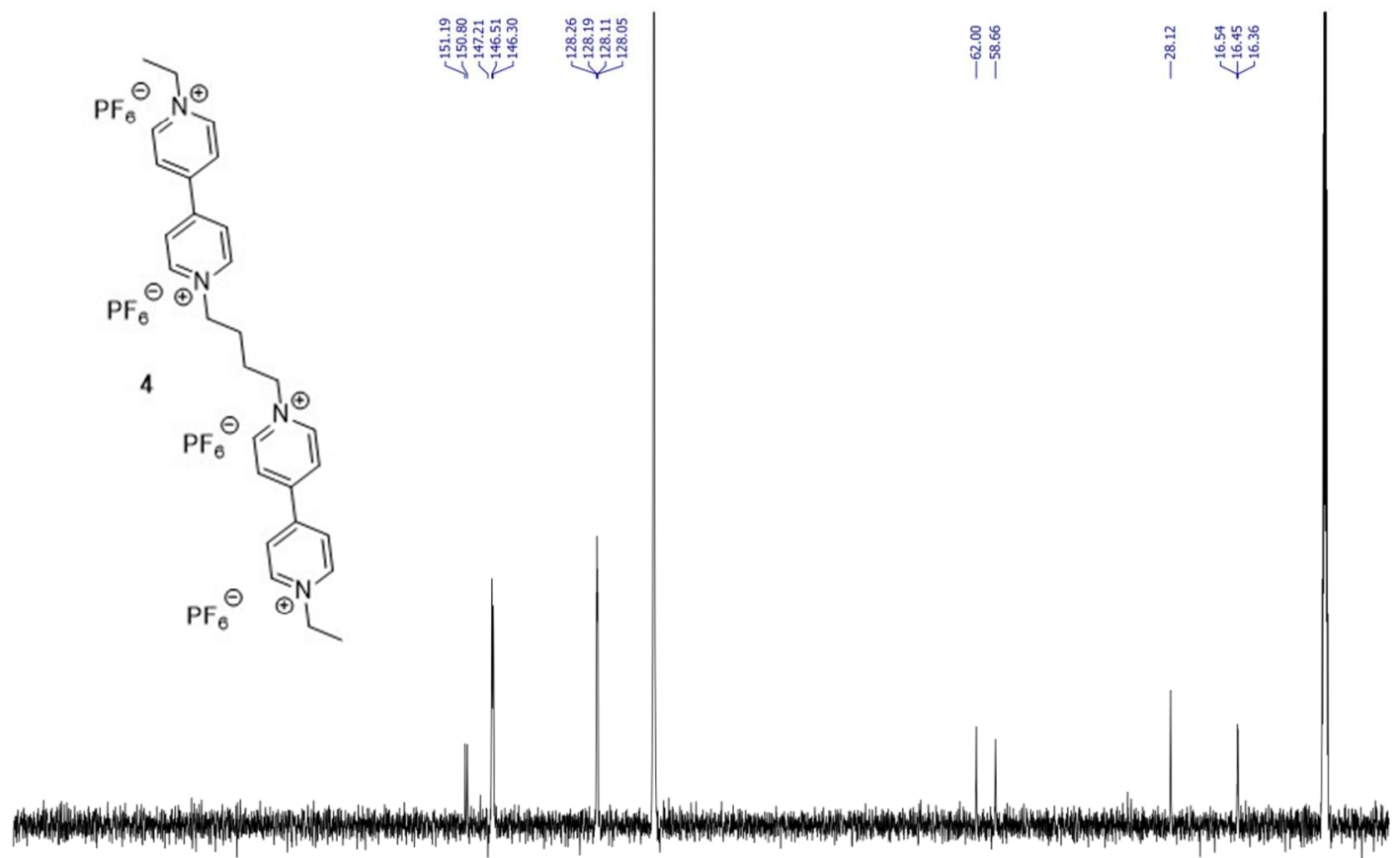

$\begin{array}{lllllllllllllllllllllllllllllllll}230 & 220 & 210 & 200 & 190 & 180 & 170 & 160 & 150 & 140 & 130 & 120 & 110 & 100 & 90 & 80 & 70 & 60 & 50 & 40 & 30 & 20 & 10 & 0 & -10\end{array}$ 
$470 \mathrm{MHz}, \mathrm{CD}_{3} \mathrm{CN}$
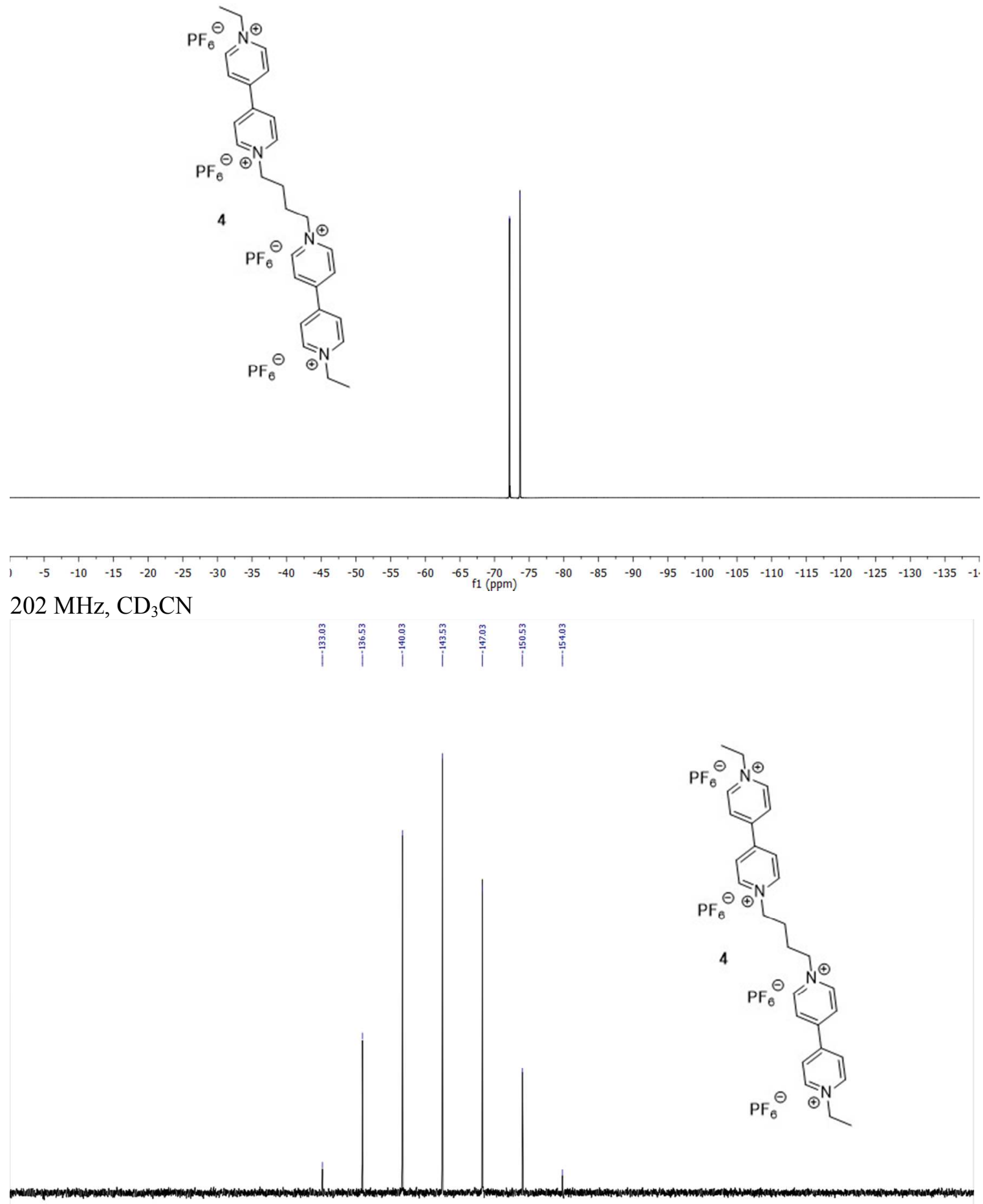
1,5-pentyl bis(viologen) 5 NMRs

$499 \mathrm{MHz}, \mathrm{CD}_{3} \mathrm{CN}$

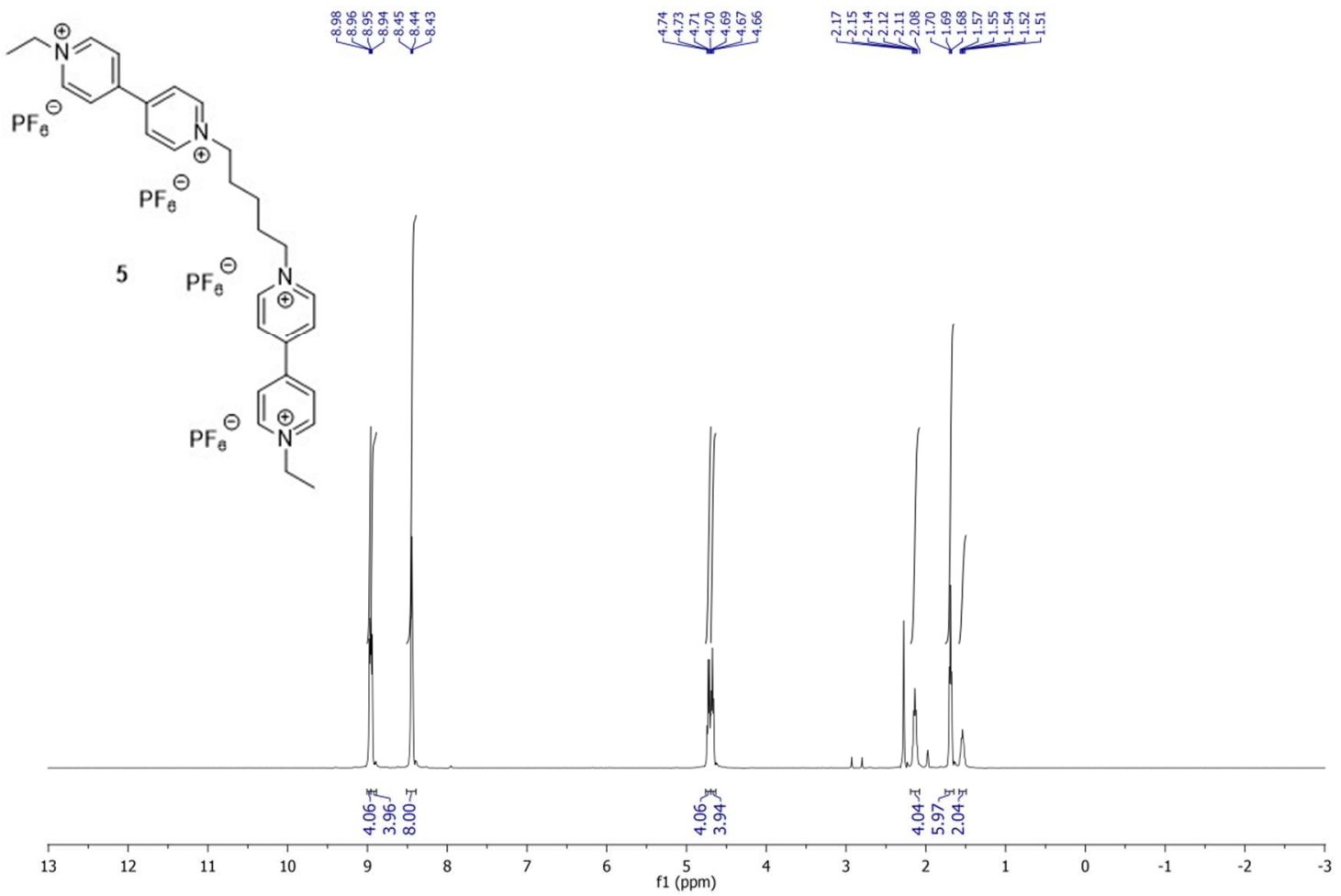

$126 \mathrm{MHz}, \mathrm{CD}_{3} \mathrm{CN}$

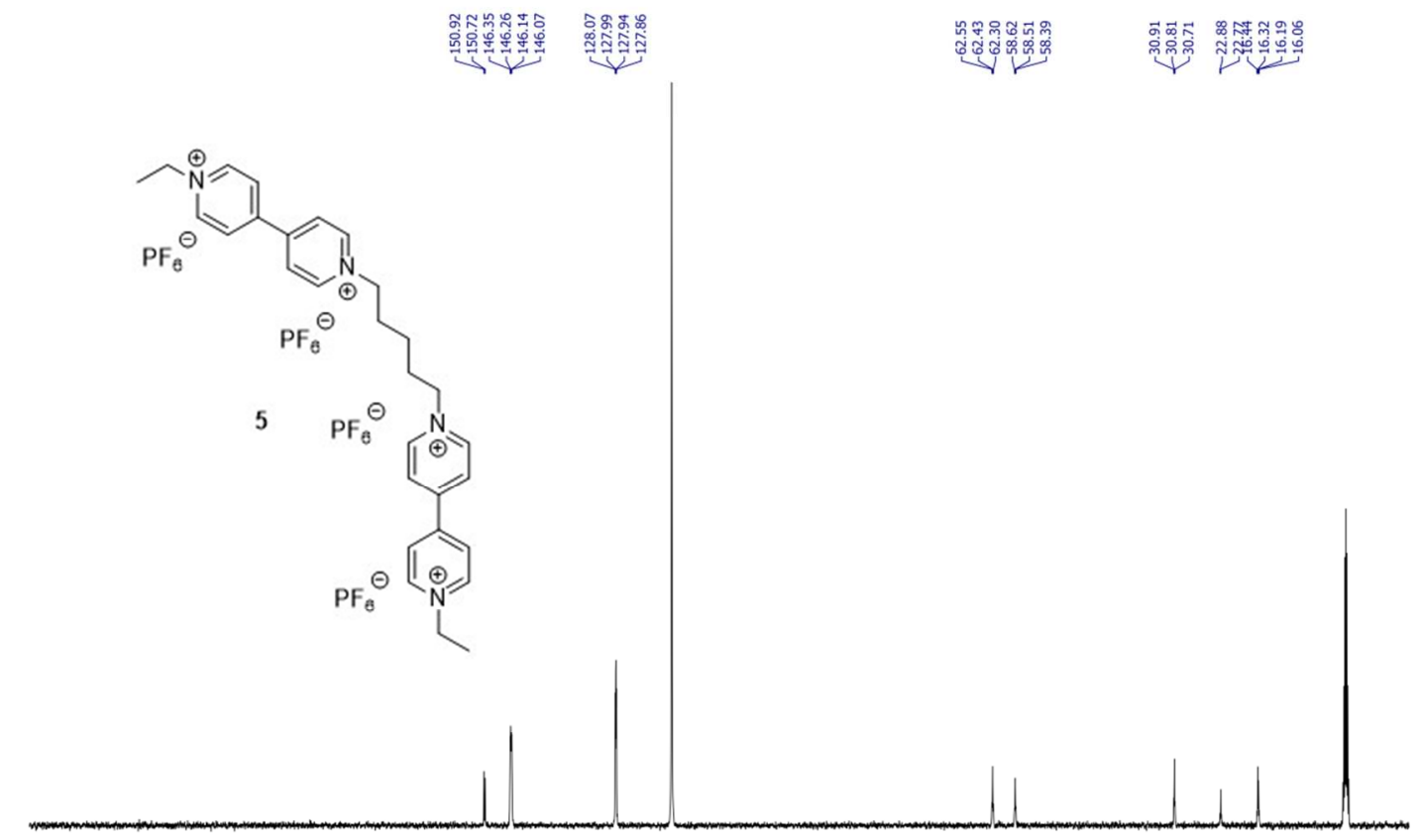

\begin{tabular}{rllllllllllllllllllllllllllllllllll}
\hline 230 & 220 & 210 & 200 & 190 & 180 & 170 & 160 & 150 & 140 & 130 & 120 & 110 & 100 & 90 & 80 & 70 & 60 & 50 & 40 & 30 & 20 & 10 & 0 & -10
\end{tabular}

$470 \mathrm{MHz}, \mathrm{CD}_{3} \mathrm{CN}$ 

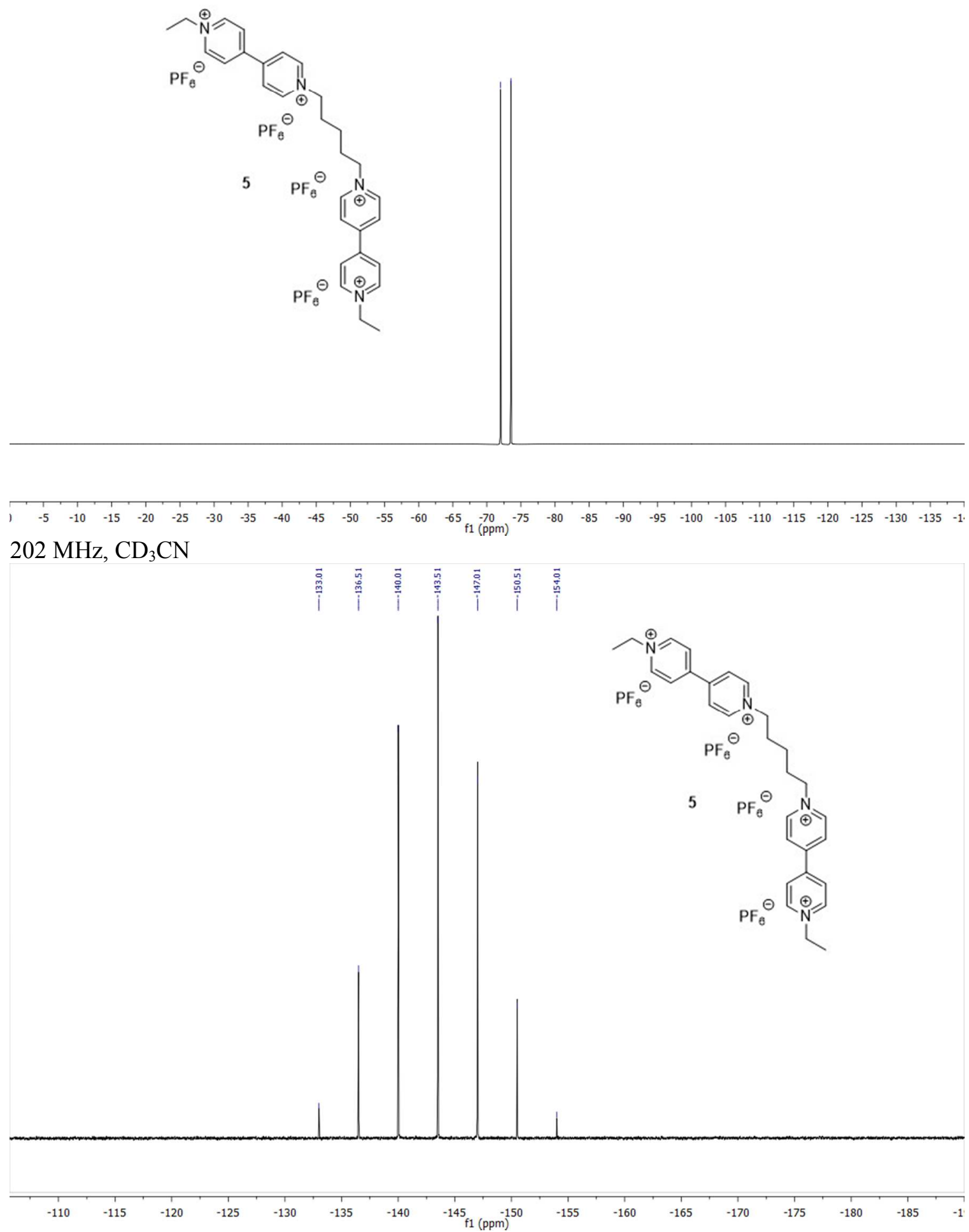
1,6-hexyl bis(viologen) 6 NMRs $499 \mathrm{MHz}, \mathrm{CD}_{3} \mathrm{CN}$
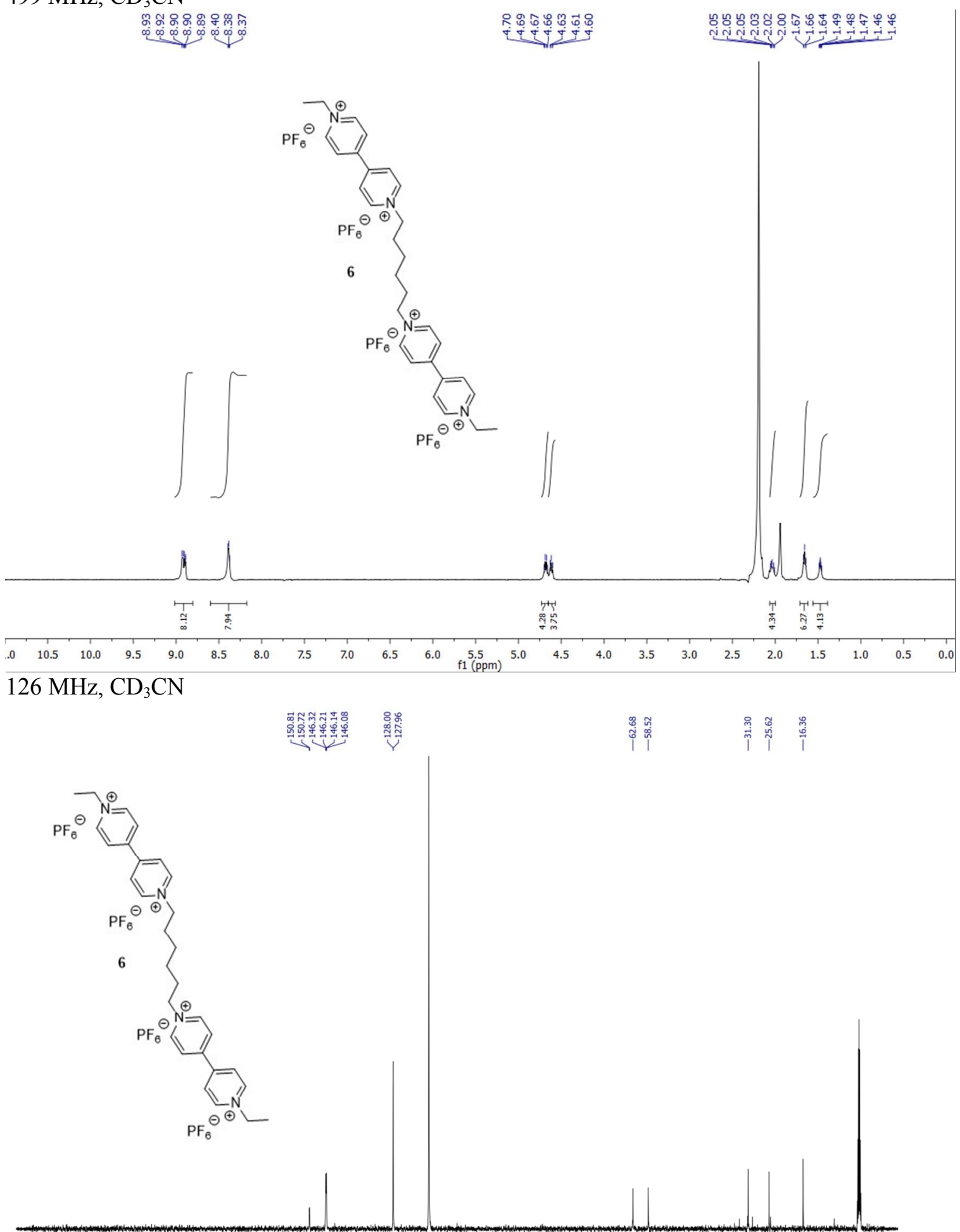

\begin{tabular}{lllllllllllllllllllllllllllllllllll}
\hline 230 & 220 & 210 & 200 & 190 & 180 & 170 & 160 & 150 & 140 & 130 & 120 & 110 & 100 & 90 & 80 & 70 & 60 & 50 & 40 & 30 & 20 & 10 & 0
\end{tabular} 


\section{$470 \mathrm{MHz}, \mathrm{CD}_{3} \mathrm{CN}$}

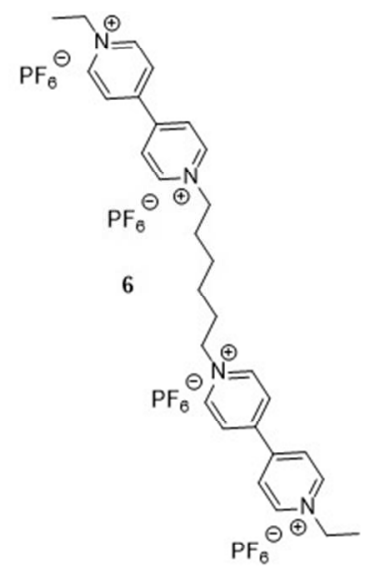

\begin{tabular}{llllllllllllllllllllllllllllllllllll}
\hline & -5 & -10 & -15 & -20 & -25 & -30 & -35 & -40 & -45 & -50 & -55 & -60 & -65 & -70 & -75 & -80 & -85 & -90 & -95 & -100 & -105 & -110 & -115 & -120 & -125 & -130 & -135 & -1
\end{tabular} $243 \mathrm{MHz}, \mathrm{CD}_{3} \mathrm{CN}$

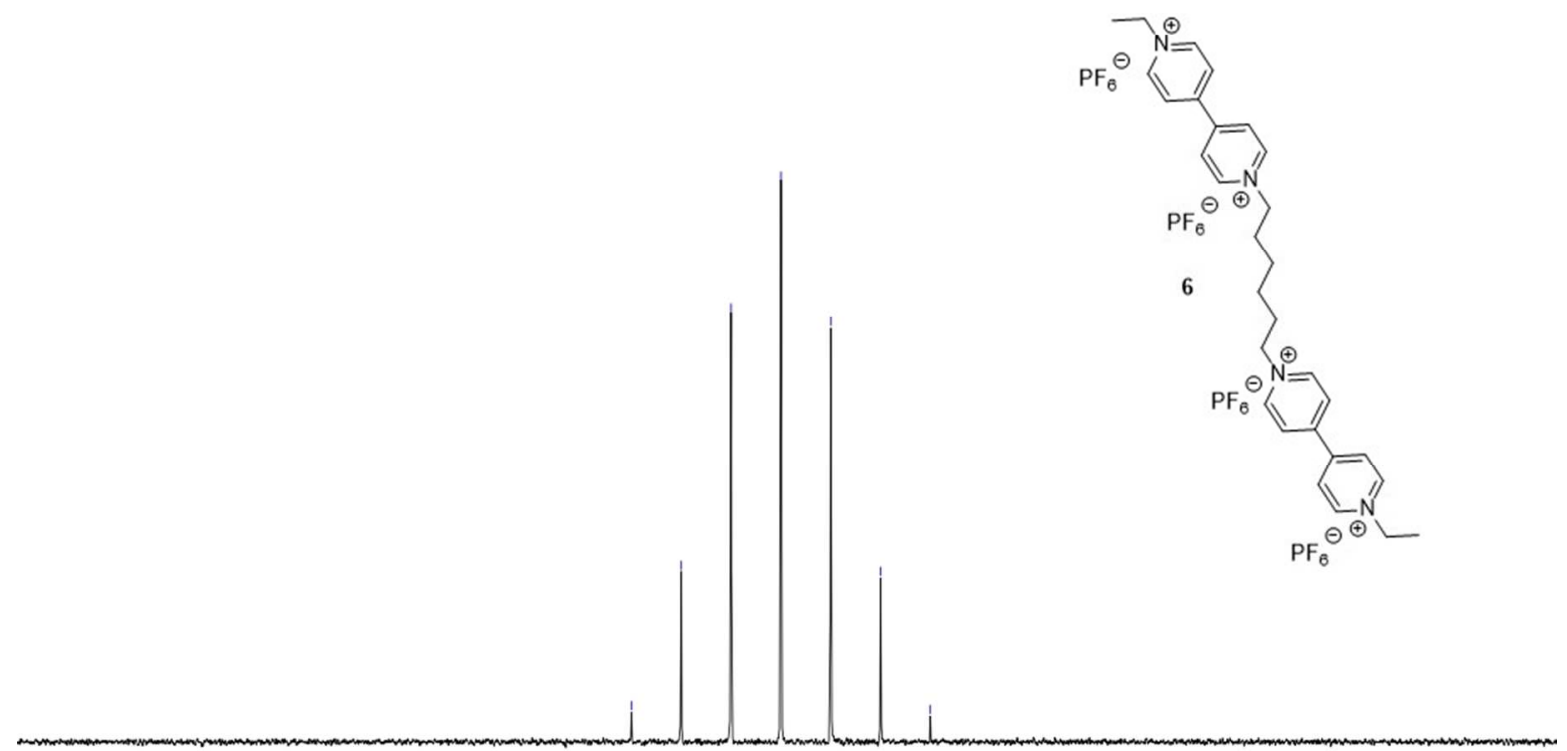


1,7-heptyl bis(viologen) 7 NMRs $500 \mathrm{MHz}, \mathrm{CD}_{3} \mathrm{CN}$

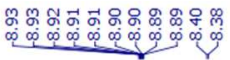

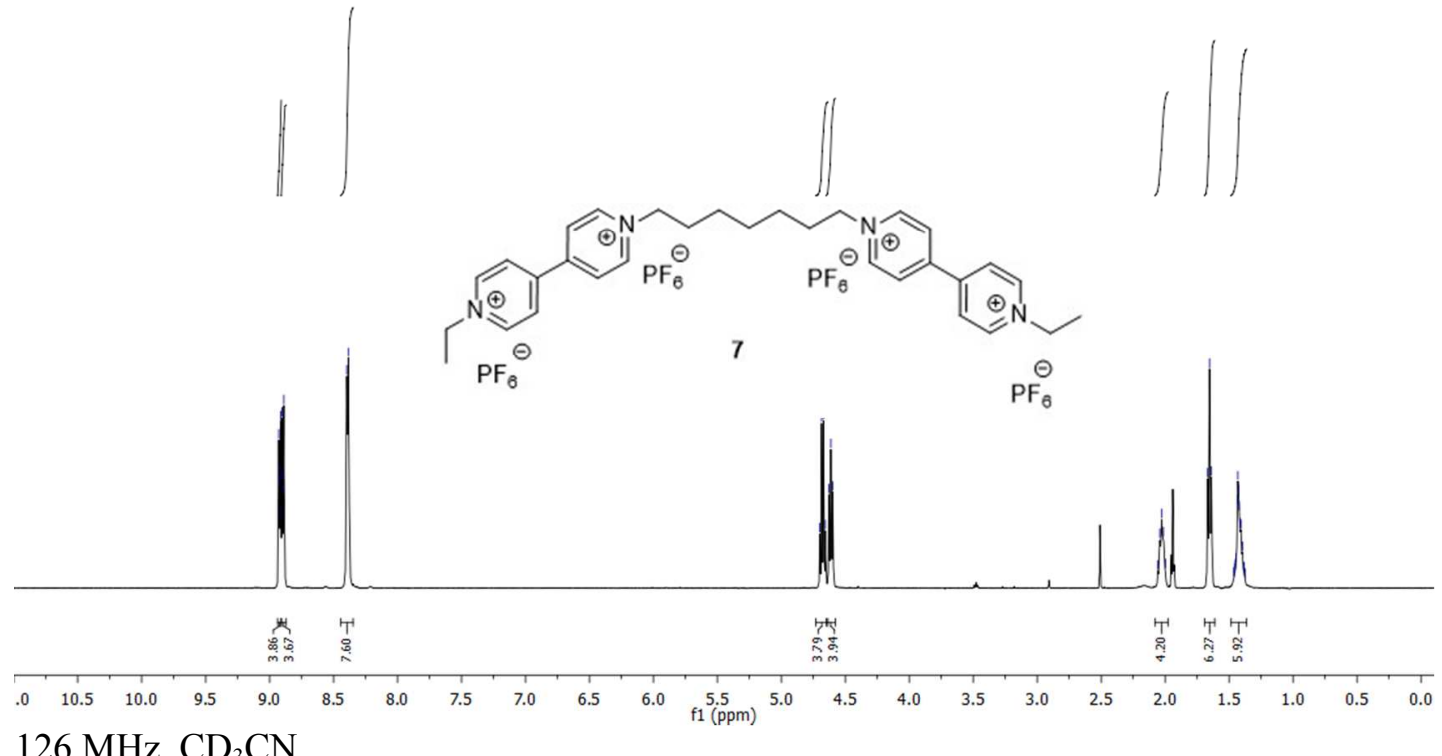
$126 \mathrm{MHz}, \mathrm{CD}_{3} \mathrm{CN}$

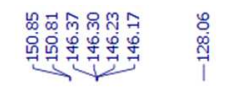

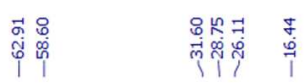

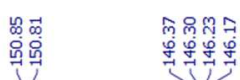
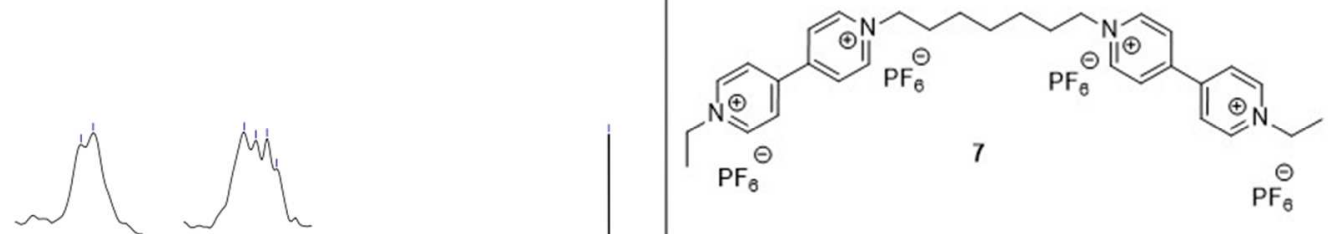

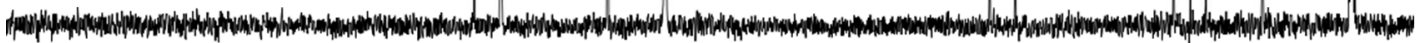

$\begin{array}{llllllllllllllllllllllll}30 & 220 & 210 & 200 & 190 & 180 & 170 & 160 & 150 & 140 & 130 & 120 & \begin{array}{l}110 \\ \mathrm{f} 1(\mathrm{ppm})\end{array} & 100 & 90 & 80 & 70 & 60 & 50 & 40 & 30 & 20 & 10 & 0\end{array}$ 

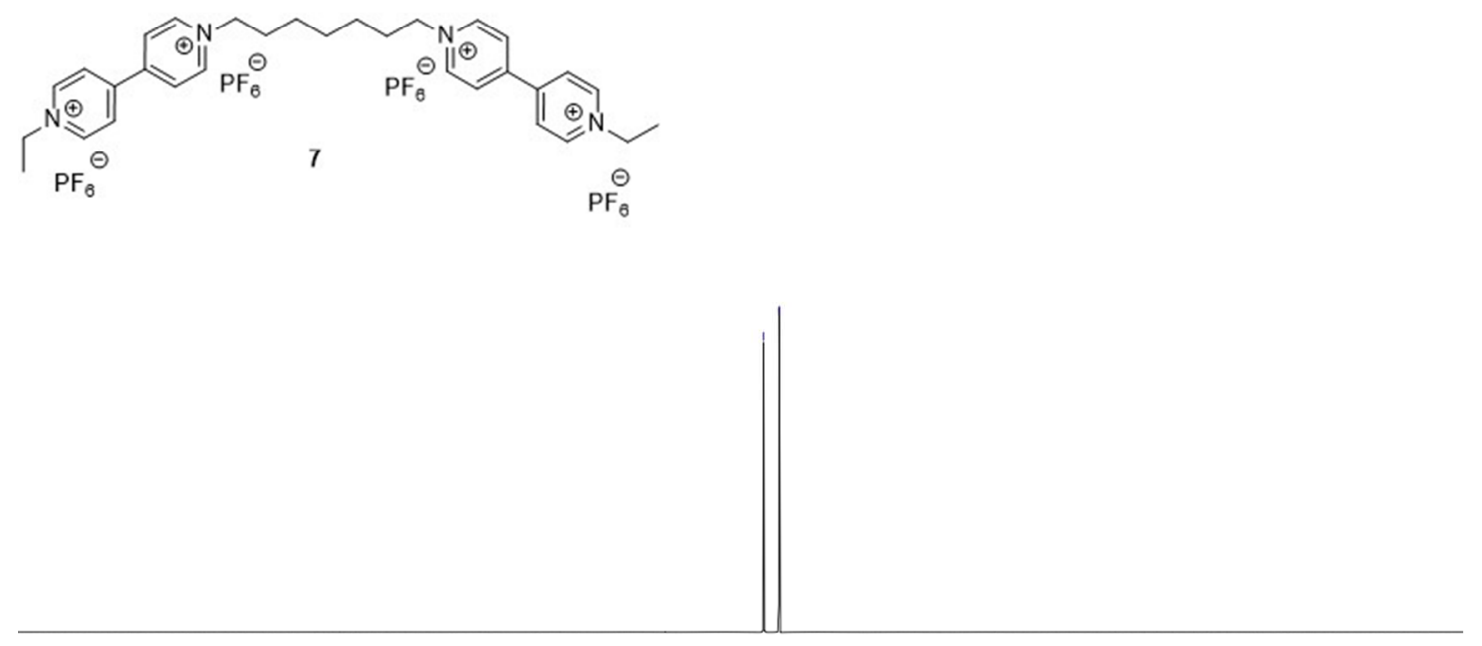

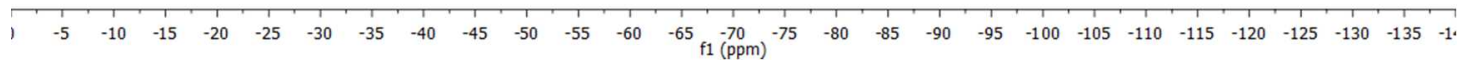
$202 \mathrm{MHz}, \mathrm{CD}_{3} \mathrm{CN}$

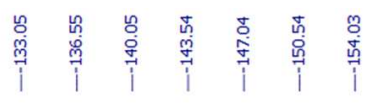

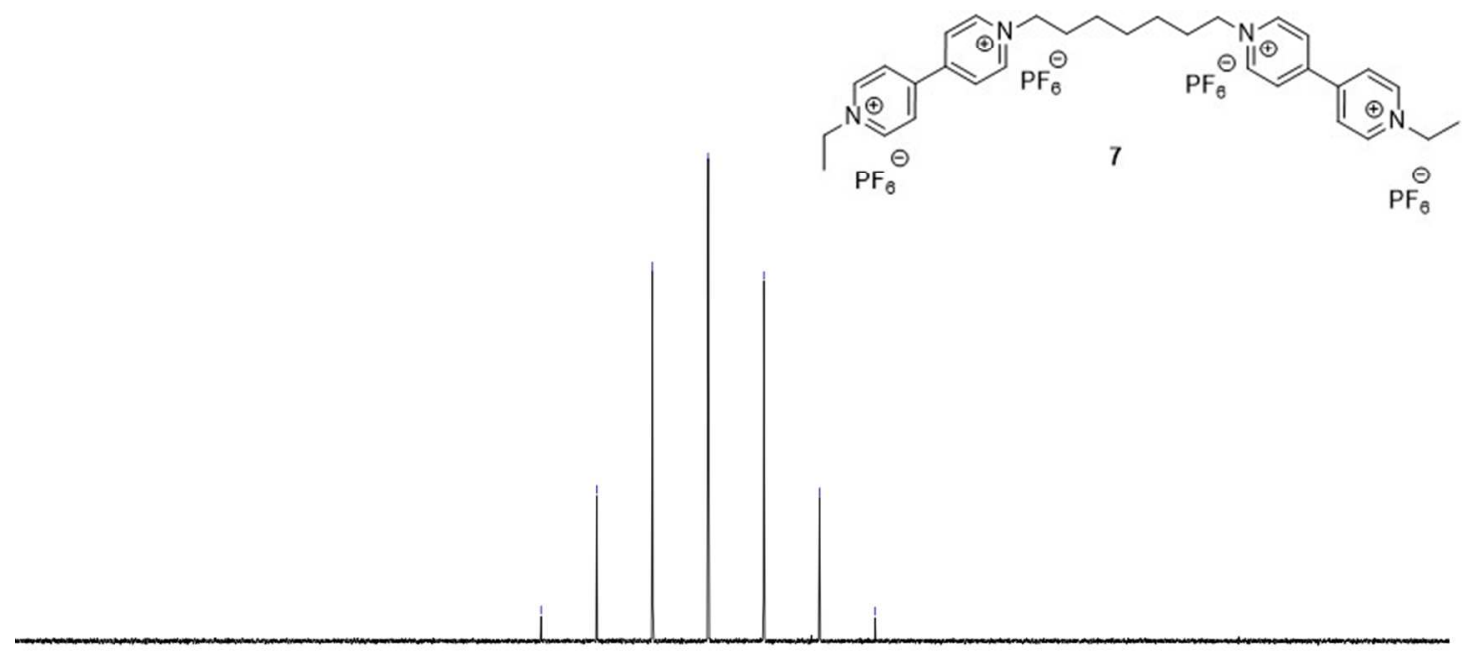


ortho-xylyl bis(viologen) tetra(hexafluorophoshate) 8 NMRs $400 \mathrm{MHz}, \mathrm{CD}_{3} \mathrm{CN}$

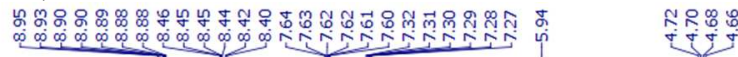

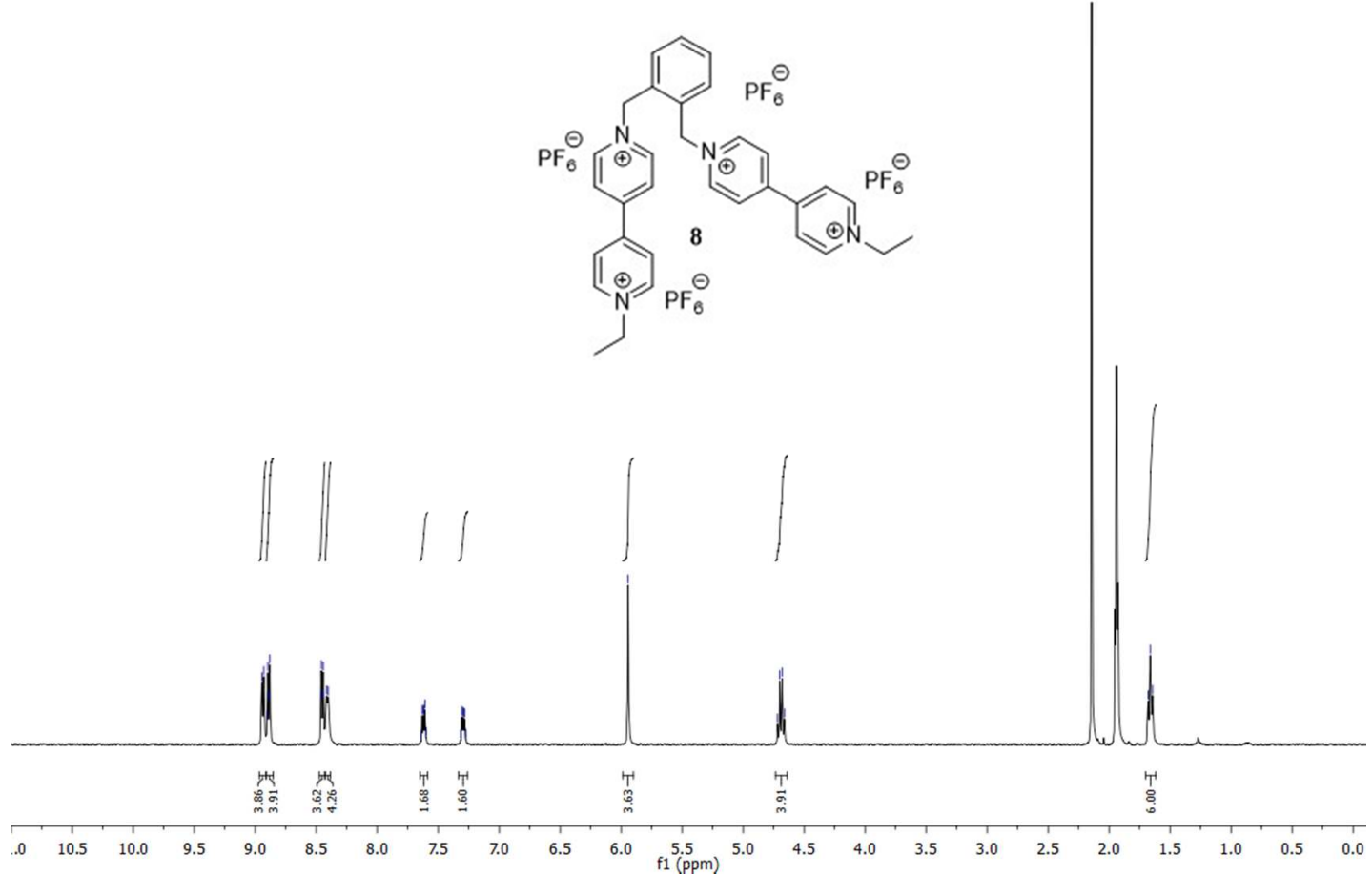
$151 \mathrm{MHz}, \mathrm{CD}_{3} \mathrm{CN}$

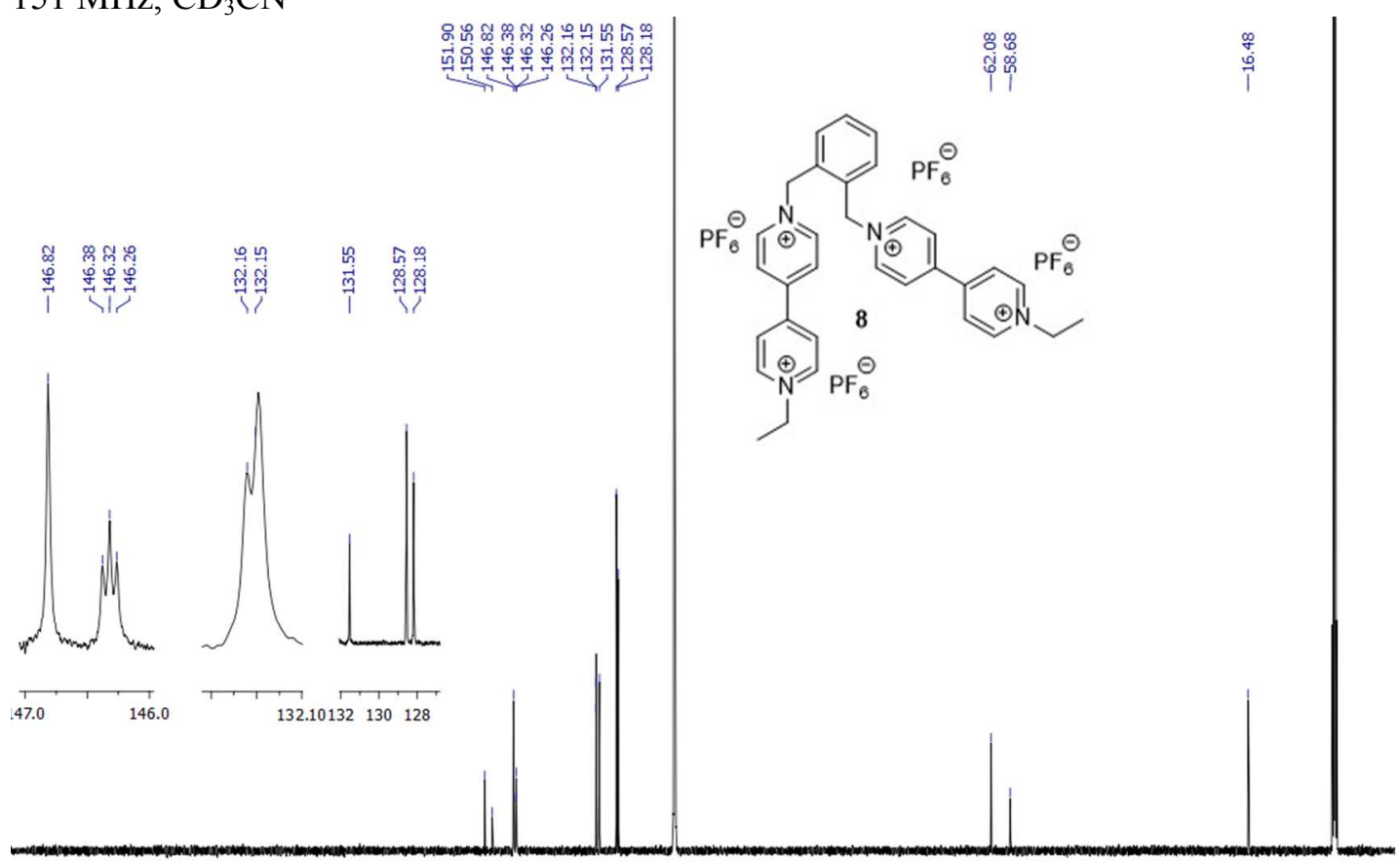

$\begin{array}{llllllllllllllllllllllll}230 & 220 & 210 & 200 & 190 & 180 & 170 & 160 & 150 & 140 & 130 & 120 & 110 & 100 & 90 & 80 & 70 & 60 & 50 & 40 & 30 & 20 & 10 & 0\end{array}$ 
$376 \mathrm{MHz}, \mathrm{CD}_{3} \mathrm{CN}$

तil

(n)

\begin{tabular}{llllllllllllllllllllllllllllllllllll}
\hline & -5 & -10 & -15 & -20 & -25 & -30 & -35 & -40 & -45 & -50 & -55 & -60 & -65 & -70 & -75 & -80 & -85 & -90 & -95 & -100 & -105 & -110 & -115 & -120 & -125 & -130 & -135 & -1
\end{tabular} $202 \mathrm{MHz}, \mathrm{CD}_{3} \mathrm{CN}$

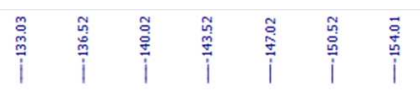
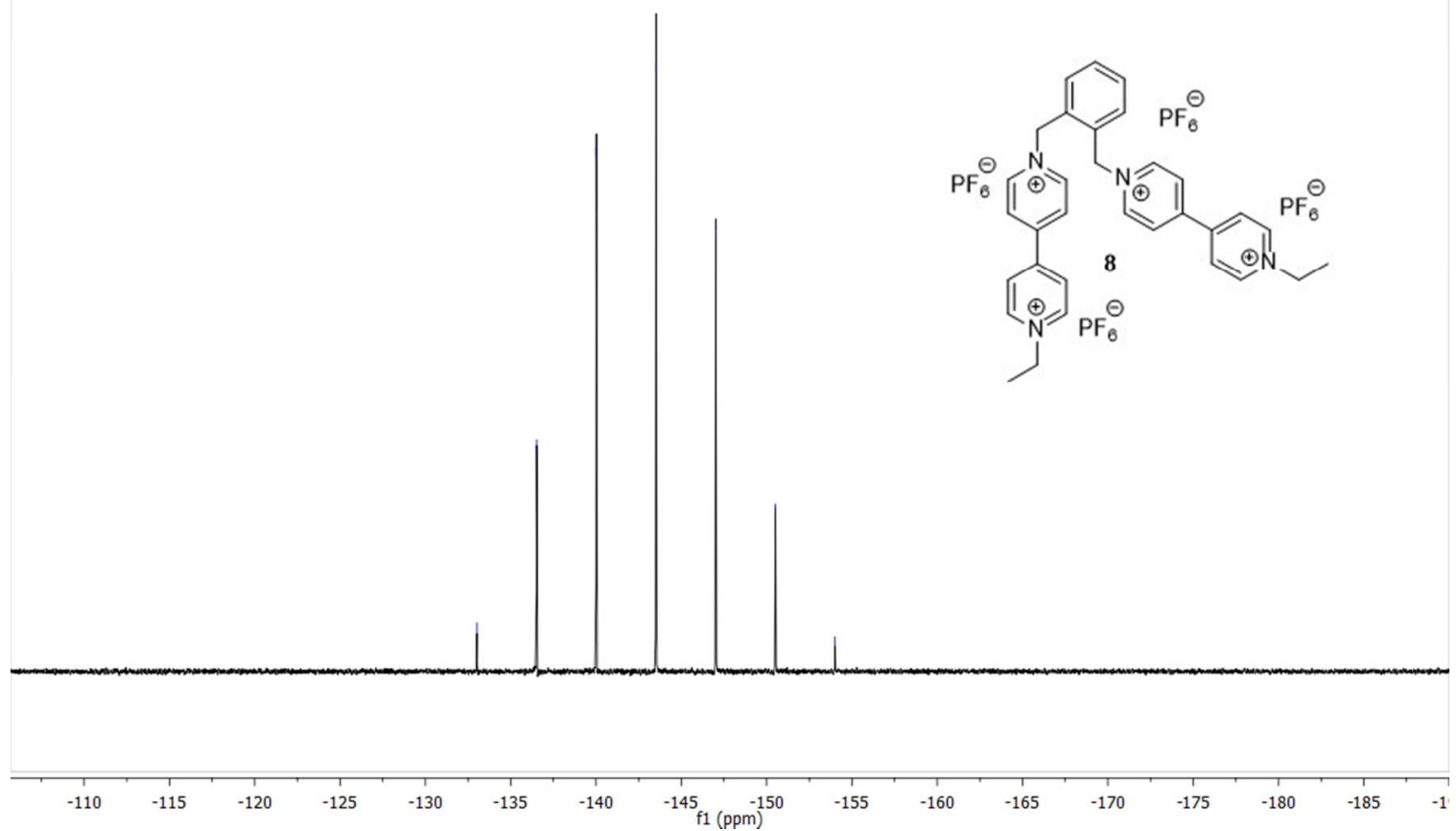
meta-xylyl bis(viologen) tetra(hexafluorophoshate)9 NMRs $400 \mathrm{MHz}, \mathrm{CD}_{3} \mathrm{CN}$

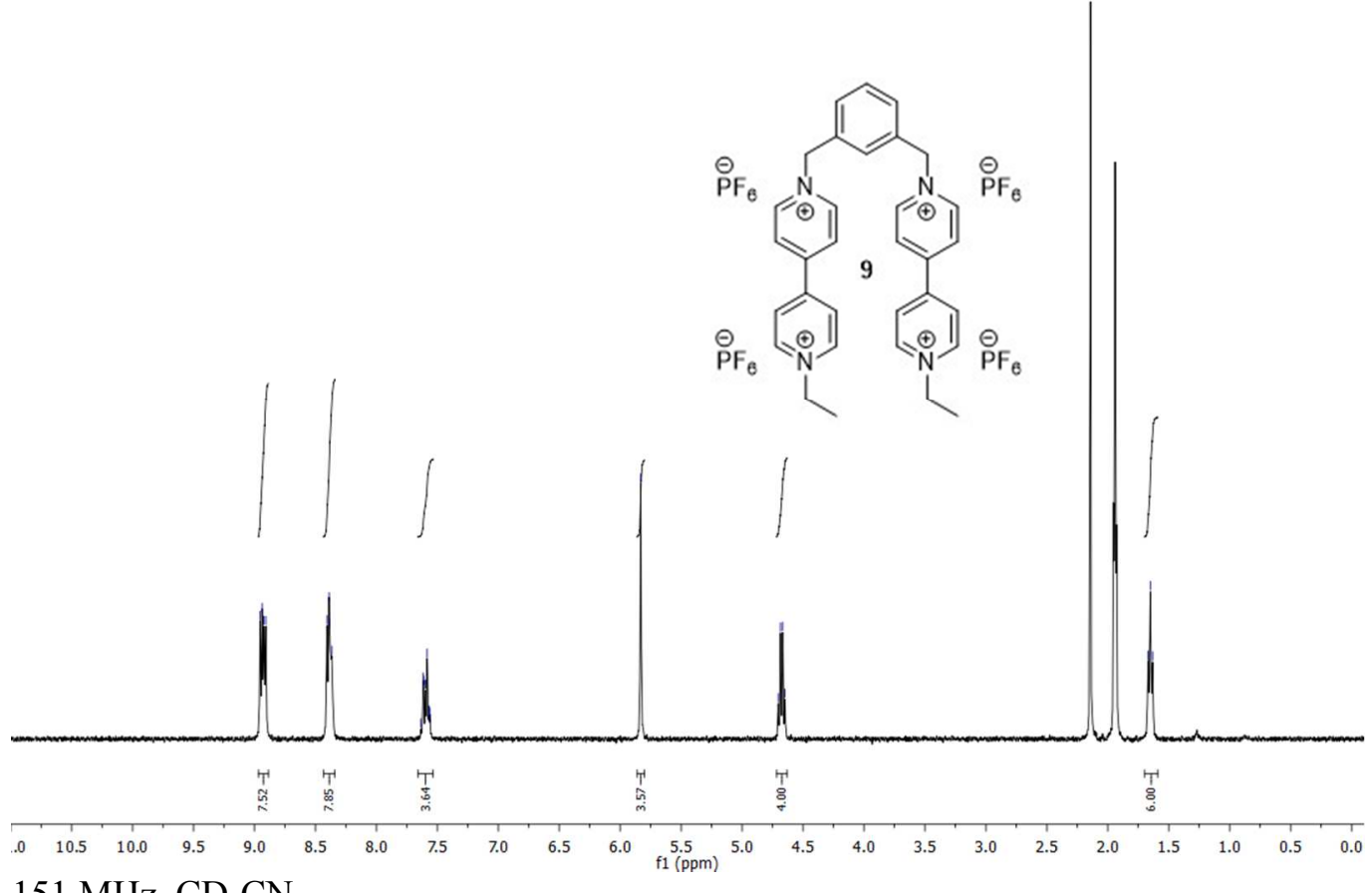
$151 \mathrm{MHz}, \mathrm{CD}_{3} \mathrm{CN}$
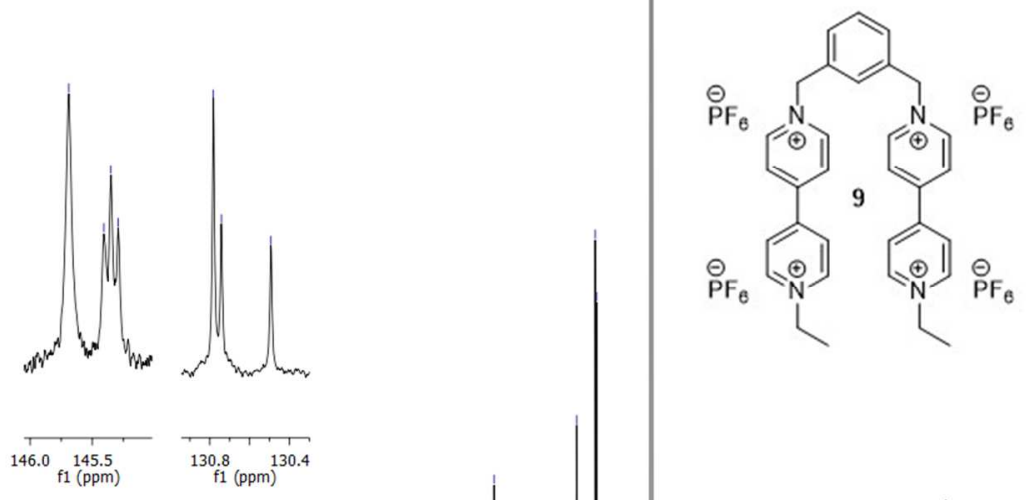

$\begin{array}{llllllllllllllllllllllllllllllllll}230 & 220 & 210 & 200 & 190 & 180 & 170 & 160 & 150 & 140 & 130 & 120 & 110 & 100 & 90 & 80 & 70 & 60 & 50 & 40 & 30 & 20 & 10 & 0 & -1\end{array}$ 

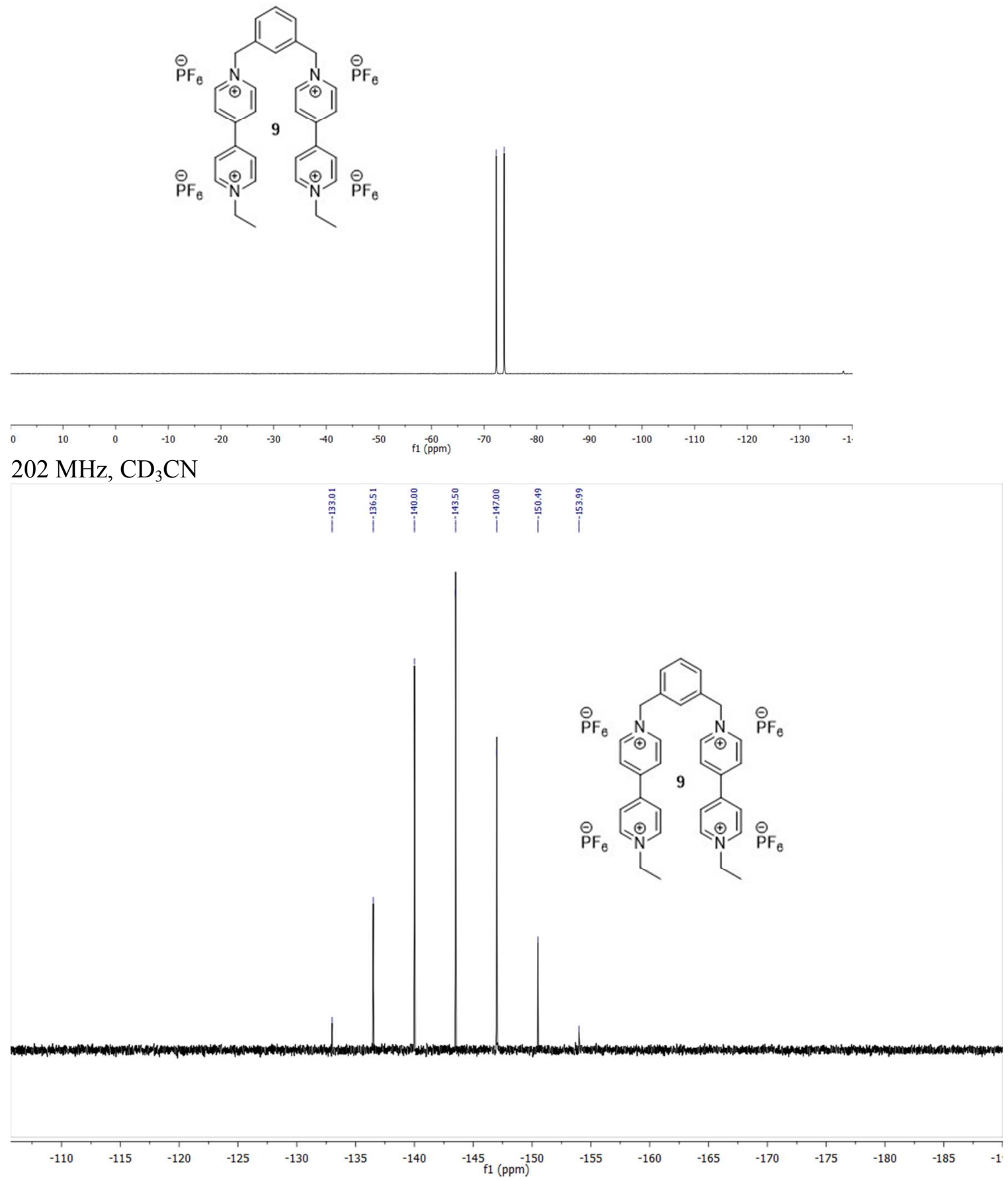
Poly 3,4-di[(1-ethylviologen)methyl]styrene tetra hexafluorophosphate $\mathbf{1 0}$ NMRs $600 \mathrm{MHz}, \mathrm{CD}_{3} \mathrm{CN}$
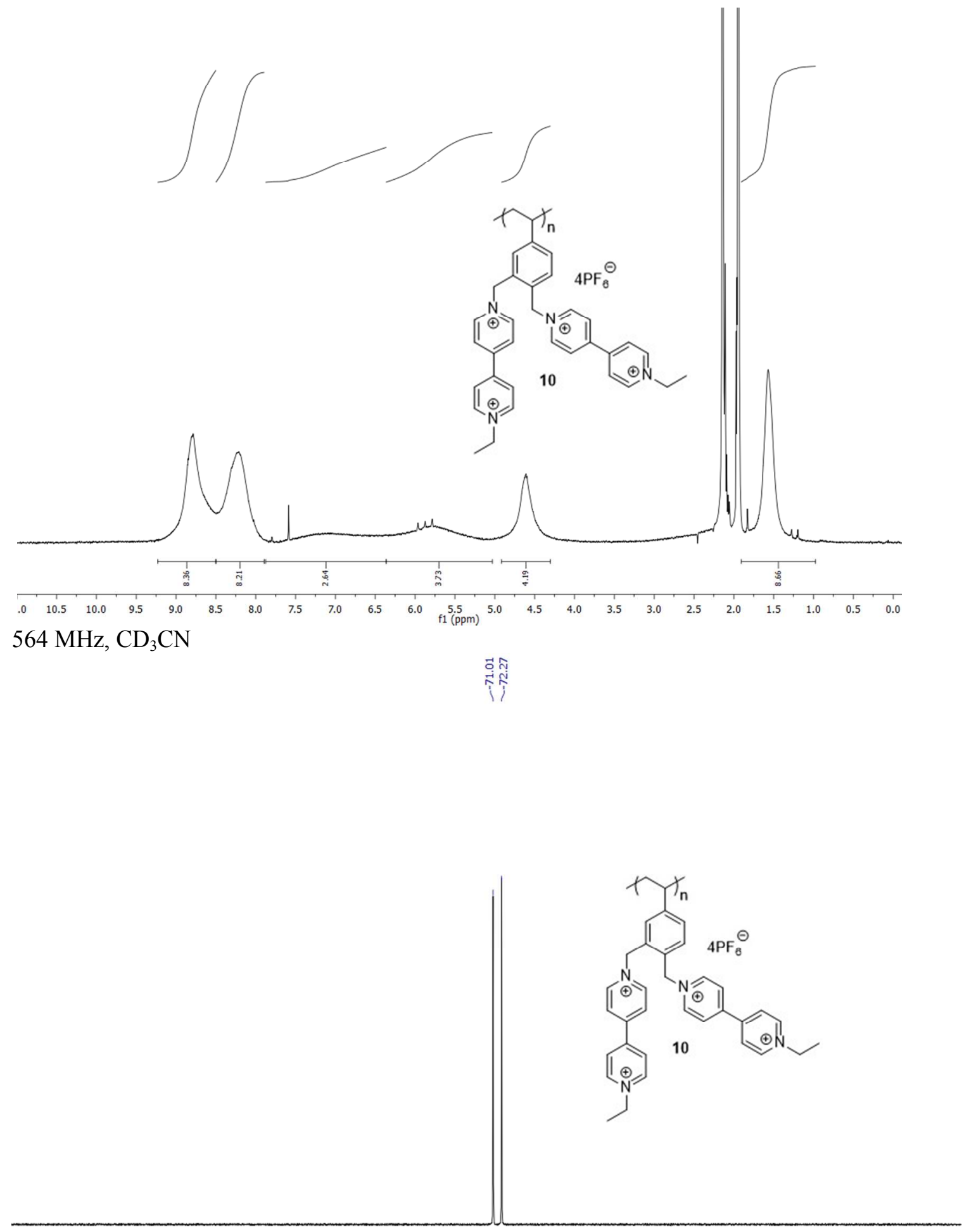
$243 \mathrm{MHz}, \mathrm{CD}_{3} \mathrm{CN}$
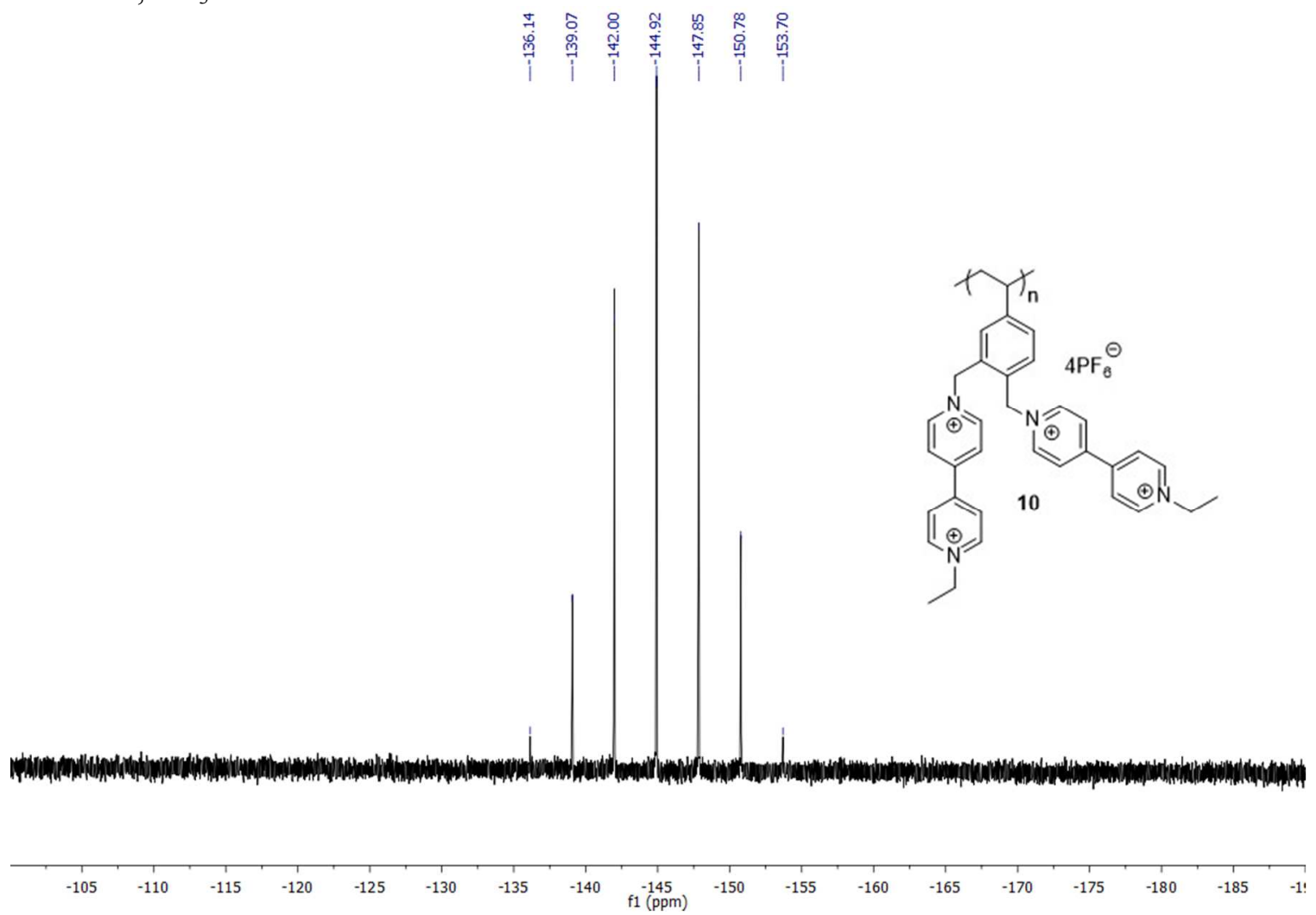
Poly 3,5-di[(1-ethylviologen)methyl]styrene tetra hexafluorophosphate 11 NMRs
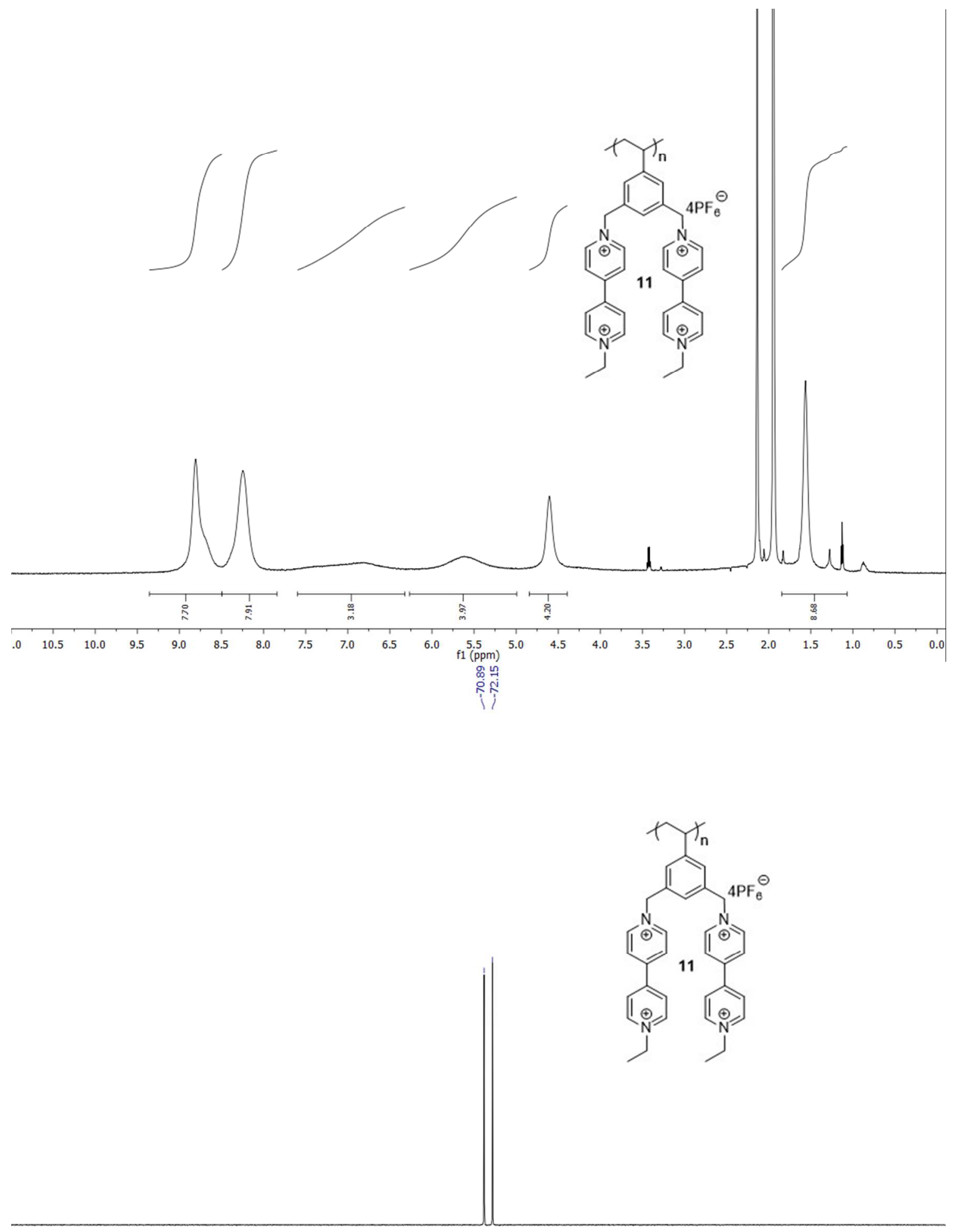

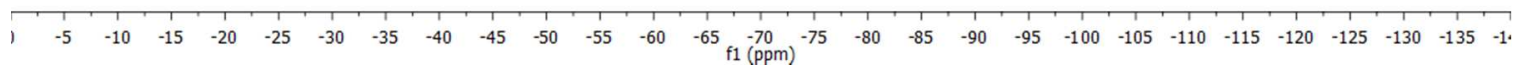




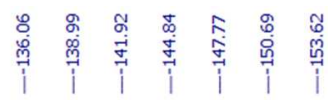

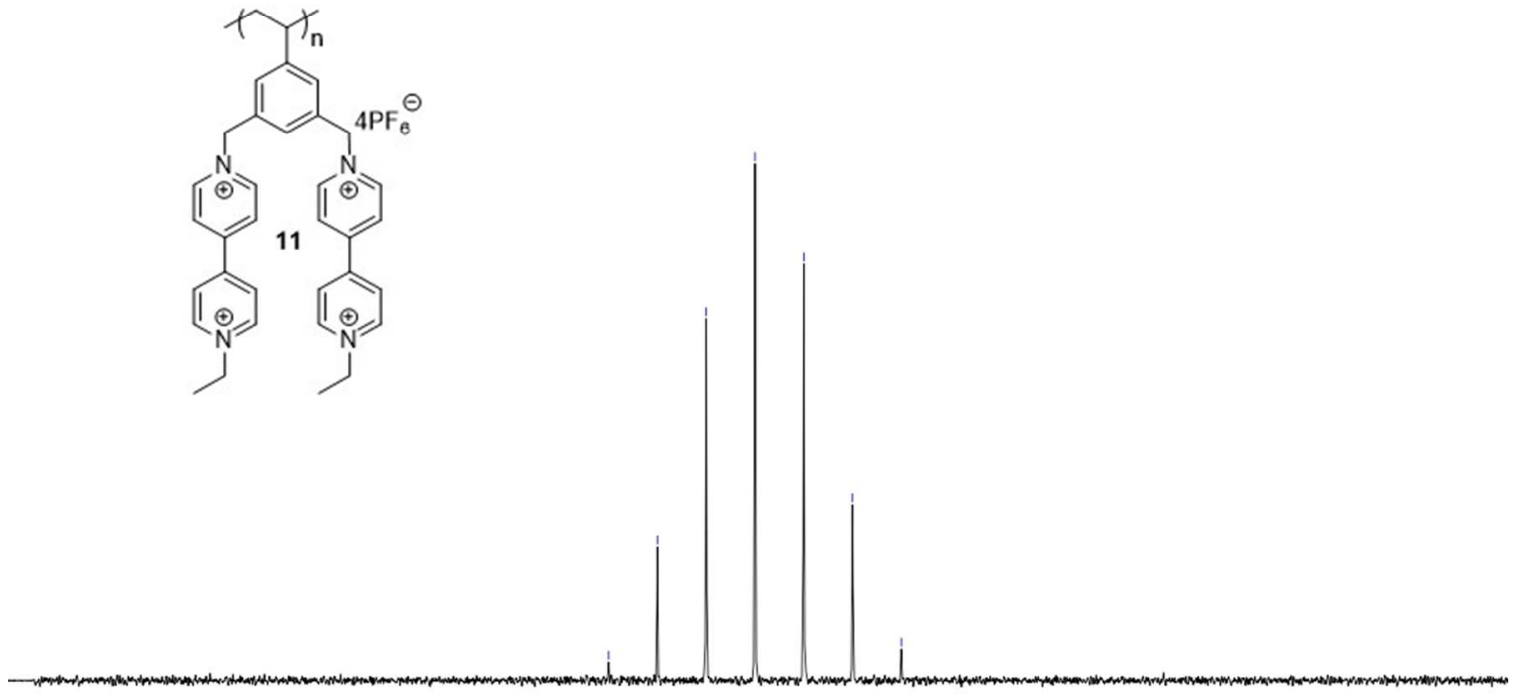


3,4-di(chloromethyl)styrene 14 (monomer) NMRs $400 \mathrm{MHz}, \mathrm{CDCl}_{3}$

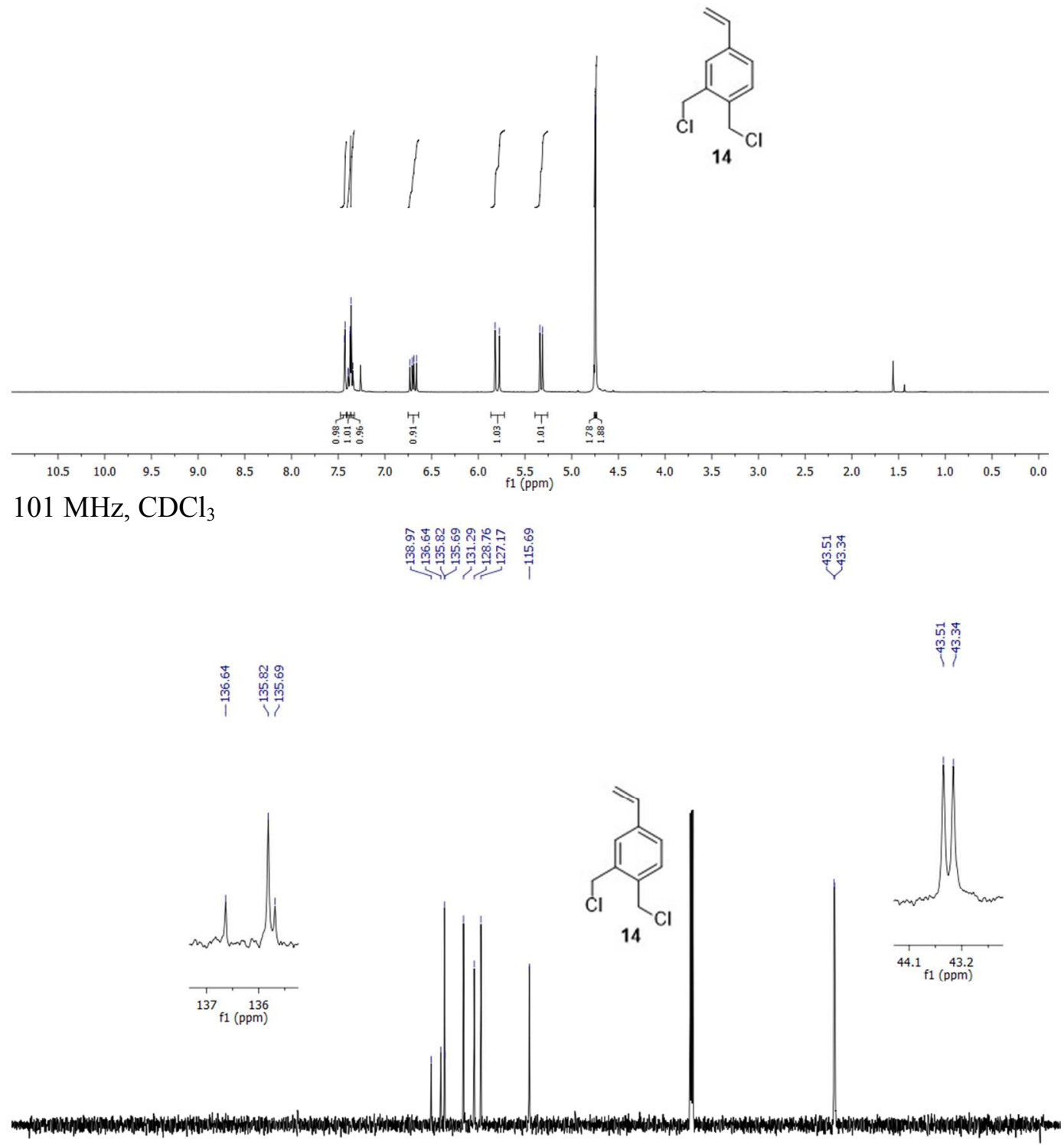

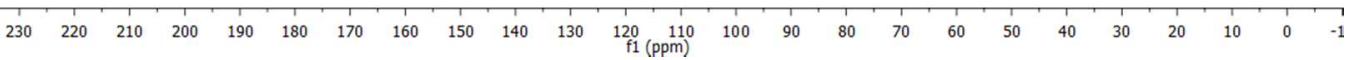


Poly 3,5-di(chloromethyl)styrene 15 NMR $499 \mathrm{MHz}, \mathrm{CDCl}_{3}$

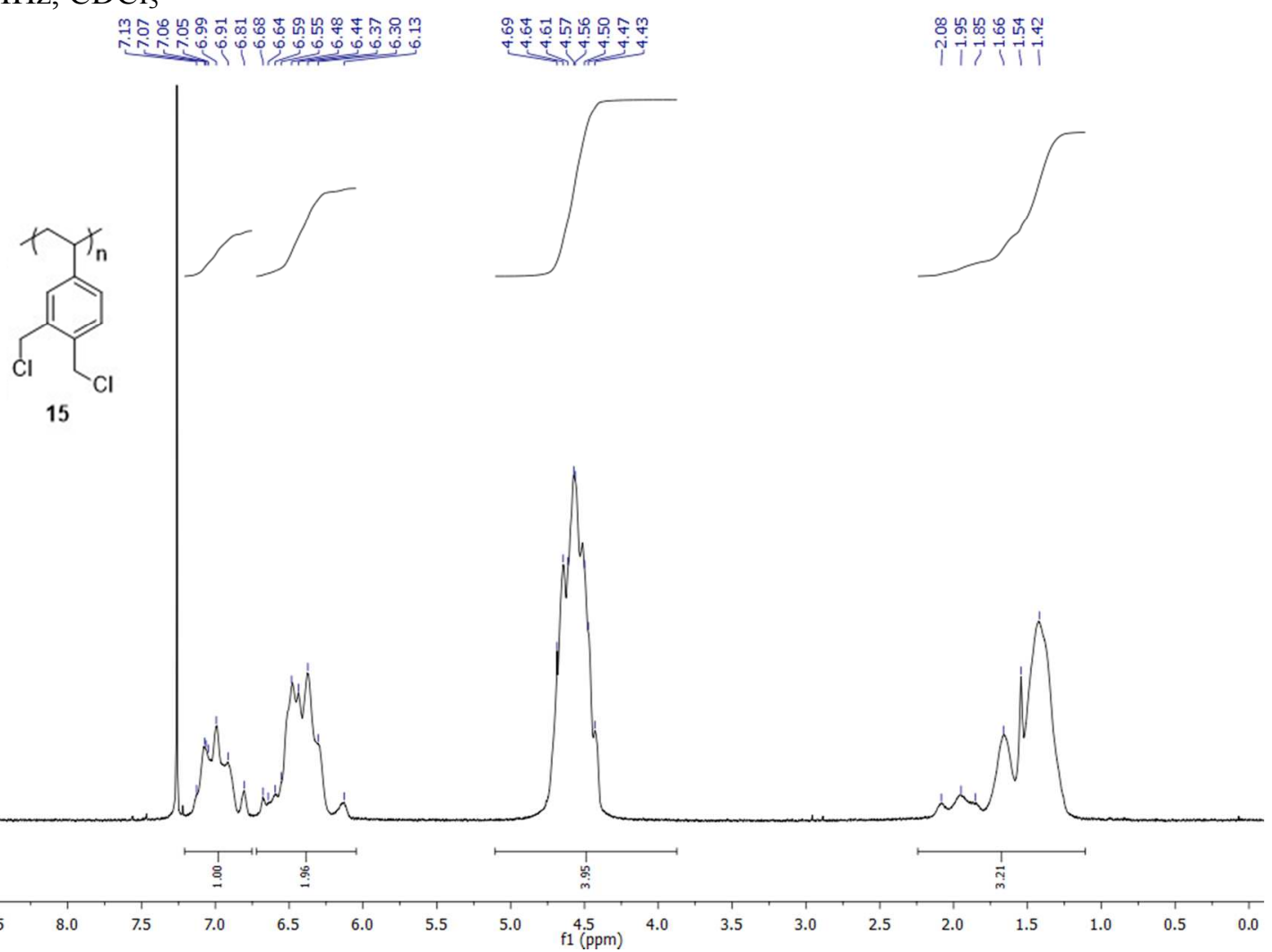


3,5-di(chloromethyl)styrene $\mathbf{1 8}$ (monomer) NMRs $499 \mathrm{MHz}, \mathrm{CDCl}_{3}$
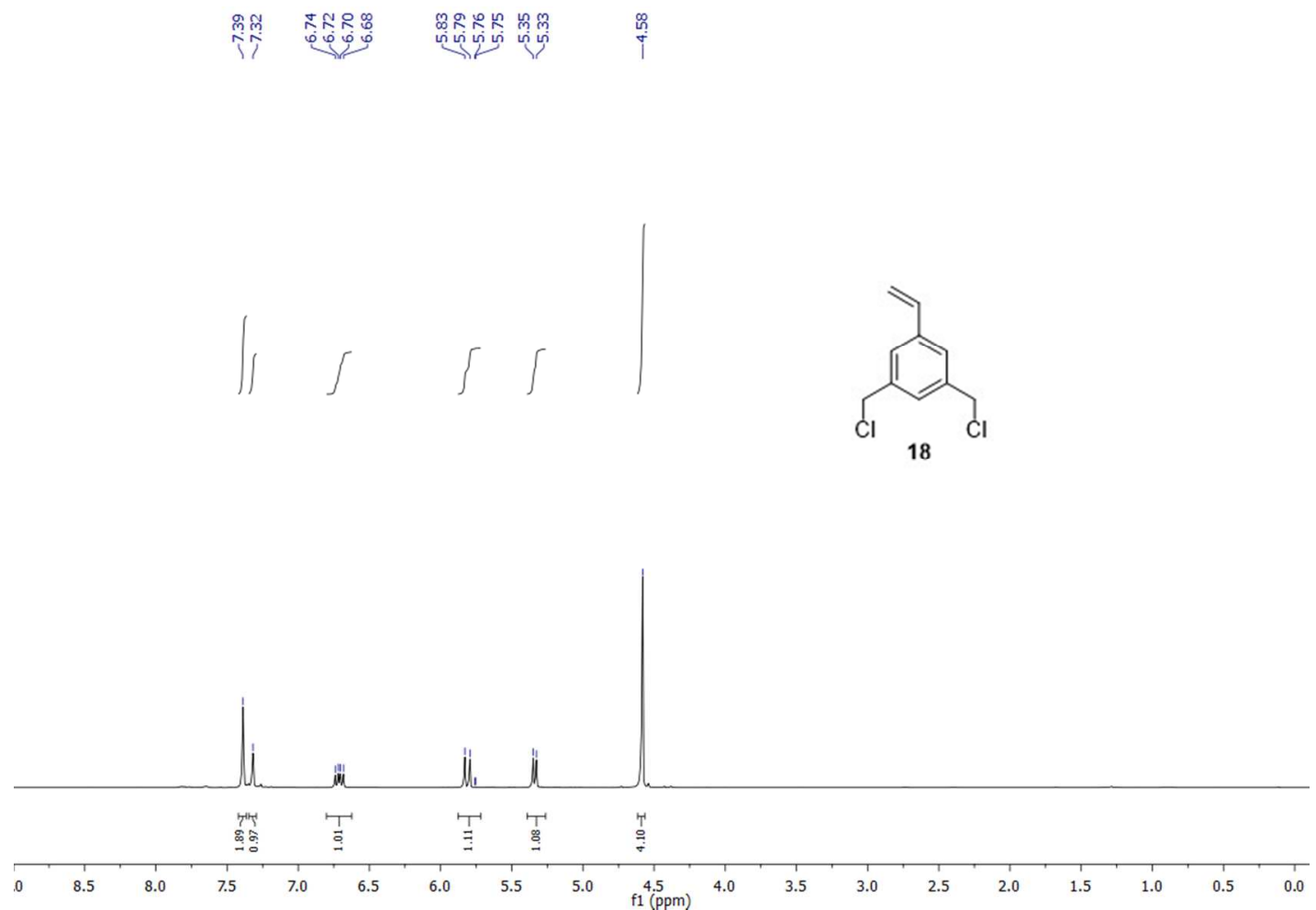

$126 \mathrm{MHz}, \mathrm{CDCl}_{3}$

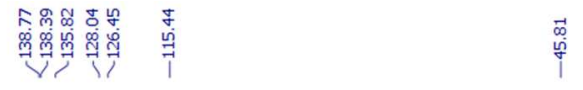

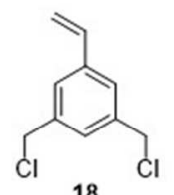

18

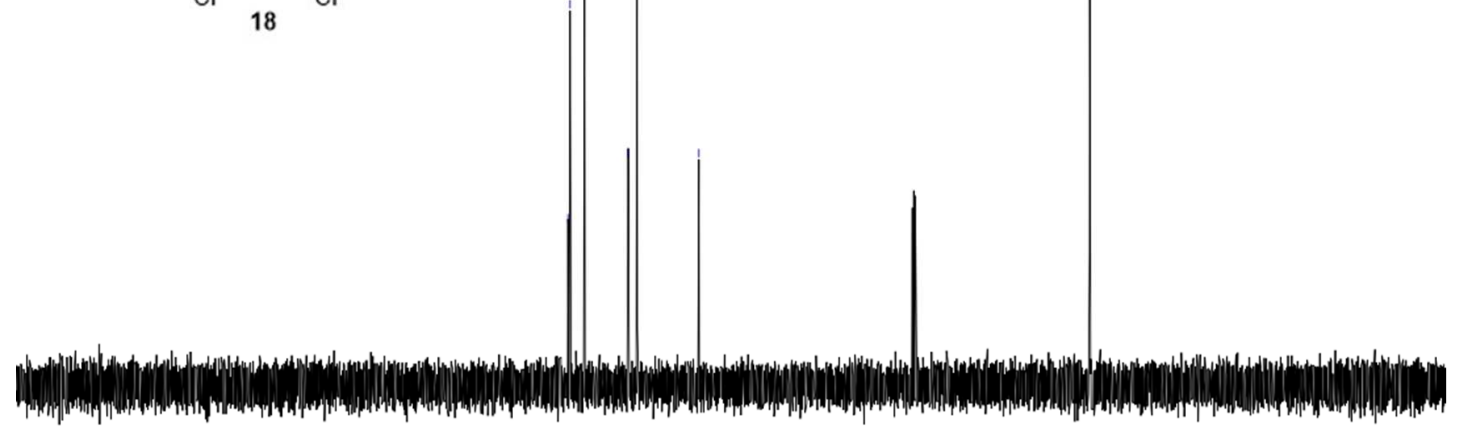

$\begin{array}{lllllllllllllllllllllllll}230 & 220 & 210 & 200 & 190 & 180 & 170 & 160 & 150 & 140 & 130 & 120 & 110 & 100 & 90 & 80 & 70 & 60 & 50 & 40 & 30 & 20 & 10 & 0 & -10\end{array}$ 
Poly 3,5-di(chloromethyl)styrene 19 NMR $499 \mathrm{MHz}, \mathrm{CDCl}_{3}$

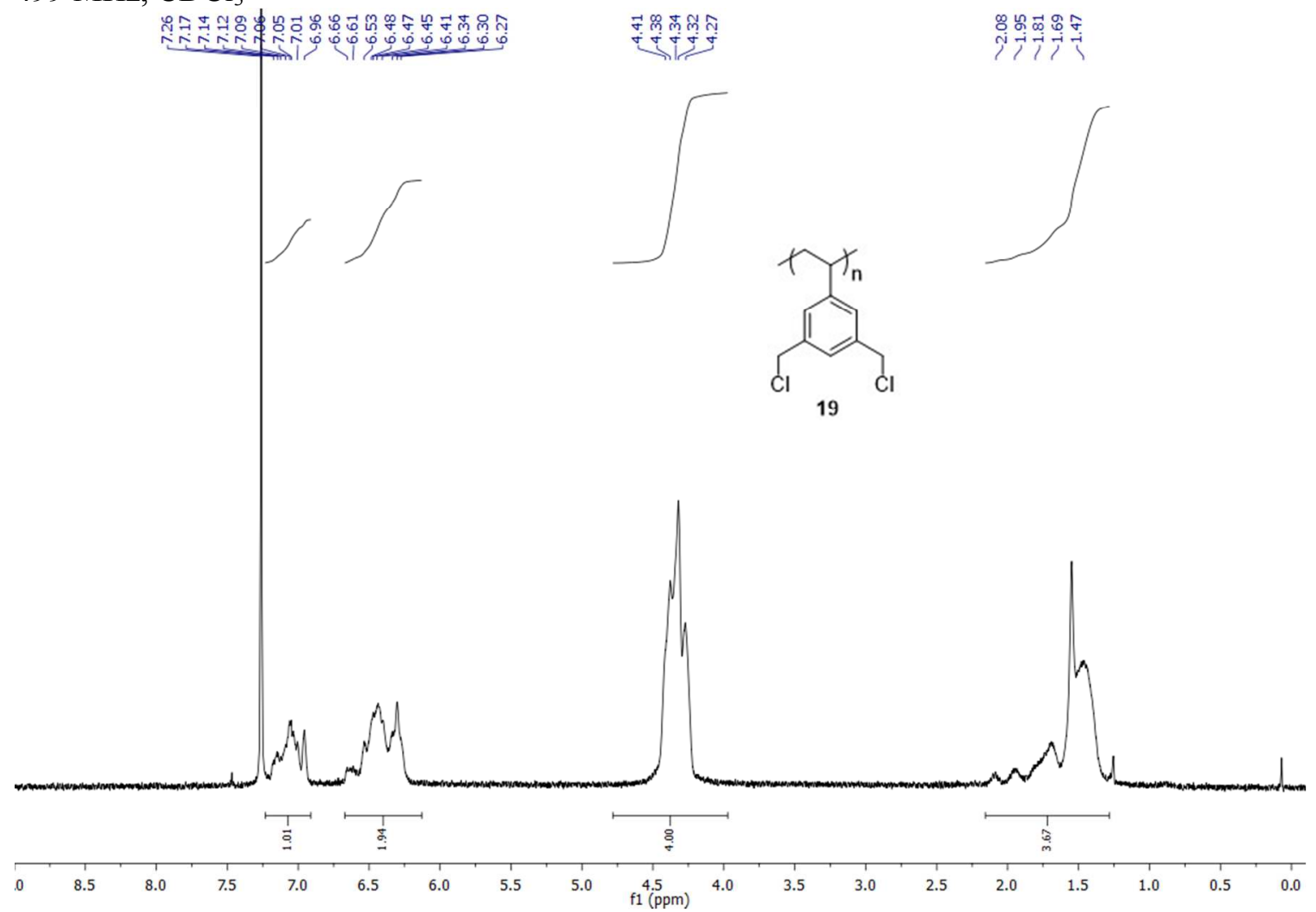




\section{Electrochemistry}

\section{SECM UME Fabrication}

A $12.5 \mu \mathrm{m}$ radius wire was purchased from Goodfellow (Huntington, England) and sealed in a patch clamp glass capillary (World Instruments) using a Narishige pipette puller (Japan). Electrical connection to the Pt UME from the back was done with silver epoxy and copper wire. The Pt UME was then exposed using sandpaper and verified for connection by performing voltammetry.

\section{Results}

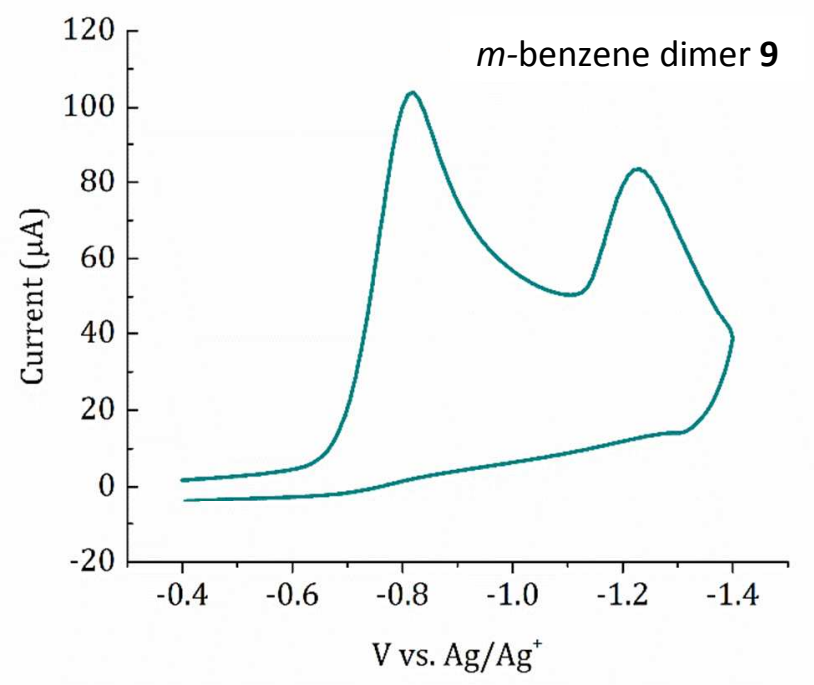

Figure S1. Cyclic Voltammogram at $200 \mathrm{mV} / \mathrm{s}$ for the $m$-benzene dimer 9 at $5 \mathrm{mM}$ accesing the second redox process. It can be observed that this process passivates the electrode surface.
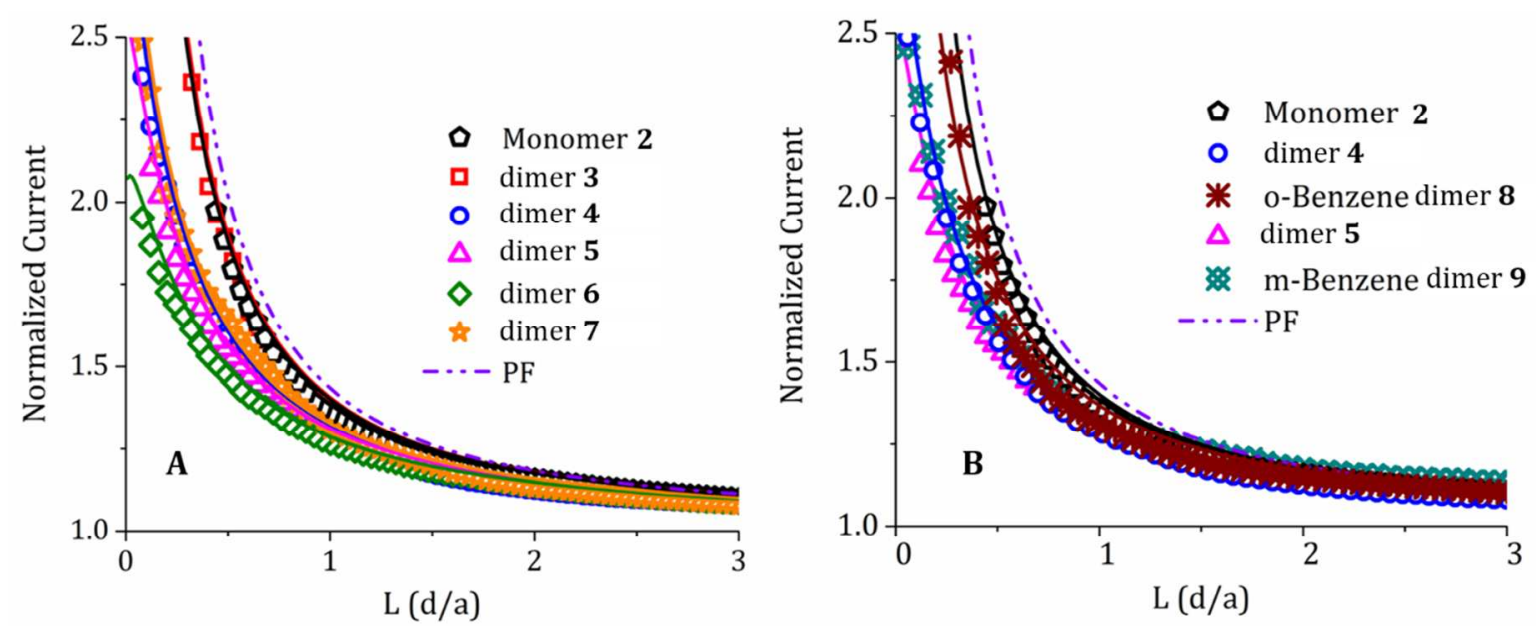

Figure S2. Scanning electrochemical microscopy feedback approach curves. All approach curves were performed in a solution of $5 \mathrm{mM}$ of the dimer (repeat unit) in $0.1 \mathrm{M} \mathrm{LiBF} 4$ supporting electrolyte in acetonitrile. All approach curves were measured using a $12.5 \mu \mathrm{m}$ radius Pt UME with an $\mathrm{Rg}$ of 2 moving at $3 \mu \mathrm{m} / \mathrm{s}$. The substrate was a $1.5 \mathrm{~mm}$ Pt disk electrode that was biased at $120 \mathrm{mV}$ positive of the $\mathrm{E} 0$ for each of the dimers. Colored open symbols represent 
experimental data points and the solid lines indicate theoretical fits. PF indicates the theoretical curve for perfect positive feedback which corresponds to pure mass transfer limited kinetics A. Approach curves for all of the alkyl based dimers. B. Approach curves with the benzene based dimers and their alkyl counterparts, dimer $\mathbf{4}$ and dimer $\mathbf{5}$.

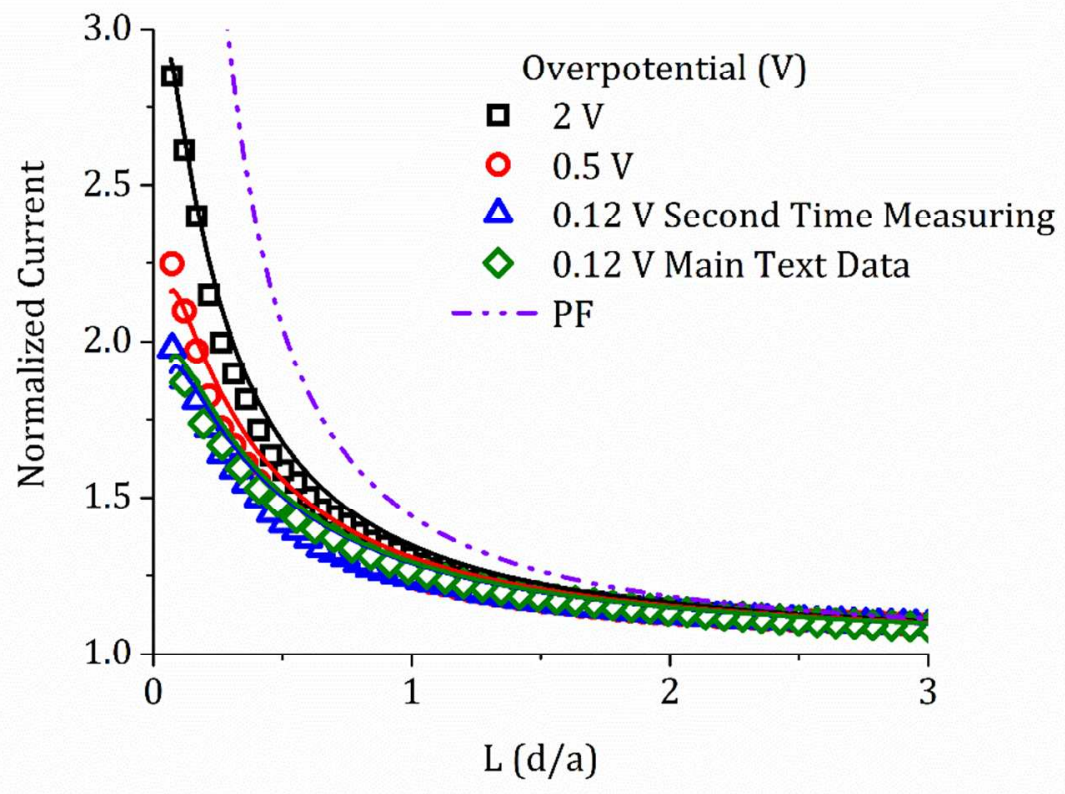

Figure S3. SECM approach curves with $5 \mathrm{mM}$ of the repeat unit of the dimer 6 in $0.1 \mathrm{M} \mathrm{LiBF} 4$ in acetonitrile. SECM tip had a radius of $12.5 \mathrm{um}$ and an $\mathrm{Rg}$ of 2 , with a motor speed of $3 \mathrm{um} / \mathrm{s}$. The feedback kinetics of dimer 6 respond to substrate overpotential in a manner predicted by ButlerVolmer theory, the feedback kinetics increase. The approach curves with $120 \mathrm{mV}$ overpotential are shown to be reproducible over different days.

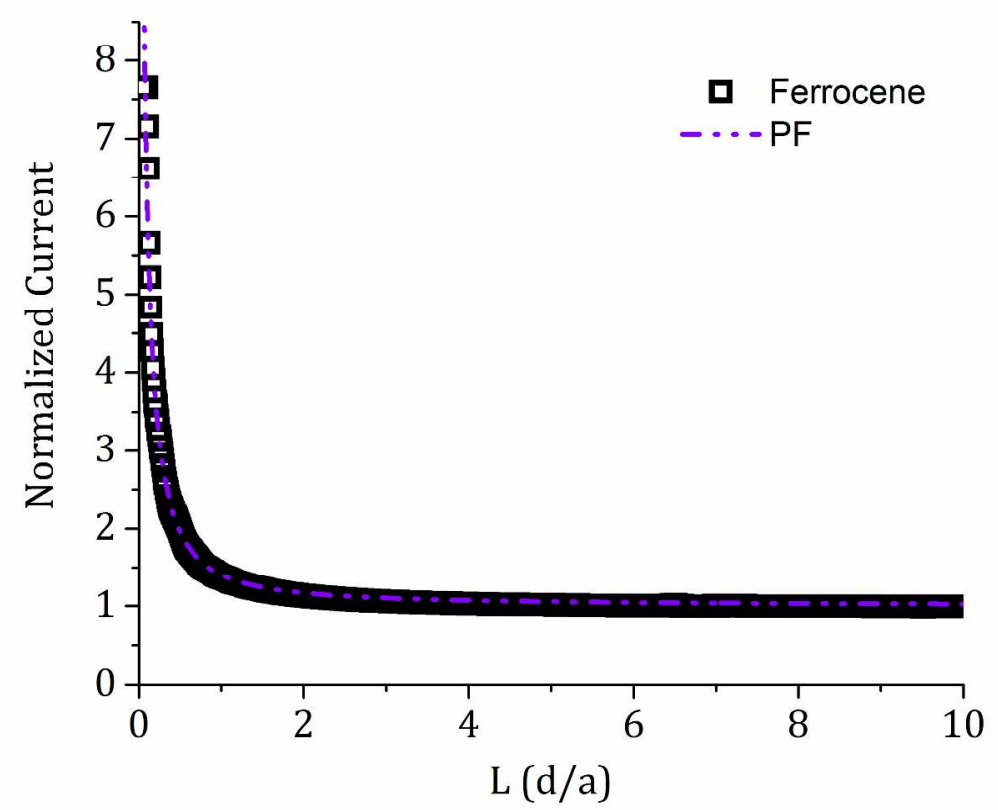


Figure S4. Calibration of the SECM tip-substrate separation distance $\mathrm{d}_{0}$ when at the approached position. Solution contained $10 \mathrm{mM}$ ferrocene in $0.1 \mathrm{M} \mathrm{LiBF}_{4}$ in acetonitrile. Identification of the $\mathrm{d}_{0}$ parameter was done by approaching a $12.5 \mu \mathrm{m}$ radius Pt UME with an Rg of 2 using the oxidation of ferrocene to a Pt macrodisk substrate poised at $-0.1 \mathrm{~V}$ vs. $\mathrm{Ag} / \mathrm{Ag}^{+}$in order to observe perfect positive feedback. Fitting of the experimental approach curve to positive feedback theory finds that the tip was separated off the electrode surface by $0.058 \mathrm{~L}$, or $725 \mathrm{~nm}$. All approach curves measured with the viologen dimers and polymers were adjusted by the $\mathrm{d}_{0}$ value of $0.058 \mathrm{~L}$ to account for this calibrated tip separation distance.

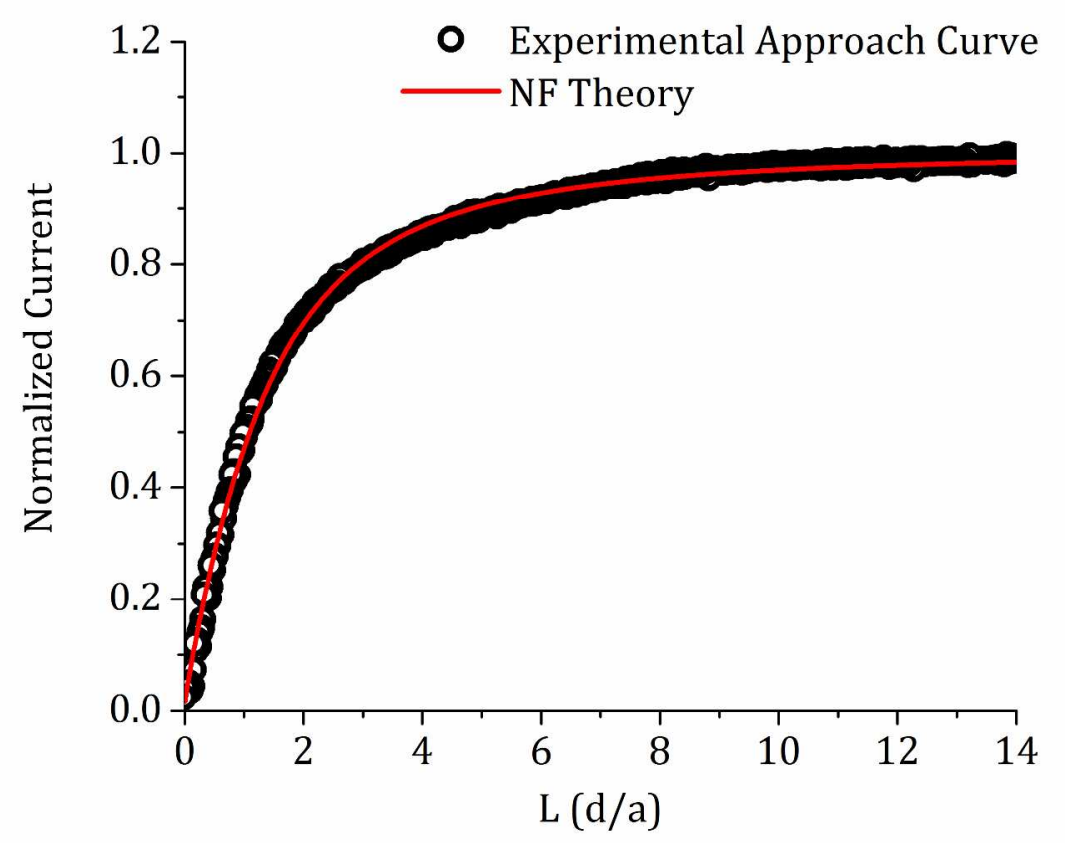

Figure S5. Calibration of the Rg for the Wollaston SECM tip with an electrode radius of $300 \mathrm{~nm}$ using negative feedback approach curves. The solution contained $10 \mathrm{mM}$ TMPD in $0.1 \mathrm{M} \mathrm{LiBF}_{4}$ in acetonitrile. The Wollaston tip was approached to a glass substrate using the first oxidation of TMPD until complete negative feedback was observed. Fitting of the approach curve to negative feedback theory finds that the electrode had an effective $\mathrm{Rg}$ of 16. At the approached position, the electrode was $77 \mathrm{~nm}$ off the surface indicating that this electrode is able to be placed very near to a substrate without crashing. 


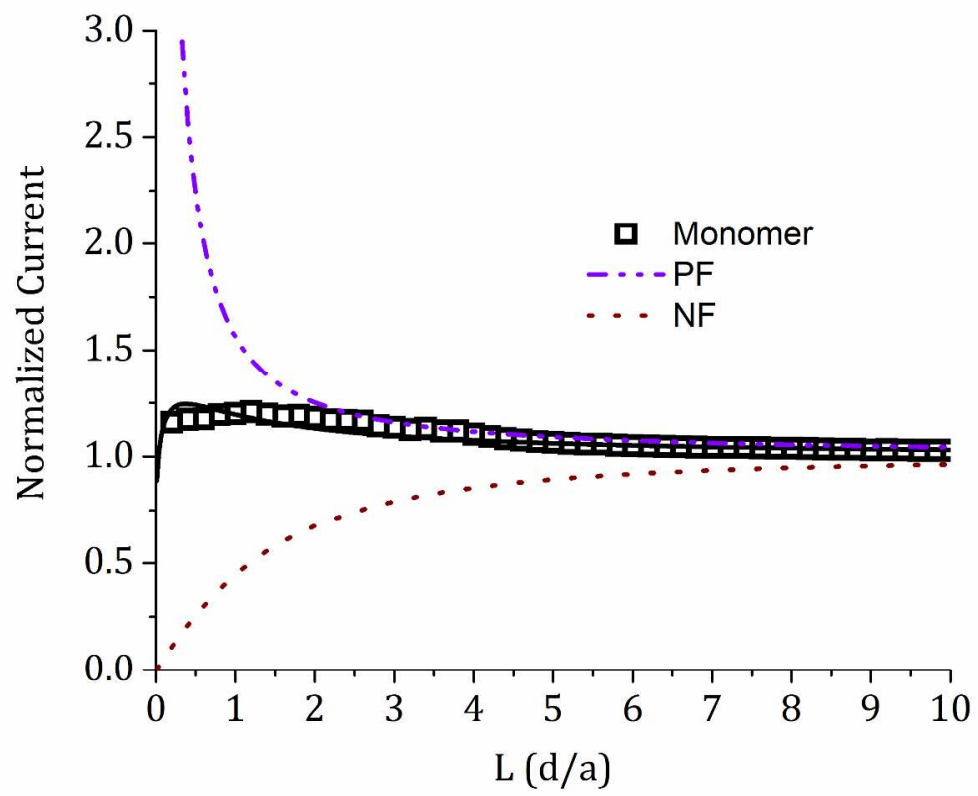

Figure S6. SECM approach curves using the Wollaston SECM tip with $10 \mathrm{mM}$ ethyl viologen monomer in a solution of $0.1 \mathrm{M} \mathrm{LiBF}_{4}$ in acetonitrile to a Pt macrodisk electrode biased at 120 $\mathrm{mV}$ positive of the redox couple. Here, the approach curves find that the kinetics for the reduction of ethyl viologen are able to be distinguished from pure positive feedback and are above negative feedback. Fitted kinetics from the approach curves find that the standard rate constant is 7.57 $\mathrm{cm} / \mathrm{s}$.

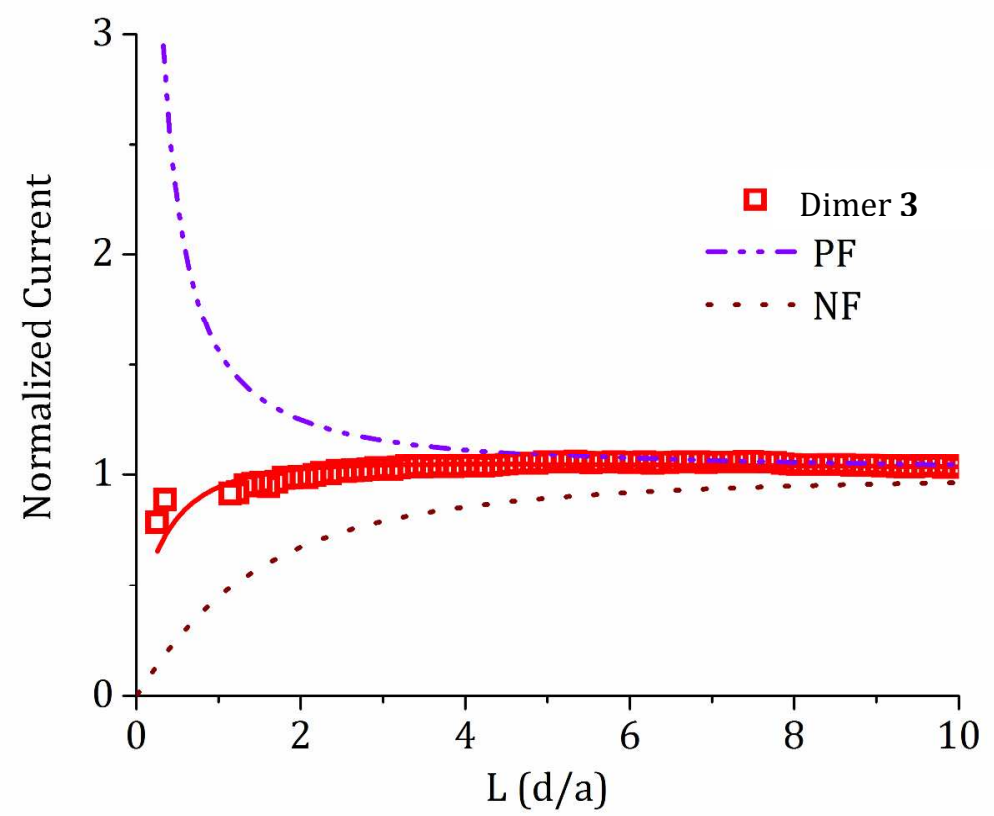

Figure S7. SECM approach curves using the Wollaston SECM tip with $5 \mathrm{mM}$ of the repeat unit of dimer 3 in a solution of $0.1 \mathrm{M} \mathrm{LiBF}_{4}$ in acetonitrile to a Pt macrodisk electrode biased at 120 
$\mathrm{mV}$ positive of the redox couple. Here, the approach curves find that the kinetics for the reduction of dimer 3 are able to be distinguished from pure positive feedback and are above negative feedback. Fitted kinetics from the approach curves find that the standard rate constant is $1.9 \mathrm{~cm} / \mathrm{s}$.

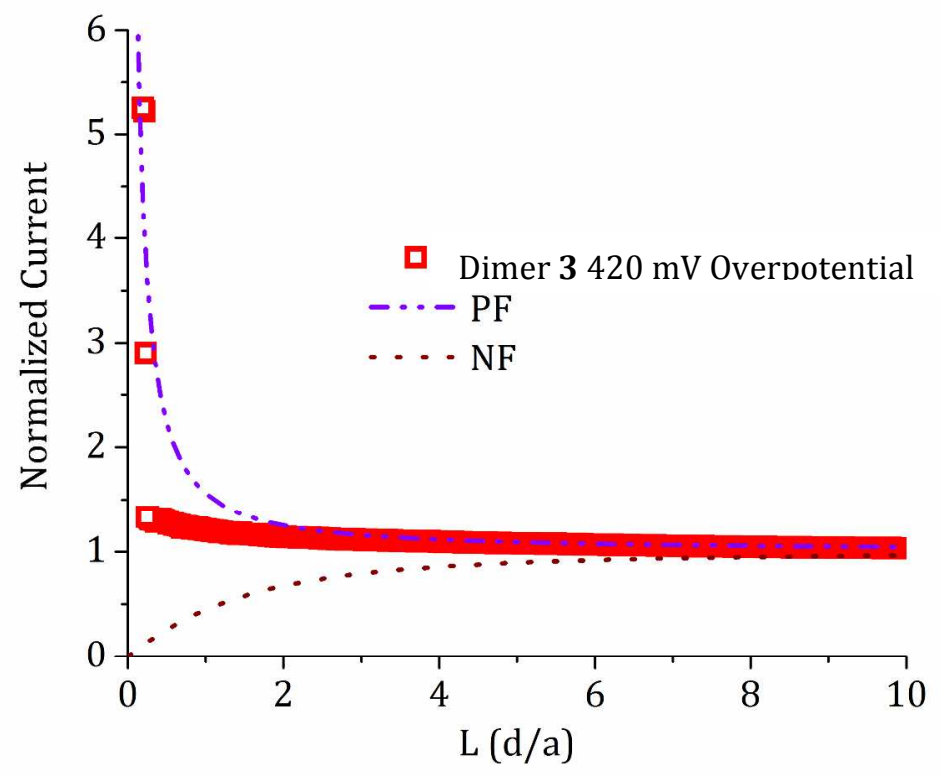

Figure S8. SECM approach curves using the Wollaston SECM tip with $5 \mathrm{mM}$ of the repeat unit of dimer 3 in a solution of $0.1 \mathrm{M} \mathrm{LiBF}_{4}$ in acetonitrile to a Pt macrodisk electrode biased at 420 $\mathrm{mV}$ positive of the redox couple. Under the conditions of $420 \mathrm{mV}$ substrate overpotential, the feedback kinetics fit approximately to mass transfer limited conditions indicating the redox couple is responding to substrate overpotential.

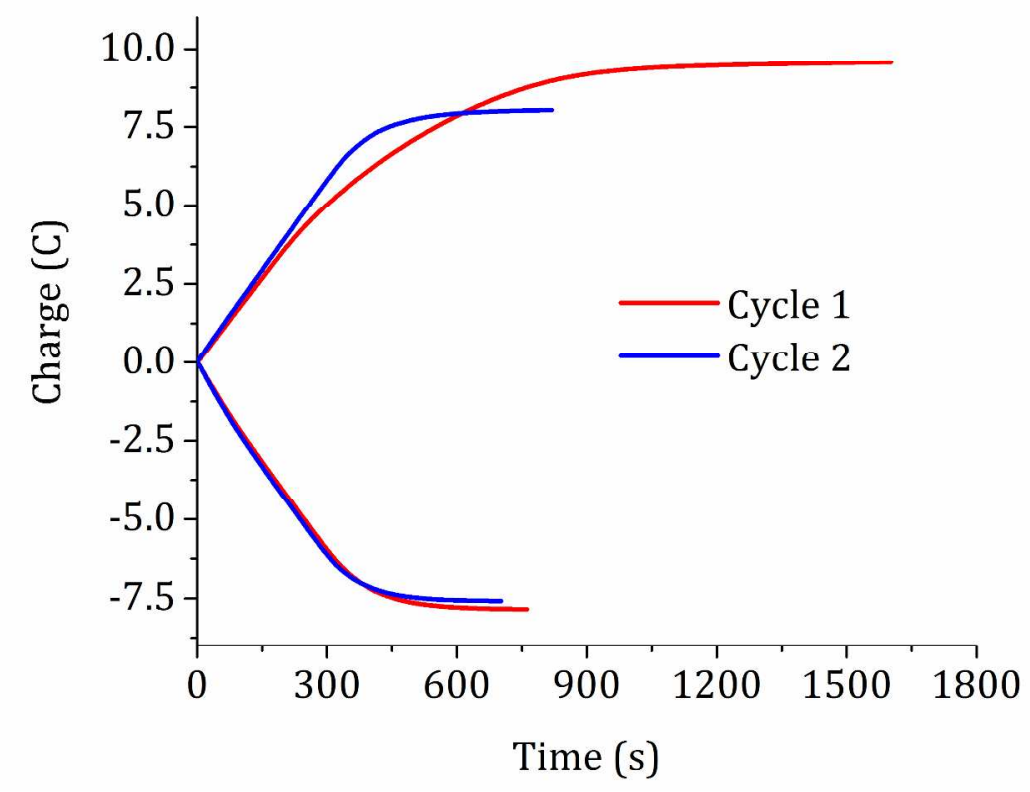

Figure S9. Bulk electrolysis for dimer 3 at $10 \mathrm{mM}$ in $0.1 \mathrm{M} \mathrm{LiBF} 4$ in acetonitrile. 


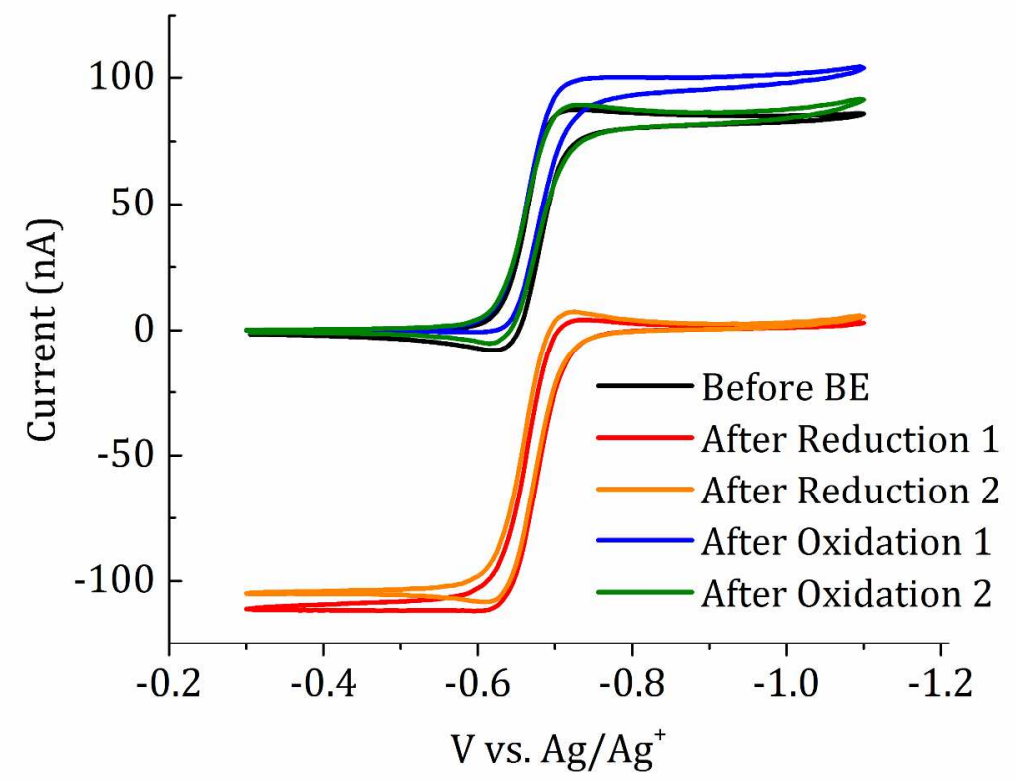

Figure S10. Resulting cyclic voltammograms before, during and after the bulk electrolysis experiments for dimer 3 at $10 \mathrm{mM}$ in $0.1 \mathrm{M} \mathrm{LiBF} 4$ in acetonitrile.

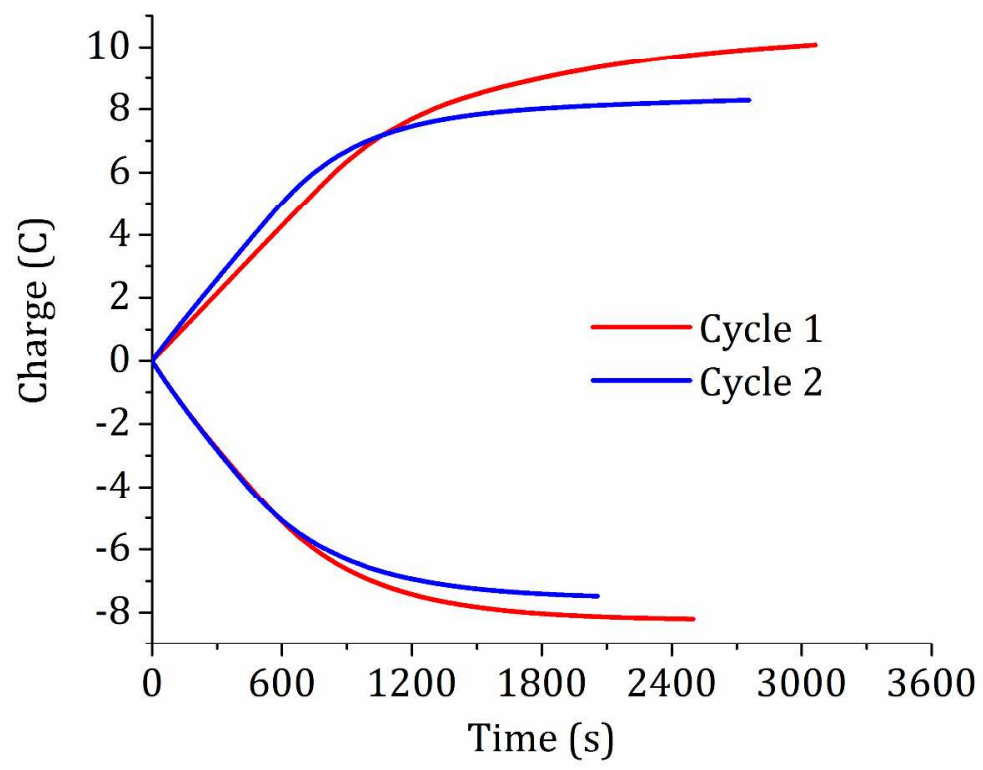

Figure S11. Bulk electrolysis for dimer 7 at $10 \mathrm{mM}$ in $0.1 \mathrm{M} \mathrm{LiBF} 4$ in acetonitrile. 


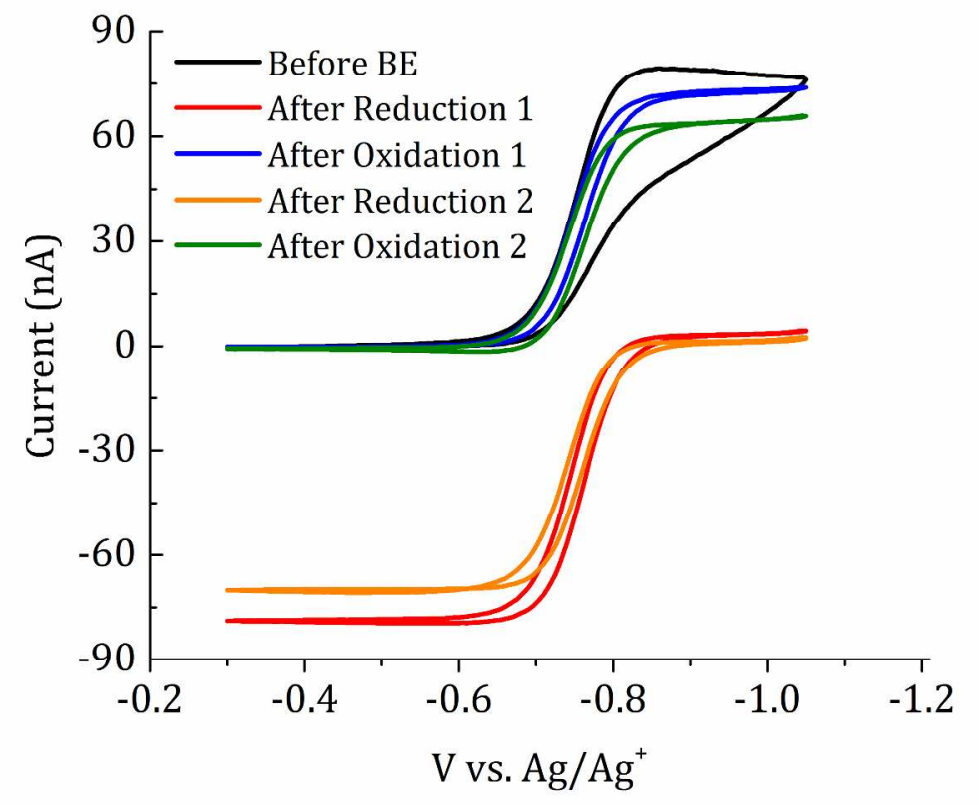

Figure S12. Resulting cyclic voltammograms before, during and after the bulk electrolysis experiments for the dimer 7 at $10 \mathrm{mM}$ in $0.1 \mathrm{M} \mathrm{LiBF} 4$ in acetonitrile.

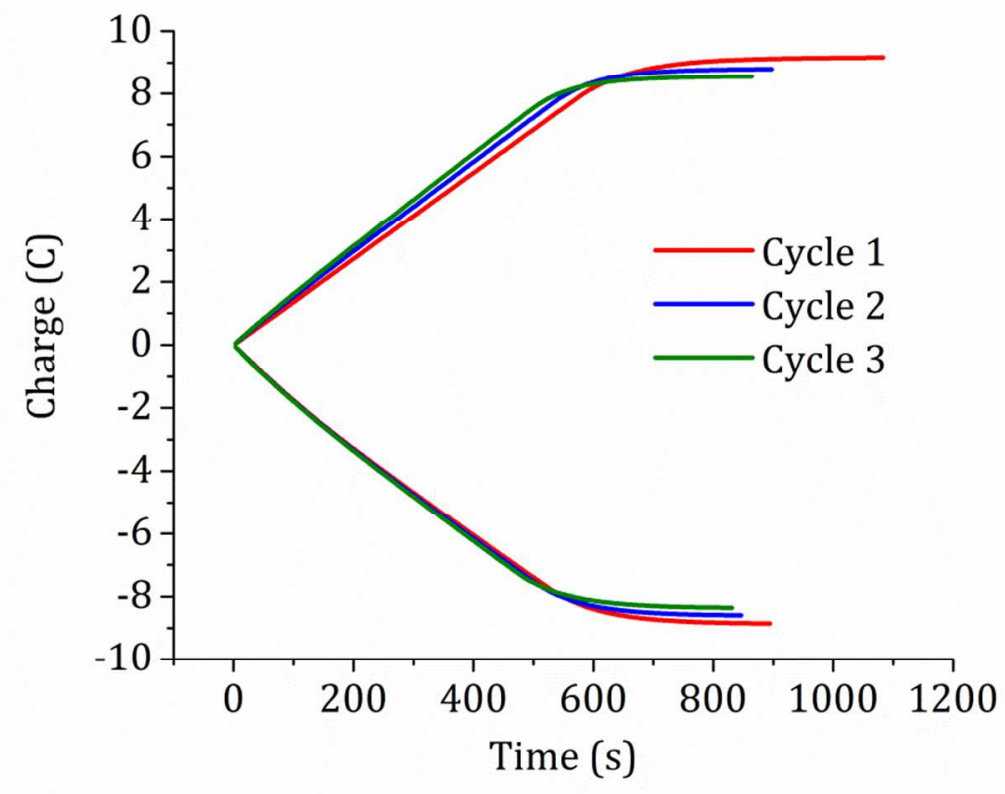

Figure S13. Bulk electrolysis for the $o$-benzene dimer 8 at $10 \mathrm{mM}$ in $0.1 \mathrm{M} \mathrm{LiBF} 4$ in acetonitrile. 


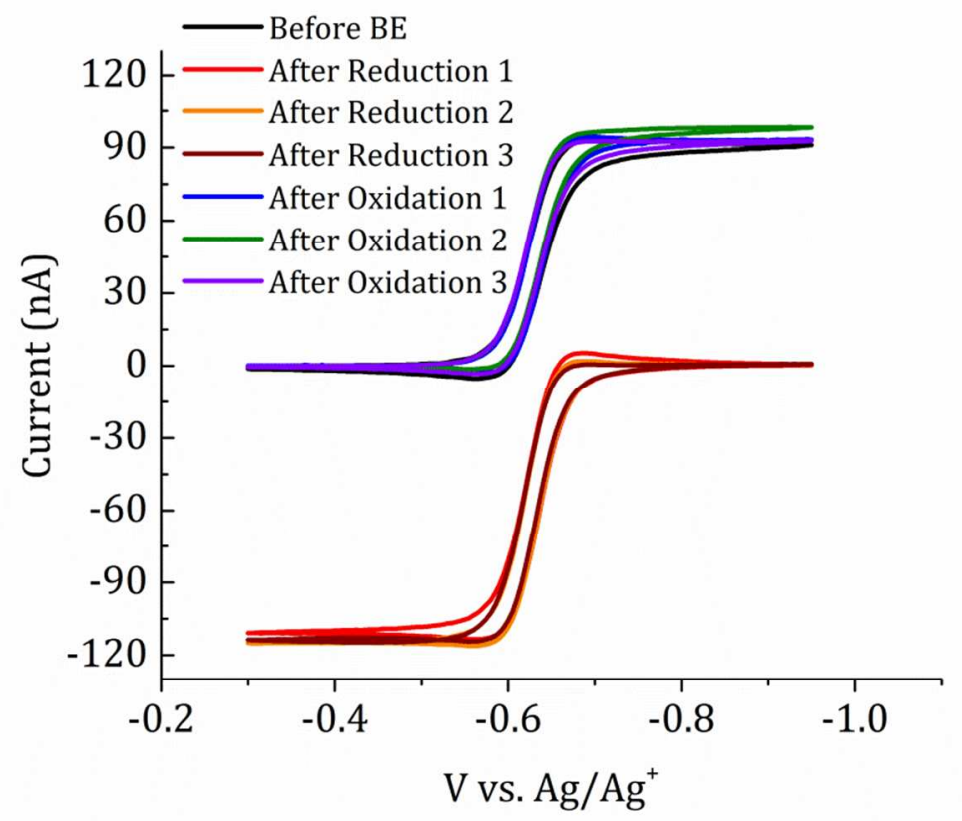

Figure S14. Resulting cyclic voltammograms before, during and after the bulk electrolysis experiments for the $o$-benzene dimer 8 at $10 \mathrm{mM}$ in $0.1 \mathrm{M} \mathrm{LiBF} 4$ in acetonitrile.

A

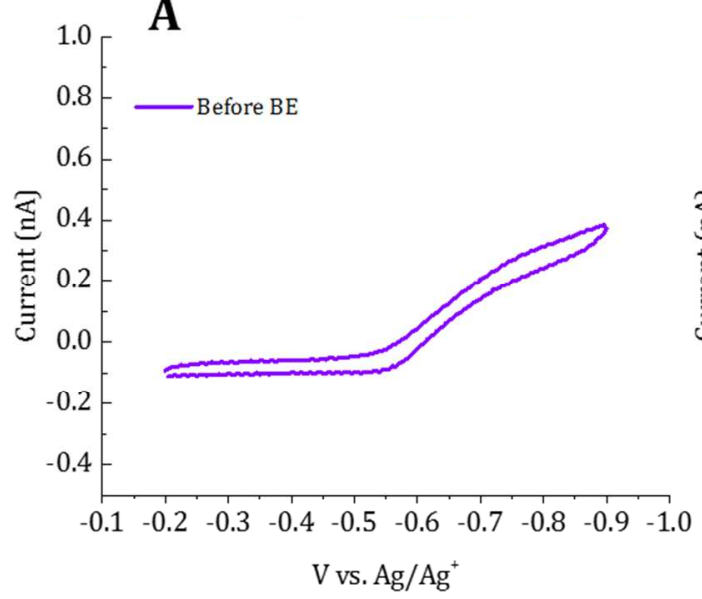

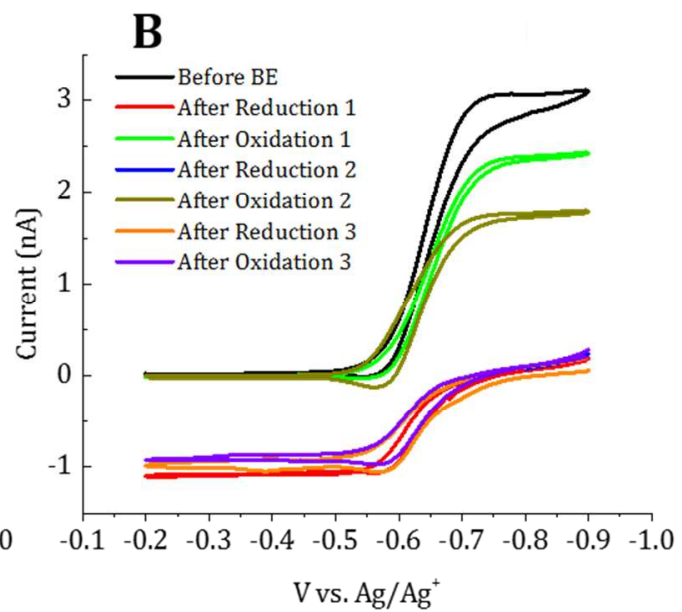

Figure S15. Resulting cyclic voltammograms before, during and after the bulk electrolysis experiments for the (A) $o$-benzene polymer 10 and (B) $m$-benzene polymer 11 at $10 \mathrm{mM}$ of monomer units in $0.1 \mathrm{M} \mathrm{LiBF} 4$ in acetonitrile. 

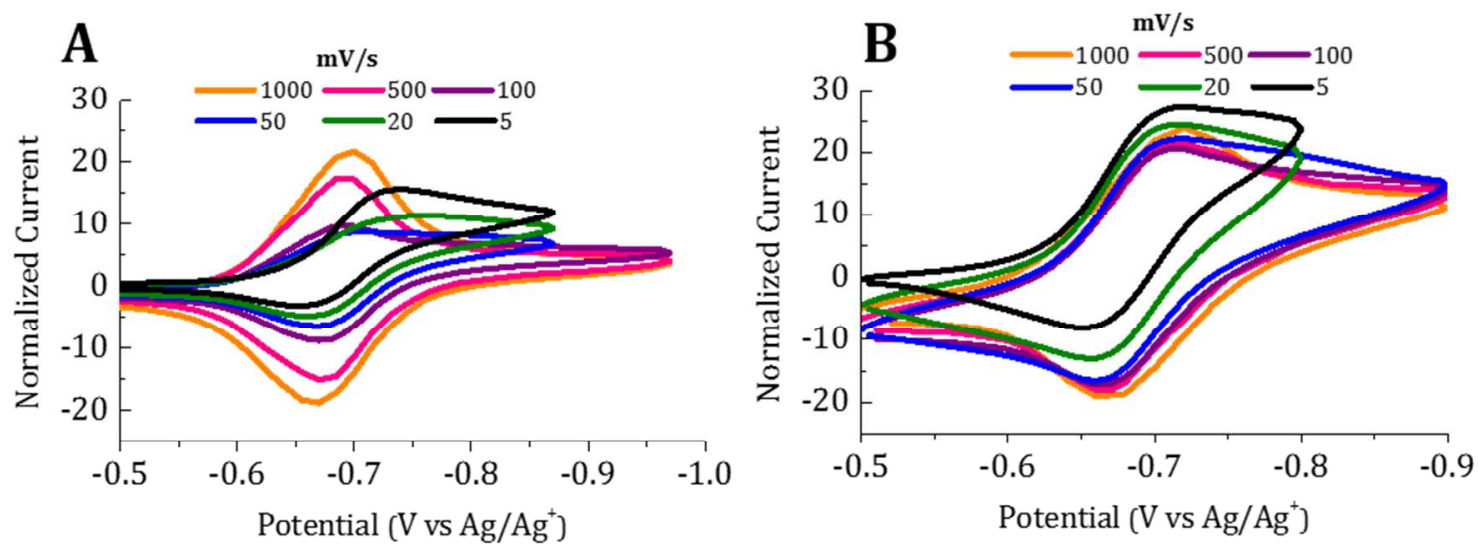

Figure S16. (A) Normalized current by the square root of scan rate for Poly $o$-benzene dimer $\mathbf{1 0}$ and (B) Normalized current by the square root of scan rate for $m$-benzene polymer 11 (2 $\mathrm{mM}$ of monomer in $0.1 \mathrm{M} \mathrm{LiBF} 4$ in acetonitrile).
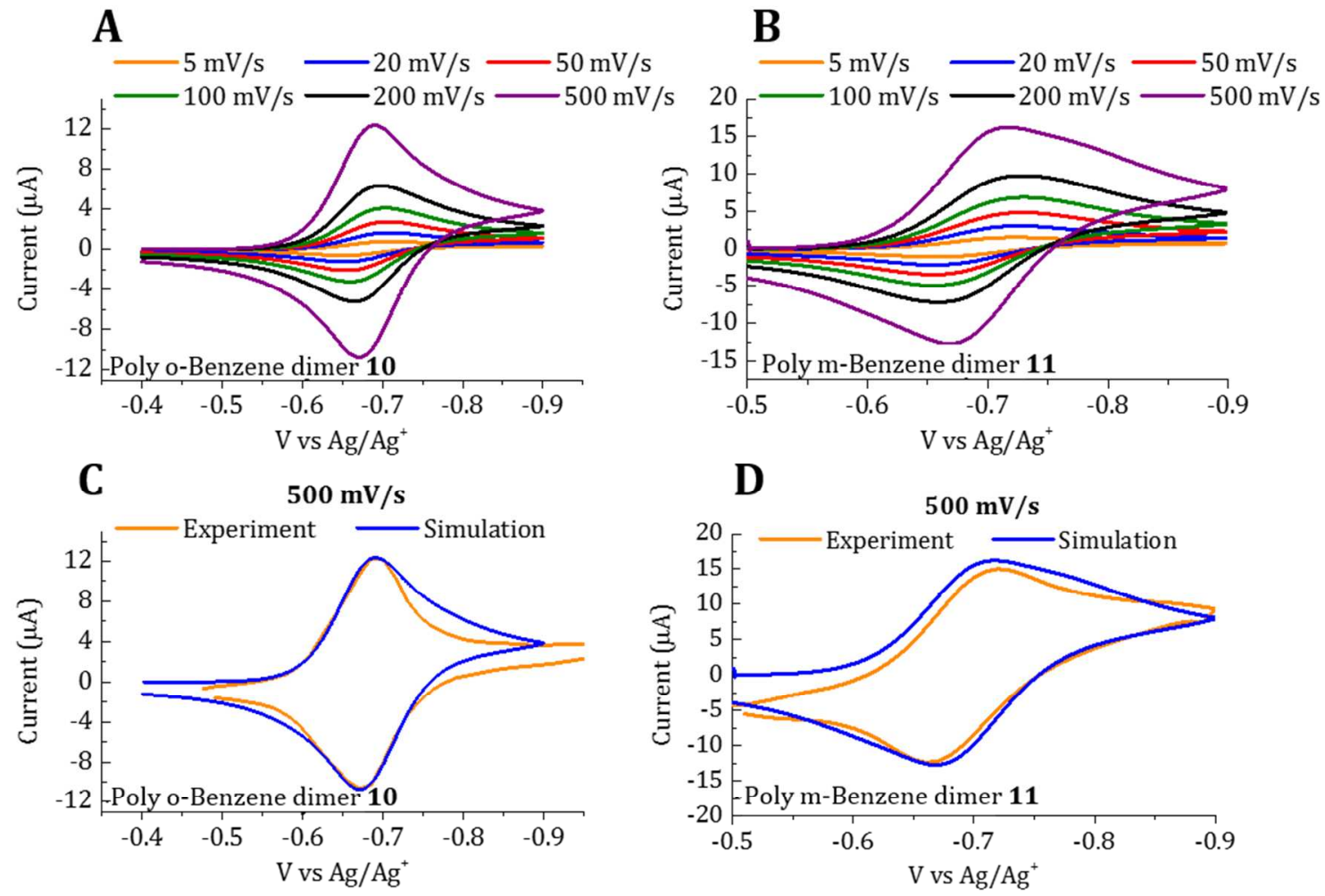

Figure S17. Simulated cyclic voltammograms using the experimentally calculated data. In the simulation we added a pre-absorption equilibrium in which the $\mathrm{K}$ of absorption $o$-Benzene polymer $\mathbf{1 0}$ is 20 times larger than the one for $m$-benzene polymer $\mathbf{1 1}$. For surface coverage we used $6 \times 10^{-10} \mathrm{~mol} / \mathrm{cm}^{2}$ and for the Marcus constant we used the $k_{e x}$ values from the polymers. Simulated scan rate dependence for (A) 10 (B) $m$-benzene polymer 11. Comparison with the experimentally obtained cyclic voltammogram at $500 \mathrm{mV} / \mathrm{s}$ for (C) $o$-benzene polymer $\mathbf{1 0}$ (D) $\mathrm{m}$ benzene polymer 11 . 

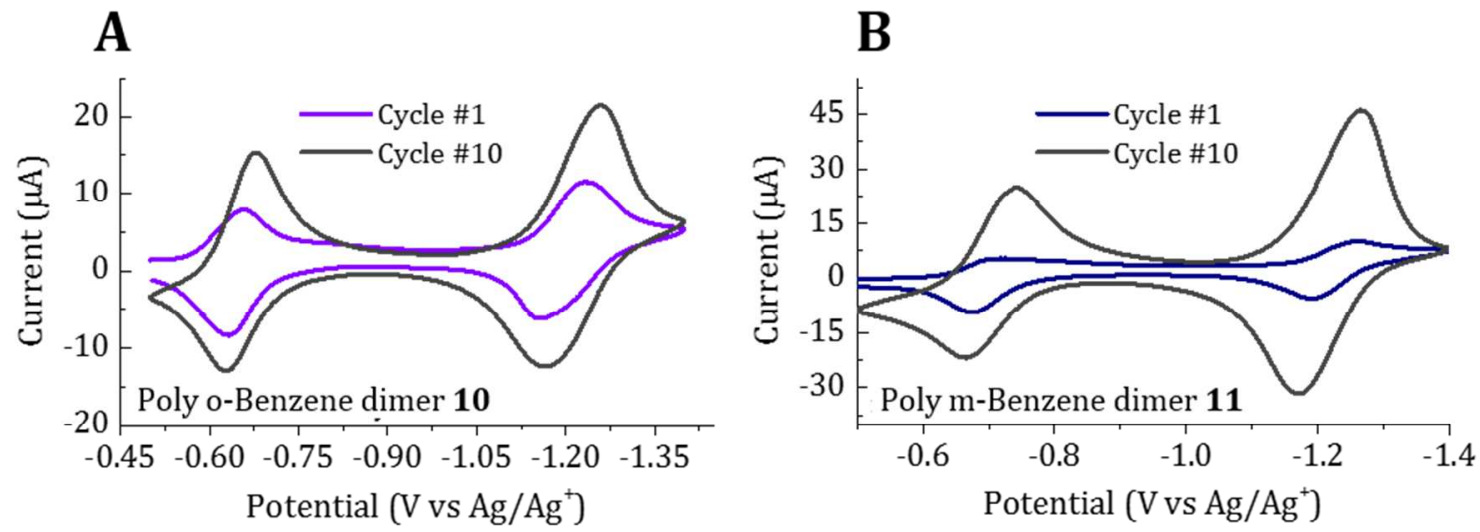

Figure S18. Cyclic voltammograms ( $1 \mathrm{mM}$ concentration of the monomer at $50 \mathrm{mV} / \mathrm{s}$ ) going to the second redox process which promote absorption. The current increase with cycle (up to 10), showing that the polymer is being deposit onto the electrode surface. (A) $o$-benzene polymer $\mathbf{1 0}$ (B) $m$-benzene polymer 11 ( $2 \mathrm{mM}$ of monomer in $0.1 \mathrm{M} \mathrm{LiBF} 4$ in acetonitrile).
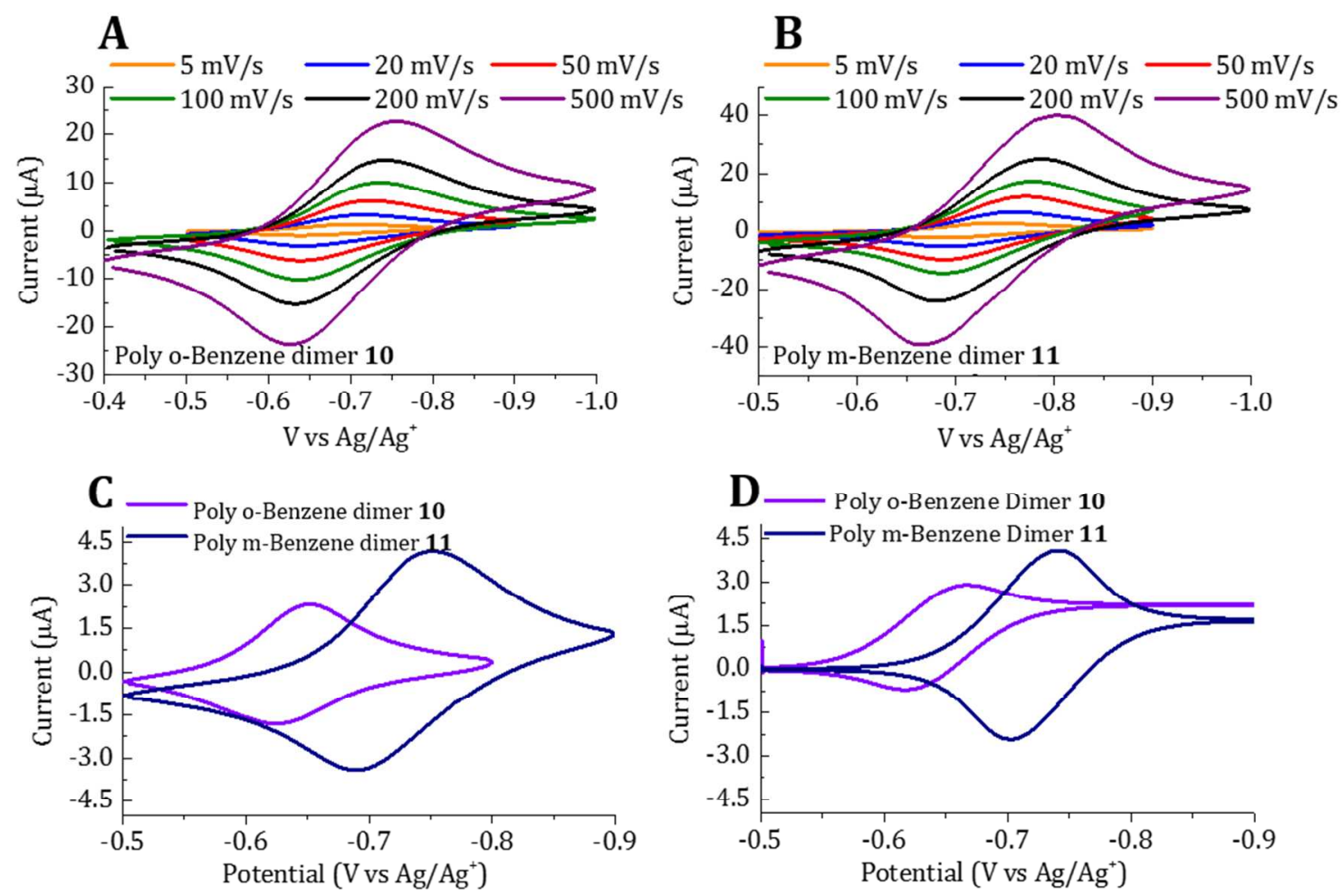

Figure S19. Scan rate dependence voltammograms for the surface confine polymers (A) $o$ benzene polymer 10, (B) $m$-benzene polymer 11, $(2 \mathrm{mM}$ of monomer in $0.1 \mathrm{M} \mathrm{LiBF} 4$ in acetonitrile) (C) Cyclic voltammograms at $10 \mathrm{mV} / \mathrm{s}$ for the resulting films after accessing the second redox process. (D) Simulated cyclic voltammograms using the experimentally calculated data. 

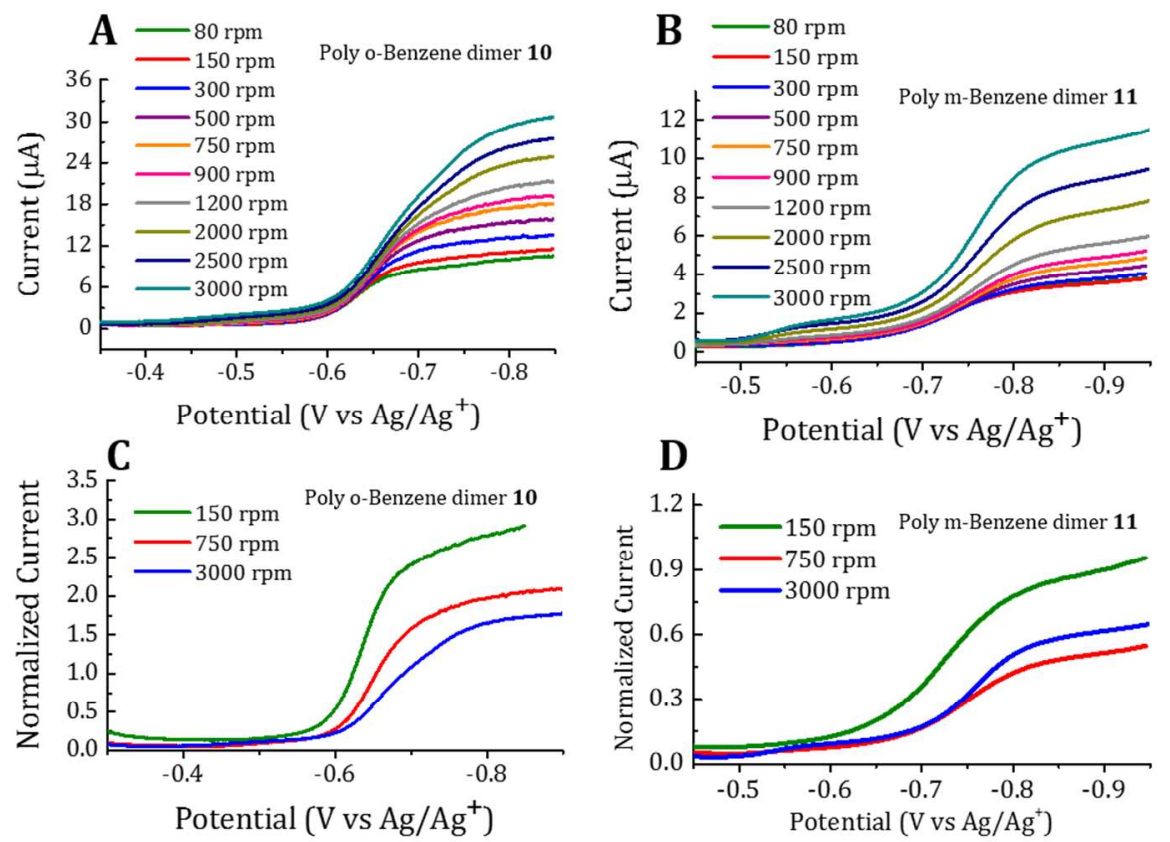

Figure S20. Rotating disk electrode voltammograms for (A) o-benzene polymer $10(1 \mathrm{mM}$ of monomer $(0.5 \mathrm{mM}$ of monomer in $0.1 \mathrm{M} \mathrm{LiBF} 4$ in acetonitrile) and (B) $m$-benzene polymer 11 $(0.5 \mathrm{mM}$ of monomer in $0.1 \mathrm{M} \mathrm{LiBF} 4$ in acetonitrile). Normalized Rotating disk electrode voltammograms for (C) $o$-benzene polymer 10 and (D) $m$-benzene polymer 11, indicating the presence of a preceding chemical step which for this case is the adsorption of the polymer onto the electrode surface.

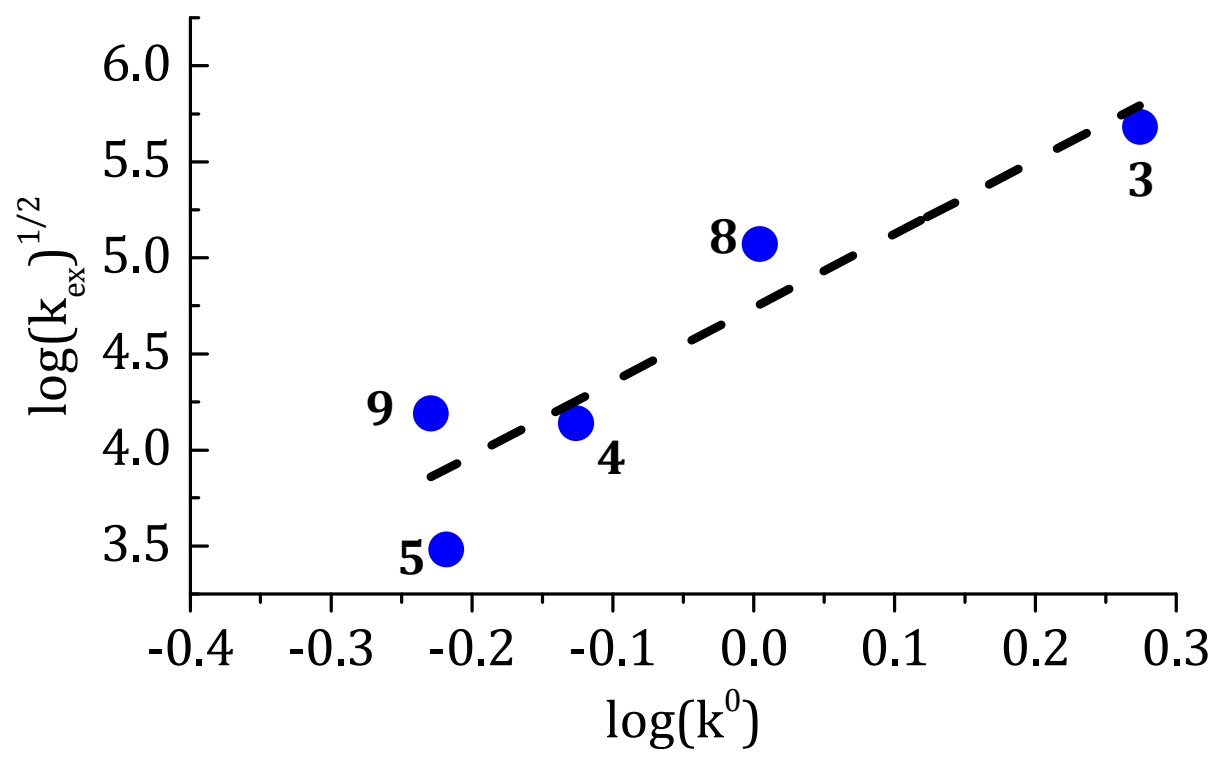

Figure S21. Marcus relation for the Viologen Based dimer species.

\section{Spectroelectrochemistry}


A

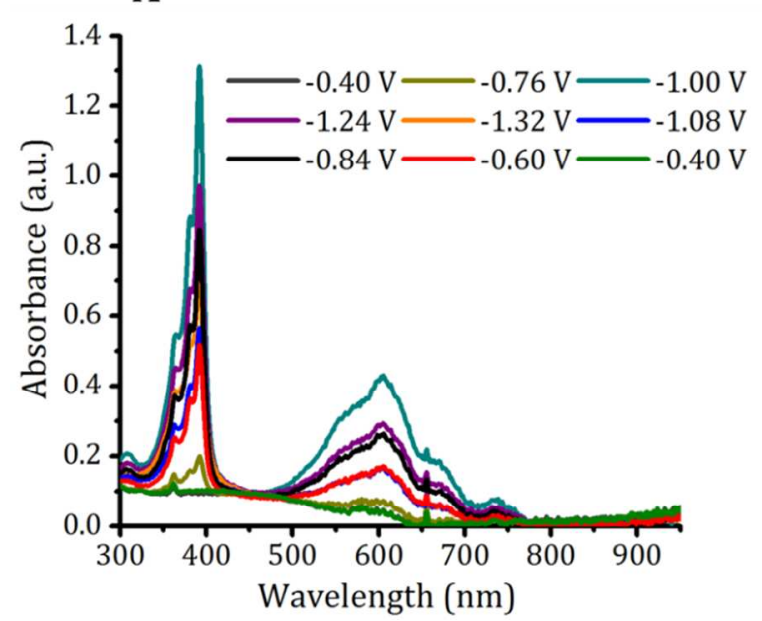

Absorbance

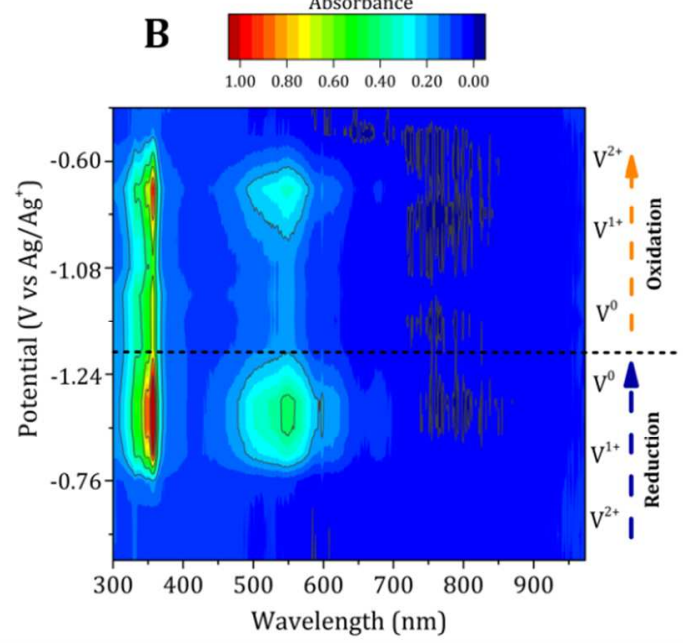

Figure S22. (A) UV-Vis spectra for the viologen monomer $2(0.5 \mathrm{mM}$ in $0.1 \mathrm{M}$ LiBF4 in acetonitrile) as a function of potential and (B) Contour plot of the in situ UV-vis spectroelectrochemistry of the viologen monomer 2.
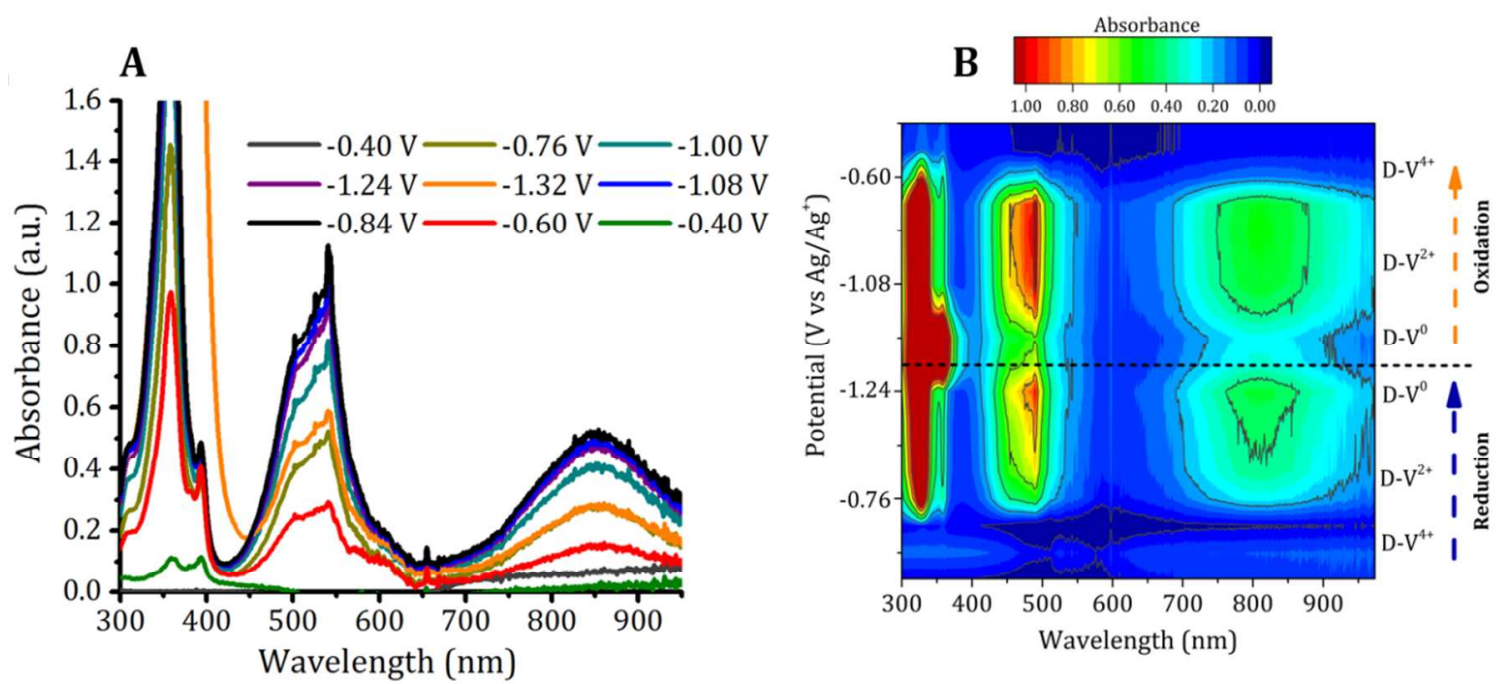

Figure S23. (A) UV-Vis spectra for the C3 dimer $3(0.5 \mathrm{mM}$ of monomer in $0.1 \mathrm{M} \mathrm{LiBF} 4$ in acetonitrile) as a function of potential and (B) Contour plot of the in situ UV-vis spectroelectrochemistry of dimer 3 . 

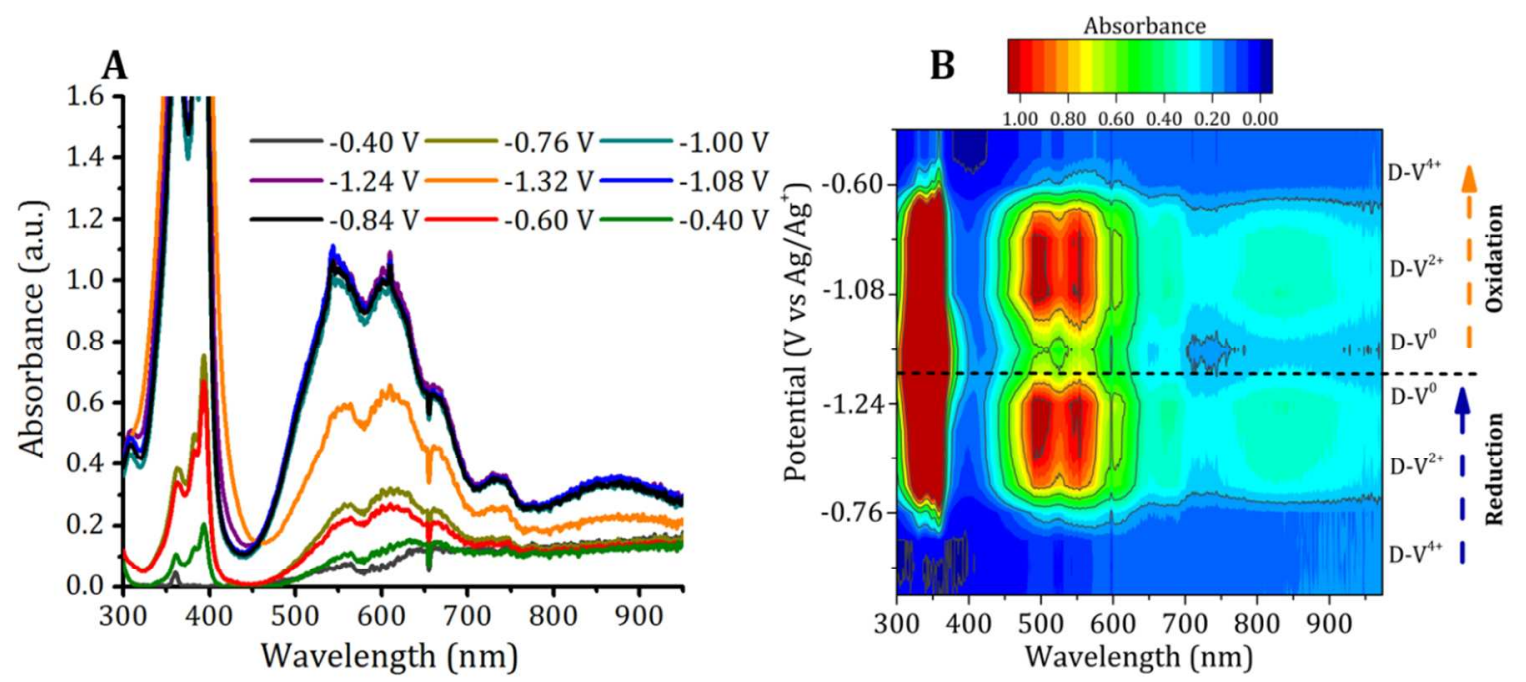

Figure S24. (A) UV-Vis spectra for dimer 4 ( $0.5 \mathrm{mM}$ of monomer in $0.1 \mathrm{M}$ LiBF4 in acetonitrile) as a function of potential and (B) Contour plot of the in situ UV-vis spectroelectrochemistry of dimer 4.
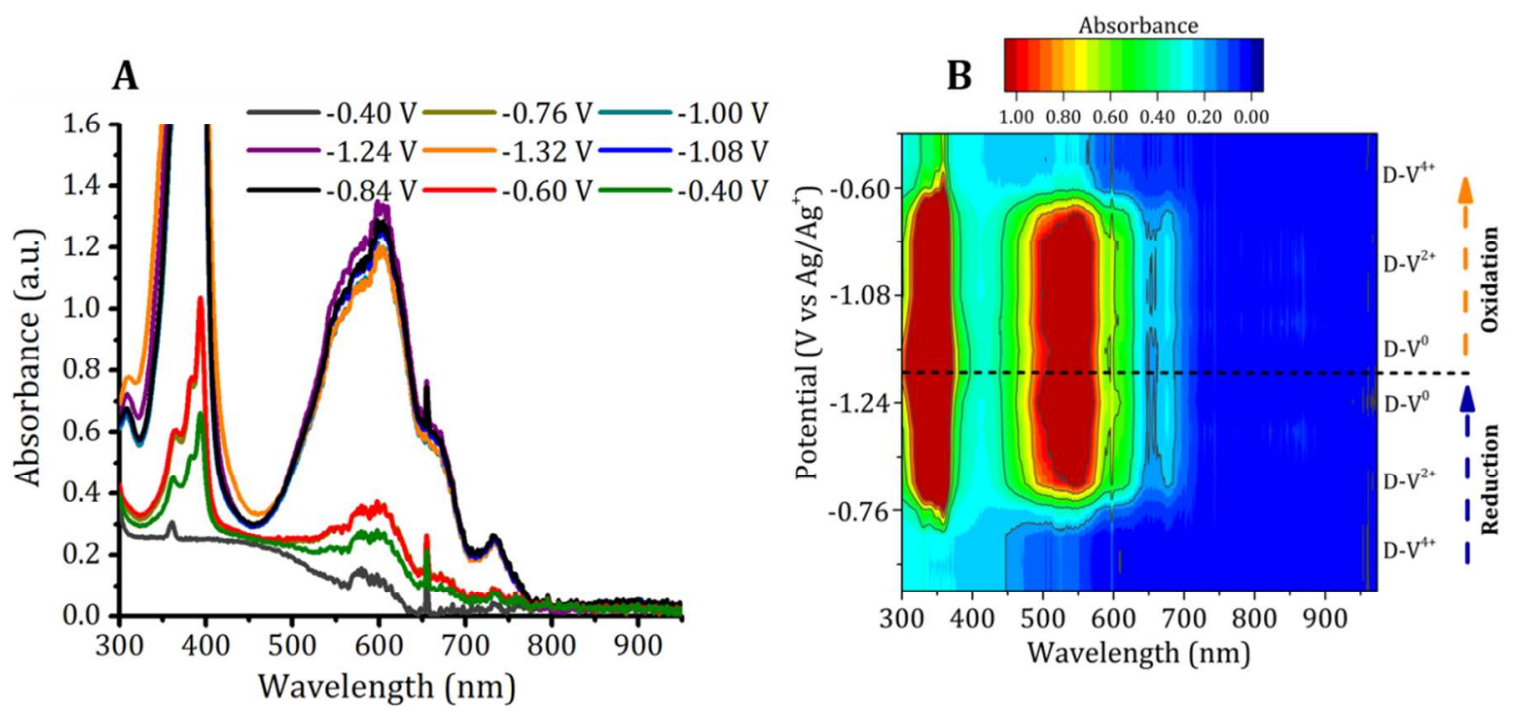

Figure S25. (A) UV-Vis spectra for dimer 5 ( $0.5 \mathrm{mM}$ of monomer in $0.1 \mathrm{M} \mathrm{LiBF} 4$ in acetonitrile) as a function of potential and (B) Contour plot of the in situ UV-vis spectroelectrochemistry of dimer 5. 

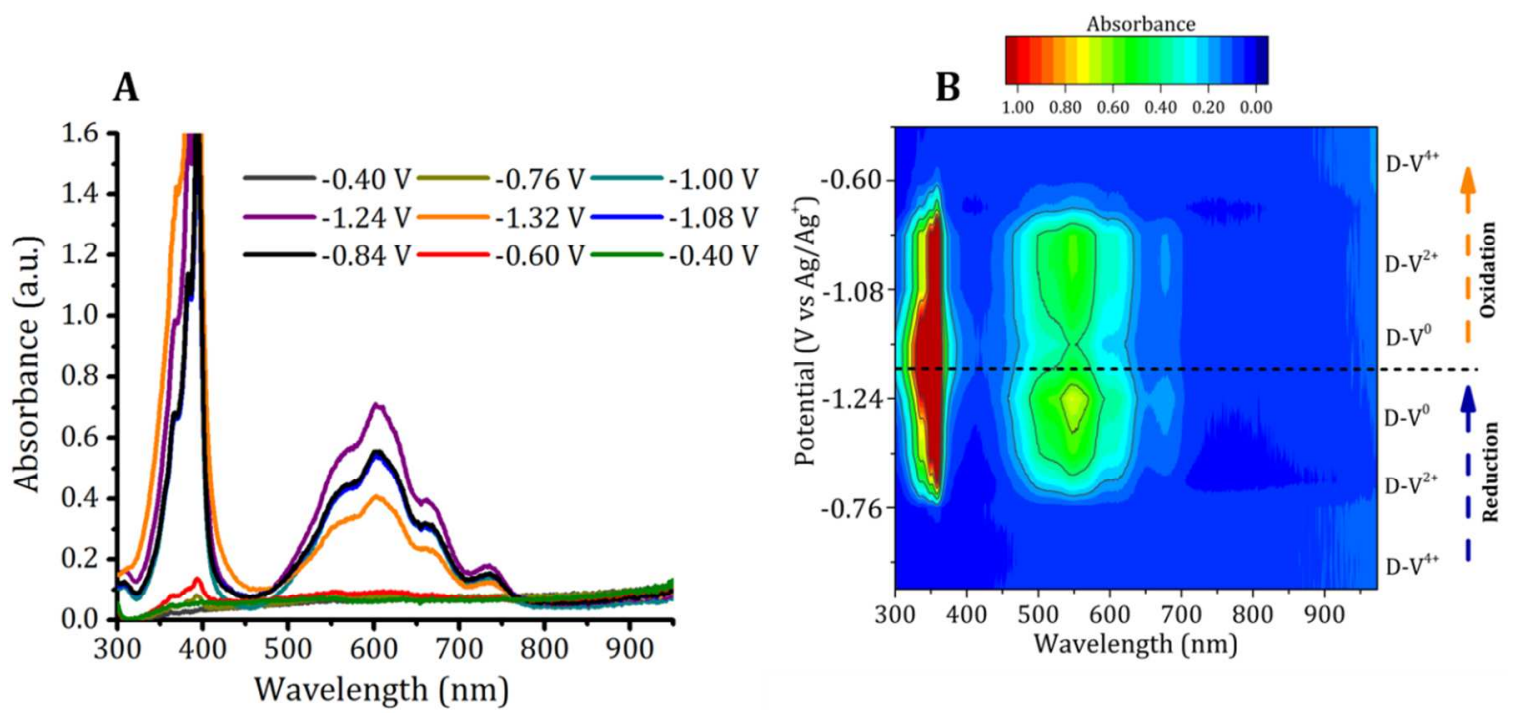

Figure S26. (A) UV-Vis spectra for dimer 6 ( $0.5 \mathrm{mM}$ of monomer in $0.1 \mathrm{M} \mathrm{LiBF} 4$ in acetonitrile) as a function of potential and (B) Contour plot of the in situ UV-vis spectroelectrochemistry of dimer 6.
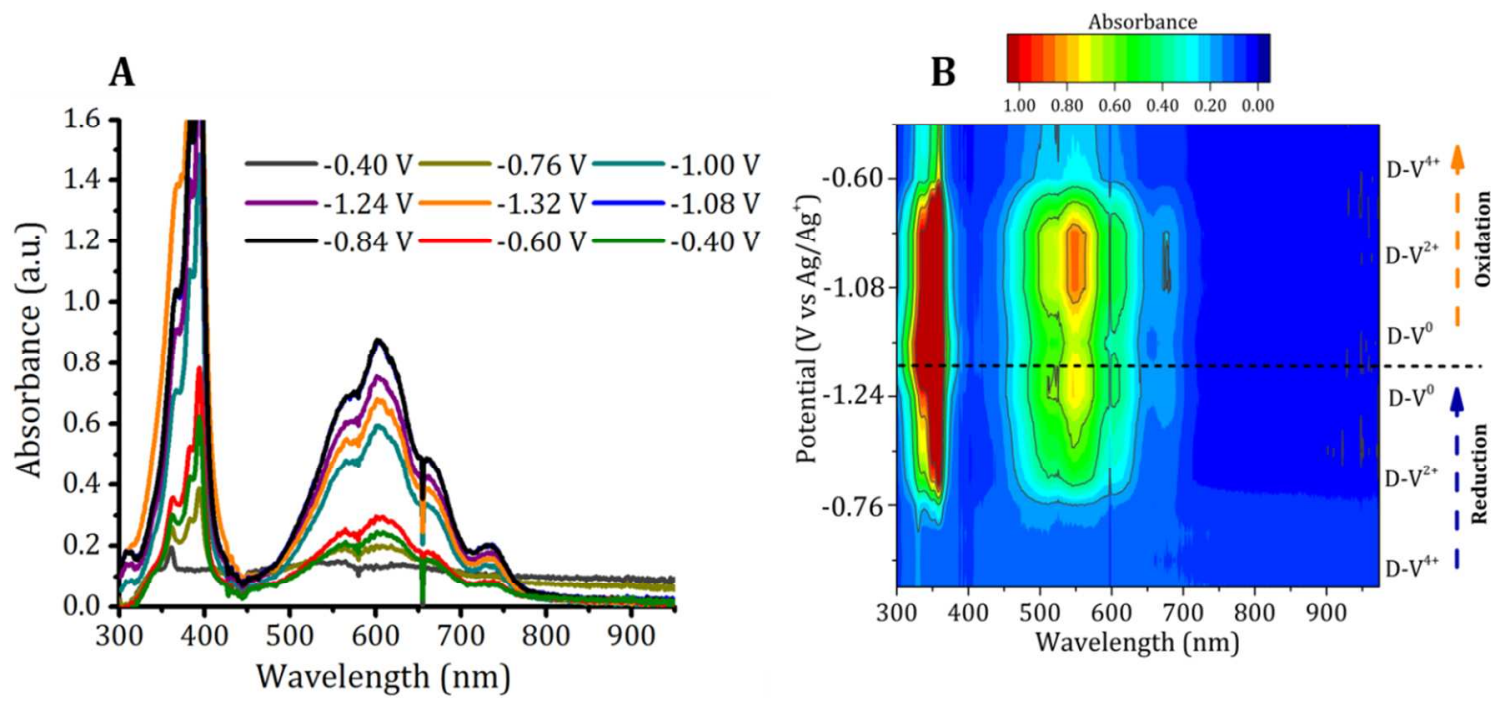

Figure S27. (A) UV-Vis spectra for dimer 7 ( $0.5 \mathrm{mM}$ of monomer in $0.1 \mathrm{M} \mathrm{LiBF} 4$ in acetonitrile) as a function of potential and (B) Contour plot of the in situ UV-vis spectroelectrochemistry of dimer 7. 
A

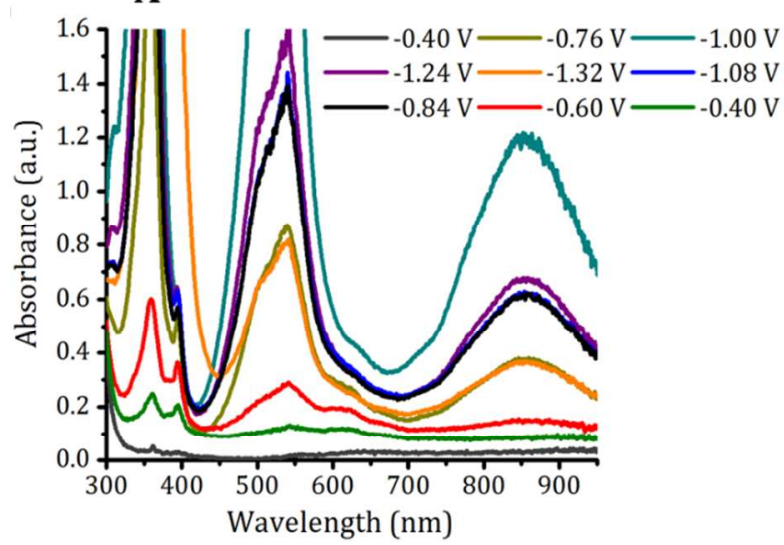

B

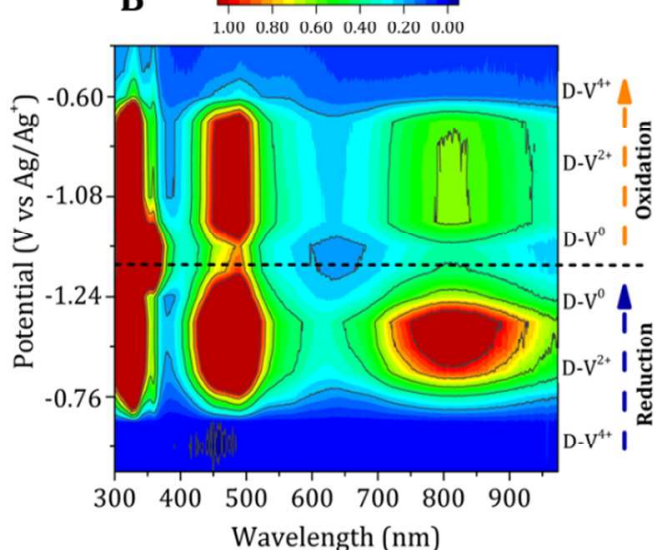

Figure S28. (A) UV-Vis spectra for the $o$-benzene dimer $8(1.0 \mathrm{mM}$ of monomer in $0.1 \mathrm{M} \mathrm{LiBF} 4$ in acetonitrile)as a function of potential and (B) Contour plot of the in situ UV-vis spectroelectrochemistry of the $o$-benzene dimer $\mathbf{8}$.

A

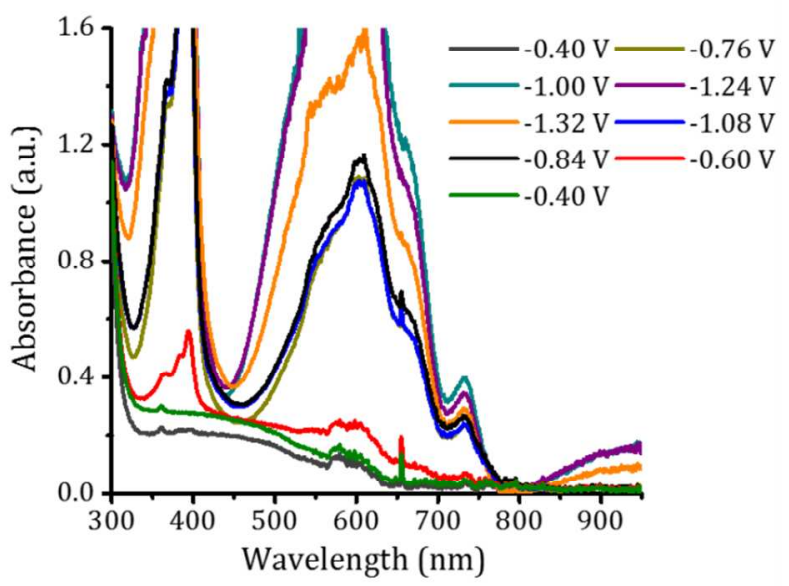

B

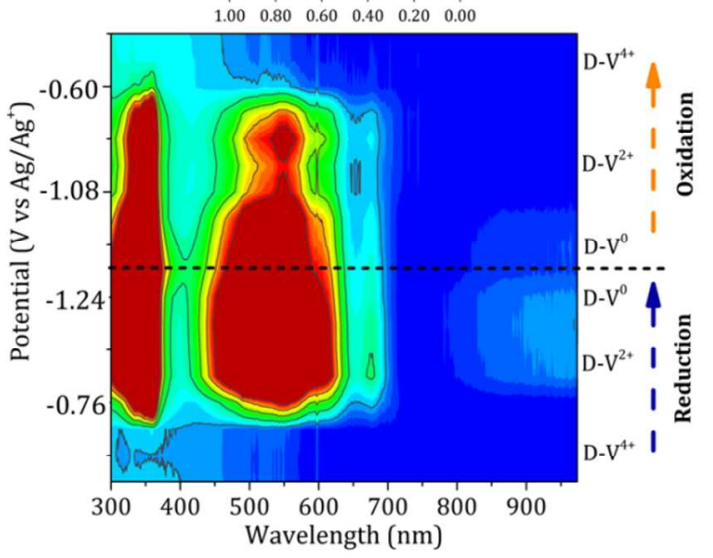

Figure S29. (A) UV-Vis spectra for the $m$-benzene dimer 9 (1.0 mM of monomer in $0.1 \mathrm{M} \mathrm{LiBF} 4$ in acetonitrile)as a function of potential and (B) Contour plot of the in situ UV-vis spectroelectrochemistry of the $m$-benzene dimer 9 . 

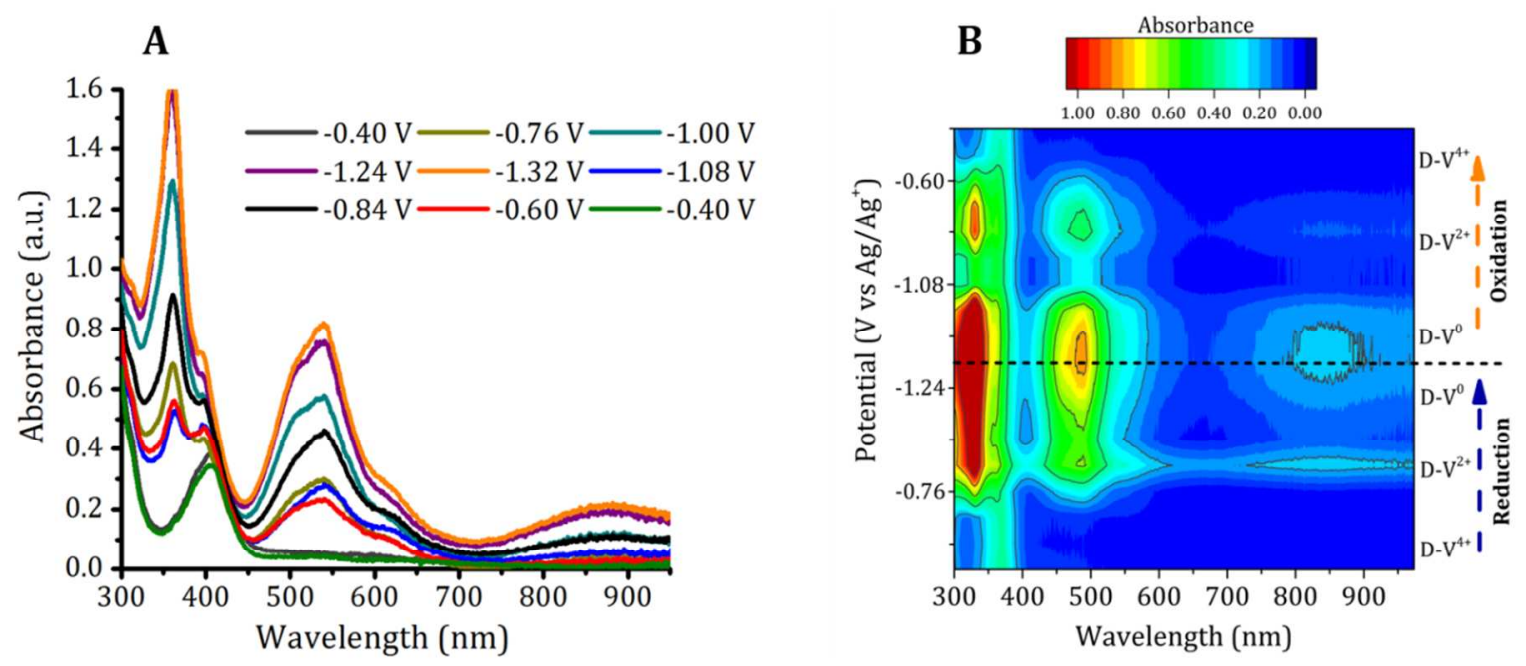

Figure S30. (A) UV-Vis spectra for the $o$-benzene polymer $10(2.0 \mathrm{mM}$ of monomer in $0.1 \mathrm{M}$ LiBF4 in acetonitrile)as a function of potential and (B) Contour plot of the in situ UV-vis spectroelectrochemistry of the Poly $o$-benzene dimer 10.
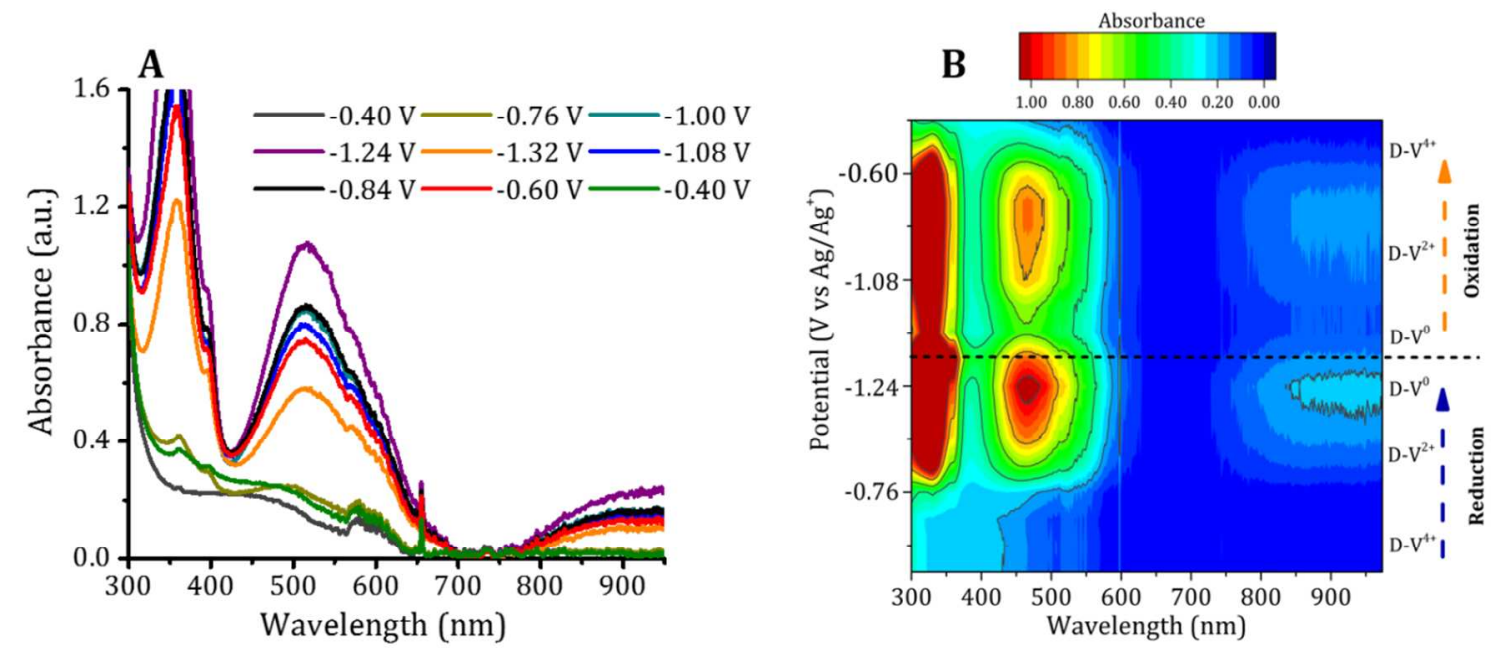

Figure S31. (A) UV-Vis spectra for the $m$-benzene polymer $11(2.0 \mathrm{mM}$ of monomer in $0.1 \mathrm{M}$ LiBF4 in acetonitrile)as a function of potential and (B) Contour plot of the in situ UV-vis spectroelectrochemistry of the $m$-benzene polymer 11 . 

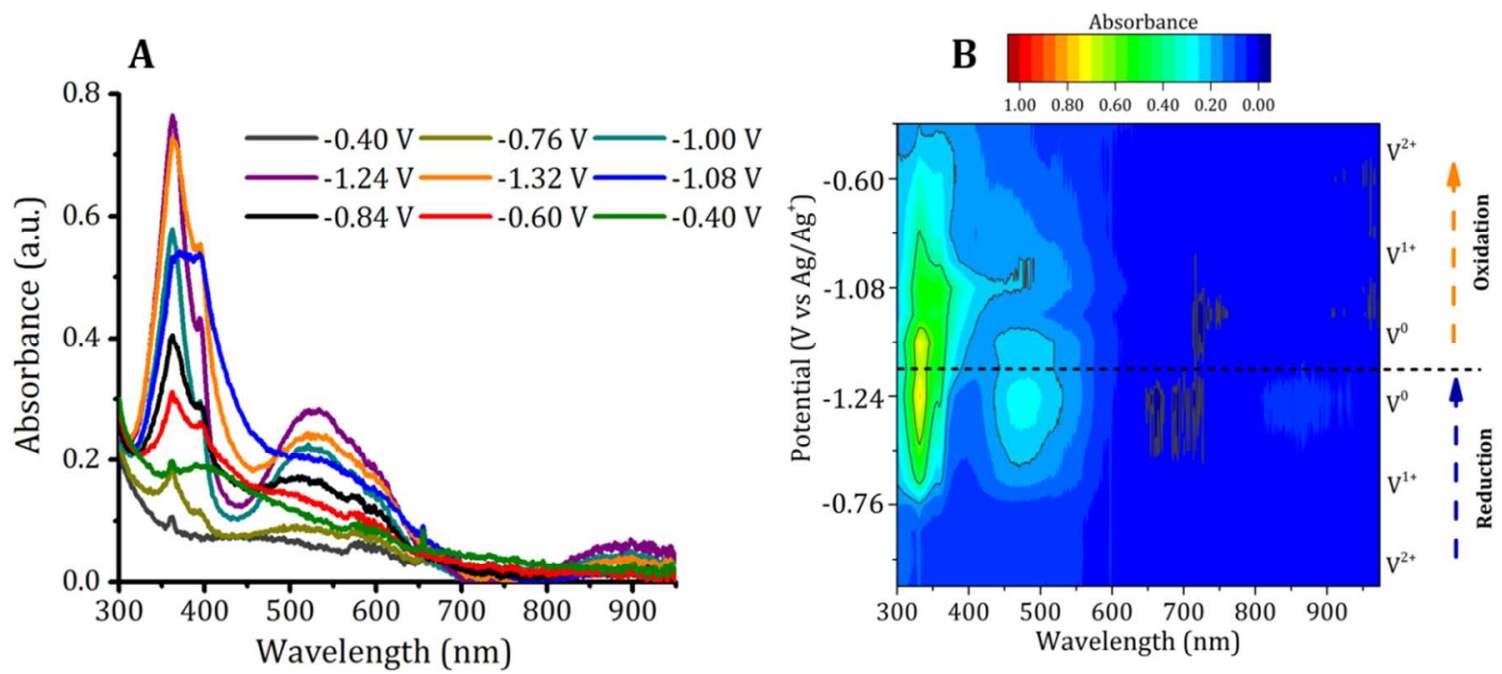

Figure S32. (A) UV-Vis spectra for the $318 \mathrm{kDa}$ benzyl Viologen Polymer 1 ( $2.0 \mathrm{mM}$ of monomer in $0.1 \mathrm{M} \mathrm{LiBF} 4$ in acetonitrile) as a function of potential and (B) Contour plot of the in situ UV-vis spectroelectrochemistry of the $318 \mathrm{kDa}$ benzyl Viologen Polymer $\mathbf{1}$.
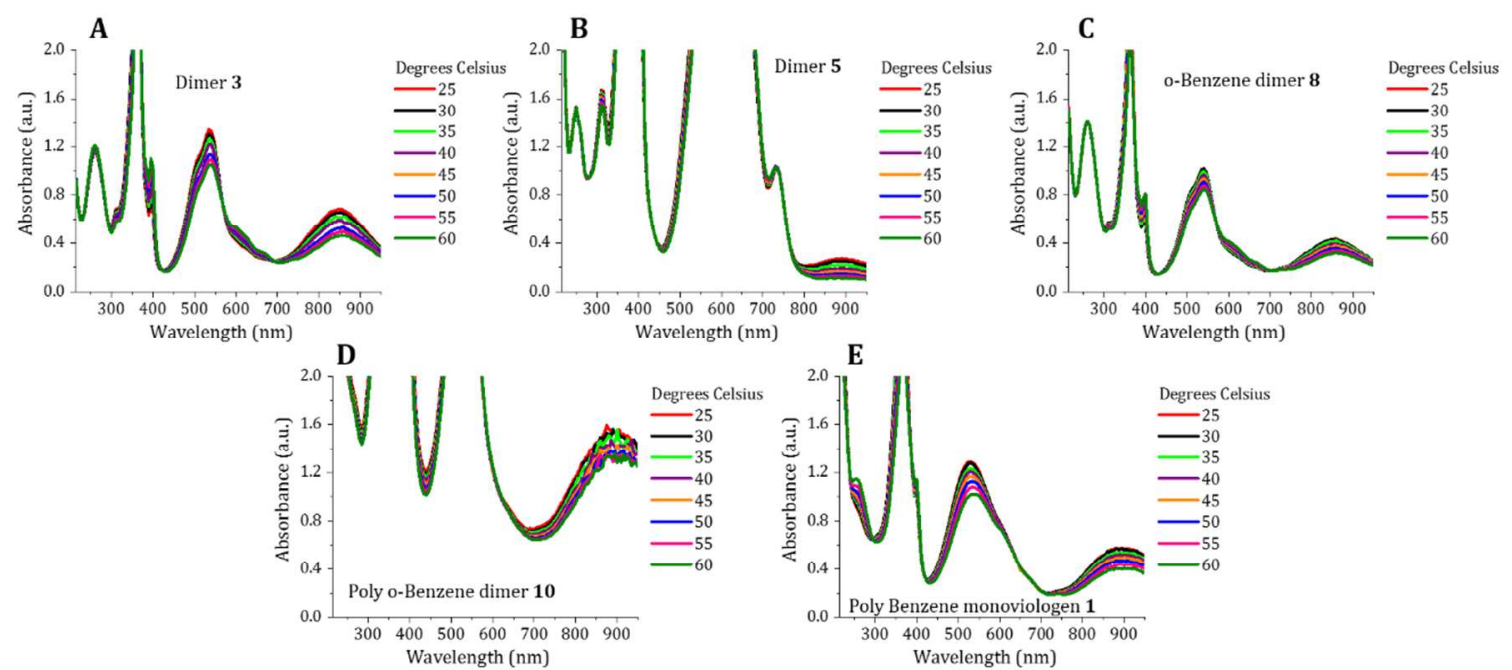

Figure S33. Temperature dependence UV-Vis data for (A) dimer $3(0.06 \mathrm{mM})$, (B) dimer $5(0.15$ $\mathrm{mM}),(\mathrm{C}) o$-benzene dimer $\mathbf{8}(0.06 \mathrm{mM})$, (D) $o$-benzene polymer $10(0.15 \mathrm{mM})$ and $(\mathrm{E}) 318 \mathrm{kDa}$ benzyl Viologen Polymer $1(0.15 \mathrm{mM})$. 


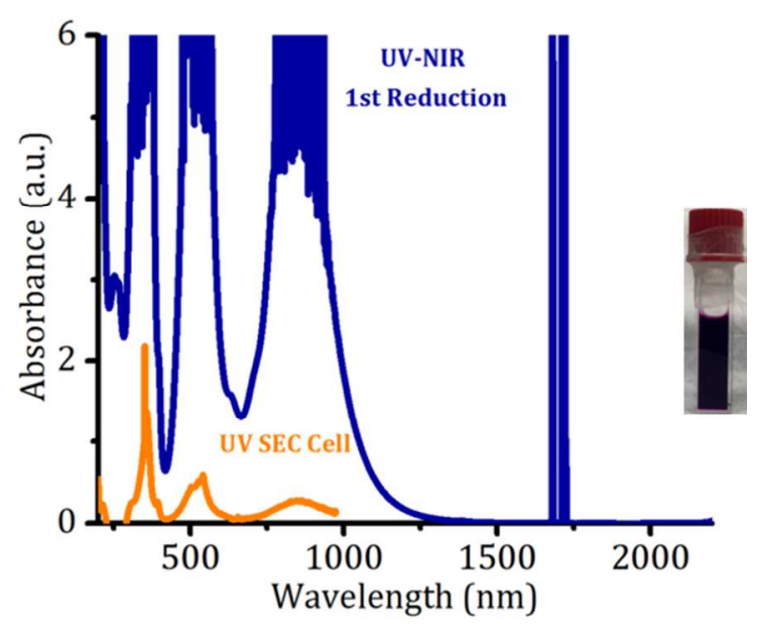

Figure S34. UV-Vis near infrared spectra for dimer $3(0.5 \mathrm{mM})$.

Table S1. Comparison between the $k_{e x}$ for the chemically and electrochemically reduced systems

\begin{tabular}{c|c|c}
\hline Molecule & Electrochemistry $\left(k_{e x}, \mathrm{~s}^{-1}\right)$ & Zn powder $\left(k_{e x}, \mathrm{~s}^{-1}\right)$ \\
\hline dimer 3 & $2.3 \times 10^{11}$ & $9.3 \times 10^{11}$ \\
dimer 4 & $1.9 \times 10^{8}$ & $9.7 \times 10^{11}$ \\
dimer 5 & $9.2 \times 10^{6}$ & $6.9 \times 10^{8}$ \\
$o$-Benzene dimer 8 & $1.4 \times 10^{10}$ & $1.6 \times 10^{11}$ \\
$m$-Benzene dimer 9 & $2.4 \times 10^{8}$ & $4.1 \times 10^{8}$ \\
$o$-Benzene polymer 10 & $6.7 \times 10^{8}$ & $5.4 \times 10^{11}$ \\
$m$-Benzene polymer 11 & $6.0 \times 10^{7}$ & $4.2 \times 10^{10}$ \\
318 kDa Polymer 1 & $8.1 \times 10^{6}$ & $5.5 \times 10^{7}$
\end{tabular}




\section{Theoretical calculation}

We have performed density functional calculations to investigate the geometric features and the relative energetics of the family of molecules presented. All calculations were performed using Gaussian09 software. ${ }^{7}$ The M062-2X/6-31+G(d) level of theory was used to compute the structure, electronic energy, vibrational frequencies, and the free energy corrections of all species described in this manuscript. ${ }^{8}$ All calculations were performed by including an $\mathrm{SMD}^{9}$ solvation model using a dielectric medium of acetonitrile to include the solvation effects in the structure and energetics. The reduction potentials $\left(E^{\text {red }}\right.$ w.r.t. $\left.\mathrm{Li} / \mathrm{Li}^{+}\right)$are computed from the computation of Gibbs free energy change $\left(\Delta G^{\text {red, }} \mathrm{eV}\right)$ at $298 \mathrm{~K}$ in the solution (dielectric) for addition of an electron to the species of interest, using the following equation:

$$
E^{r e d}=\frac{-\Delta G^{r e d}}{n F}-1.24 \mathrm{~V},
$$

where $F$ is the Faraday constant (in $\mathrm{eV}$ ) and $n$ is the number of electrons involved in the reduction process. The addition of the constant ' $-1.24 \mathrm{~V}$ ' is required to convert the free energy changes to reduction potential $\left(\mathrm{Li} / \mathrm{Li}^{+}\right.$reference electrode), a commonly used convention to compute the reduction potentials in solution. ${ }^{10,11}$ The change in energy of electrons when going from vacuum to non-aqueous solution is treated as zero, similar to what has been used by others. ${ }^{12}$ Details regarding the computation of redox potential can be found elsewhere. ${ }^{12-16}$

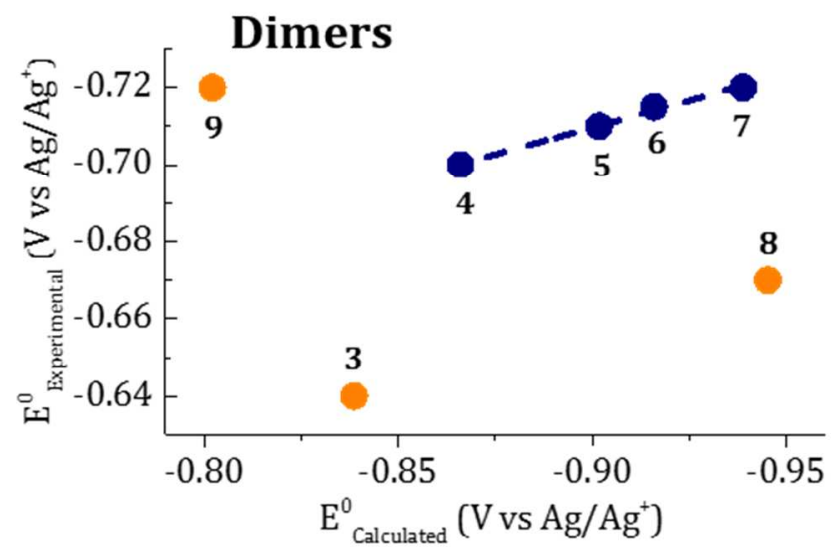

Figure S35. Linear regression showing the fit between the Calculated and Experimental reduction potentials of dimer 3 to $\mathbf{9}$. All the calculated data was done for the V-shaped structures. 

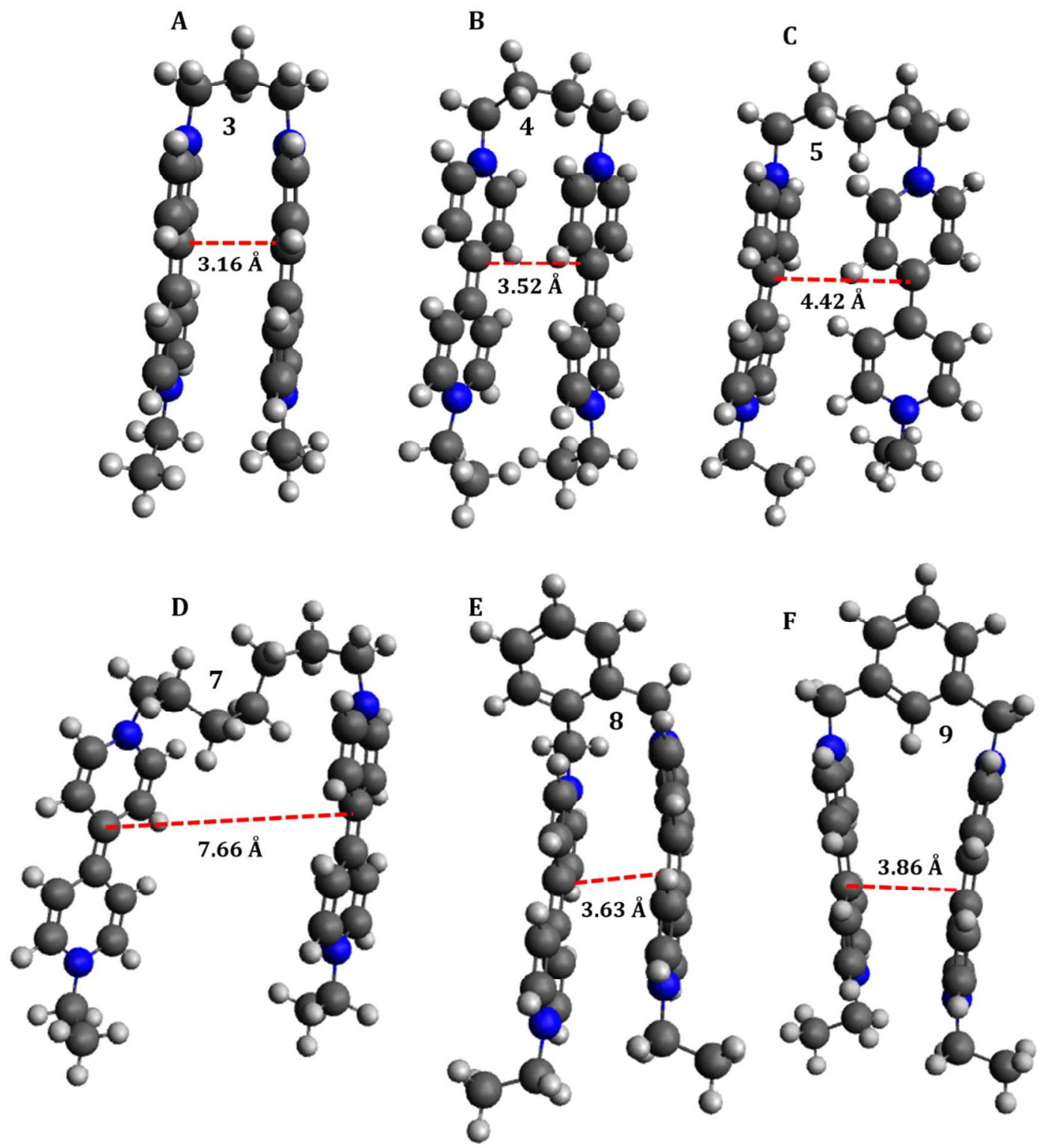

Figure S36. Optimized structures showing distance between redox centers for the $2+$ oxidation state.

Table S2. Distance between redox centers in the $4+$ and $2+$ oxidation states.

\begin{tabular}{c|c|c}
\hline Dimer & Distance $(\AA) \mathbf{4 +}$ & Distance $(\AA) \mathbf{2 +}$ \\
\hline dimer 3 & 3.65 & 3.16 \\
dimer 4 & 3.53 & 3.52 \\
dimer 5 & 4.72 & 4.42 \\
dimer 7 & 8.29 & 7.66 \\
o-benzene dimer 8 & 3.89 & 3.63 \\
m-benzene dimer 9 & 7.34 & 3.86
\end{tabular}


Polymer Film Charge Transport
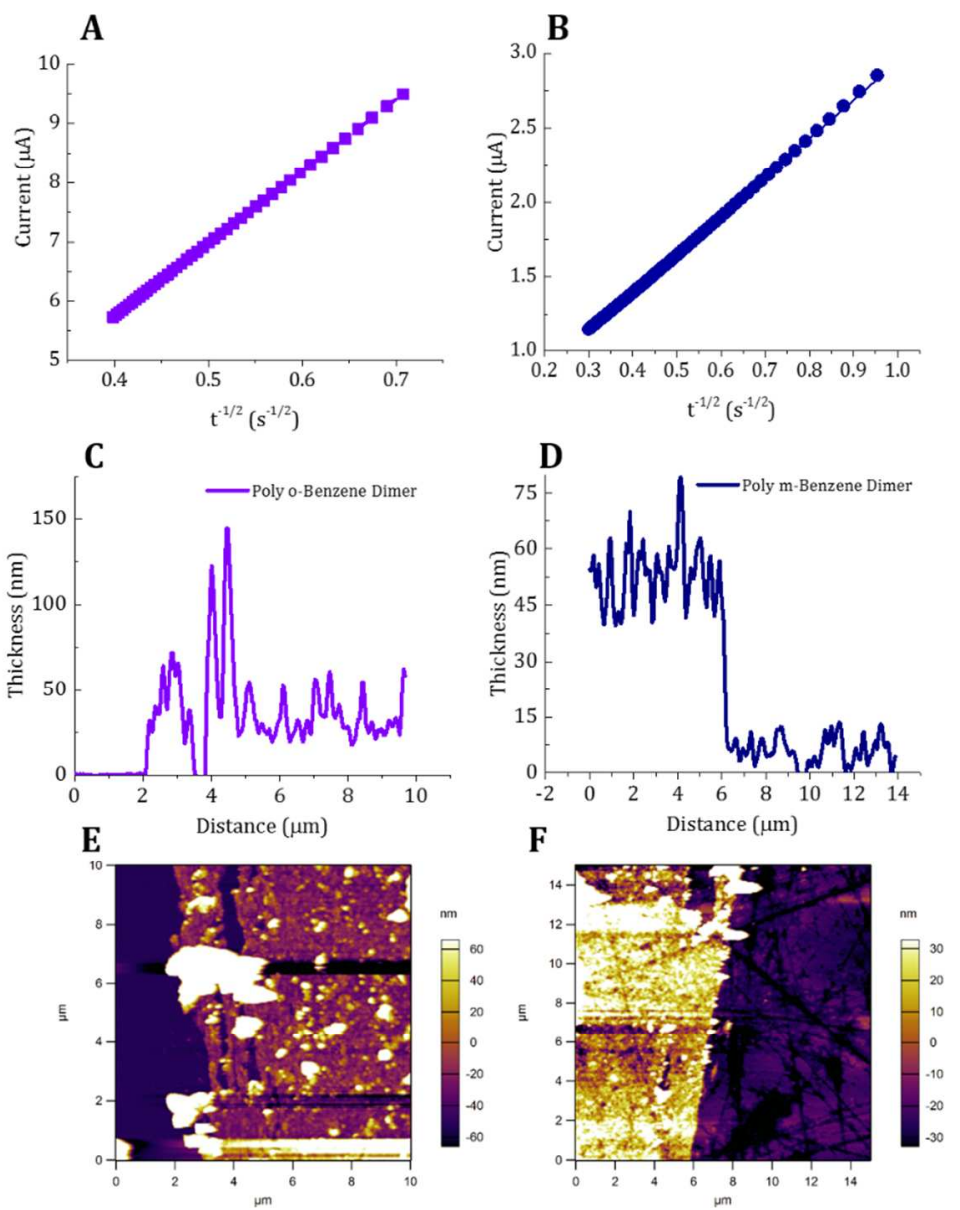

Figure S37. Cottrell Plots for the plots used to calculate the electron diffusion coefficient for (A) $o$-benzene polymer 10 and (B) $m$-benzene polymer 11. AFM line scans to determine the film thickness for (C) $o$-benzene polymer 10 and (D) $m$-benzene polymer 11. AFM image showing the morphology of the electrodeposited films for (E) $o$-benzene polymer 10 and (F) $m$-benzene polymer 11.

Table S3. Calculated electron diffusion and the charge transport rate constant for the resulting polymer films.

\begin{tabular}{c|c|c}
\hline Molecule & Electron Diffusion $\left(D_{E}, \mathrm{~cm}^{2} / \mathrm{s}\right)$ & Film Charge Transport $\left(k_{e x}, \mathrm{~s}^{-1}\right)$ \\
\hline$o$-benzene polymer 10 & $4.1 \times 10^{-10}$ & $1.9 \times 10^{5}$ \\
$m$-benzene polymer 11 & $2.5 \times 10^{-11}$ & $1.0 \times 10^{5}$ \\
Polymer 1 & $7.9 \times 10^{-11}$ & $5.3 \times 10^{4}$
\end{tabular}




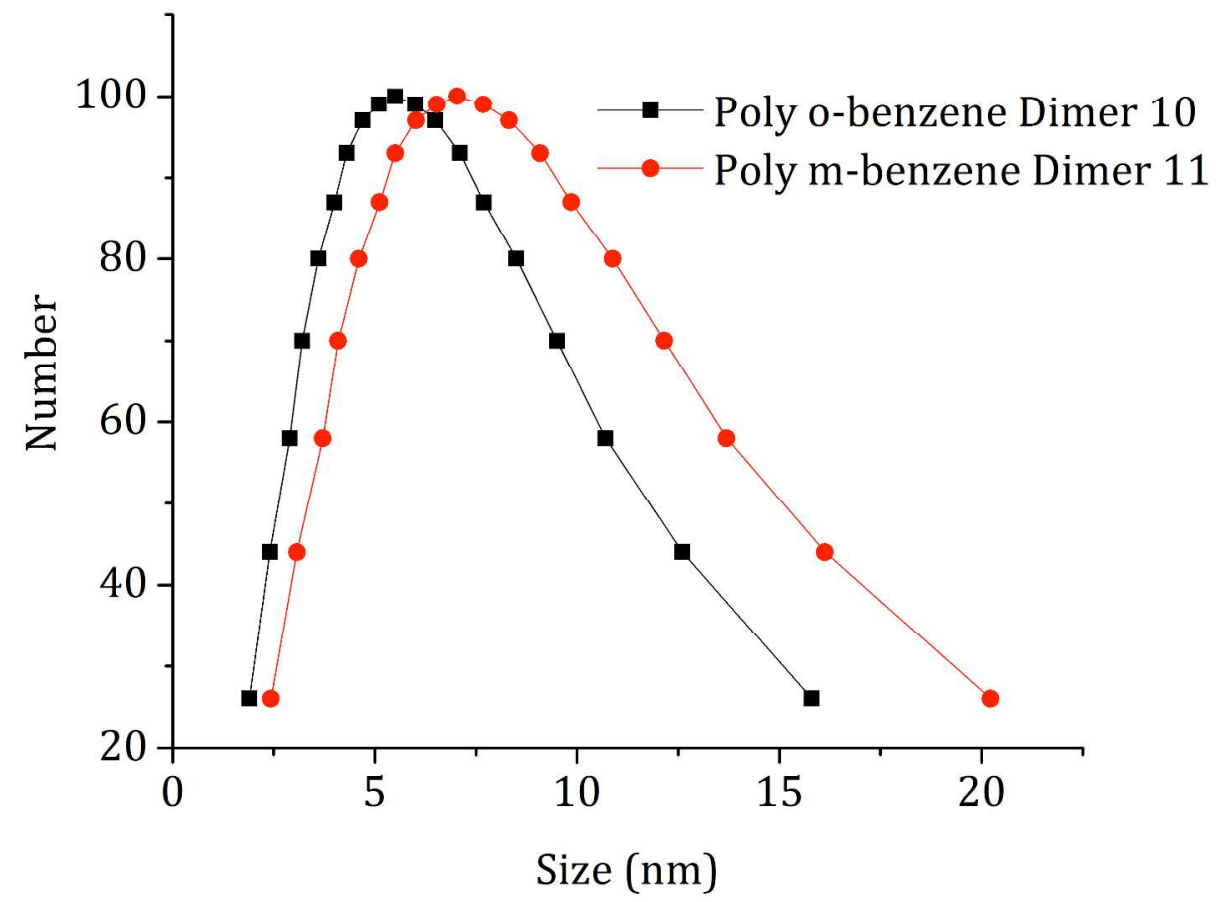

Figure S38. Dynamic light scattering to determine the hydrodynamic radius of $o$-benzene polymer $\mathbf{1 0}$ and $m$-benzene polymer 11.

\section{Calculation of Areal Impingement Rate}

To calculate the collisional frequency of species to an electrode surface, the following equation for areal impingement rate was used

$$
Z_{A}=\frac{P}{\left(2 * \pi * M * k_{B} * T\right)^{1 / 2}}
$$

Where ZA is the collisional frequency per unit area, $\mathrm{P}$ is the pressure of the system (assumed to be sea level at 101,315 Pa), $\mathrm{M}$ is the mass of the species in $\mathrm{kg}, \mathrm{kB}$ is the Bolstzmann Constant $(1.38 \times 10-23 \mathrm{~J} / \mathrm{K})$, and $\mathrm{T}$ is the temperature of the system in $\mathrm{K}$.

\section{Nanoelectrode Voltammetry for Charge Tranfer Kinetics Determination}



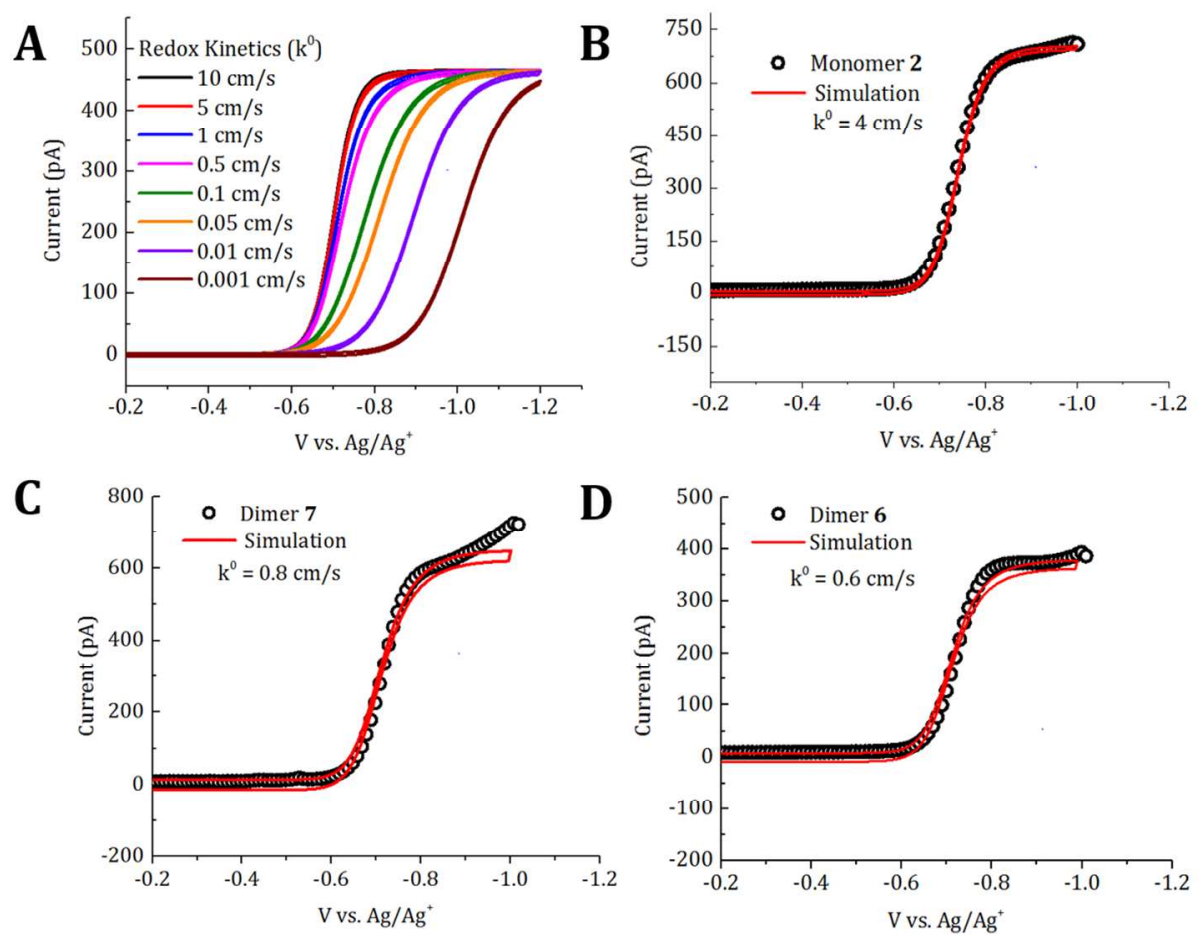

Figure S39: A. Cyclic voltammetry simulations in DigiElch (Gamry Instruments) of an arbitrary redox couple utilizing a $300 \mathrm{~nm}$ radius electrode with a concentration of active species of $5 \mathrm{mM}$ and a diffusion coefficient for both the oxidized and reduced species to be equal to $1 \times 10-5 \mathrm{~cm} 2 / \mathrm{s}$ at a scan rate of $50 \mathrm{mV} / \mathrm{s}$. The redox kinetics are swept to different magnitudes while everything else is held constant. B. Simulation and experimental voltammetry of viologen monomer 2 using a $300 \mathrm{~nm}$ radius electrode in acetonitrile with $0.1 \mathrm{M}$ TBA.PF6 electrolyte with $4 \mathrm{mM}$ viologen at a scan rate of $20 \mathrm{mV} / \mathrm{s}$. C. Simulation and experimental voltammetry of viologen dimer 7 using a $300 \mathrm{~nm}$ radius electrode in acetonitrile with $0.1 \mathrm{M}$ TBA.PF6 electrolyte with $4 \mathrm{mM}$ viologen at a scan rate of $20 \mathrm{mV} / \mathrm{s}$. D. Simulation and experimental voltammetry of viologen dimer 6 using a $300 \mathrm{~nm}$ radius electrode in acetonitrile with $0.1 \mathrm{M}$ TBA.PF6 electrolyte with $3 \mathrm{mM}$ viologen at a scan rate of $20 \mathrm{mV} / \mathrm{s}$. 

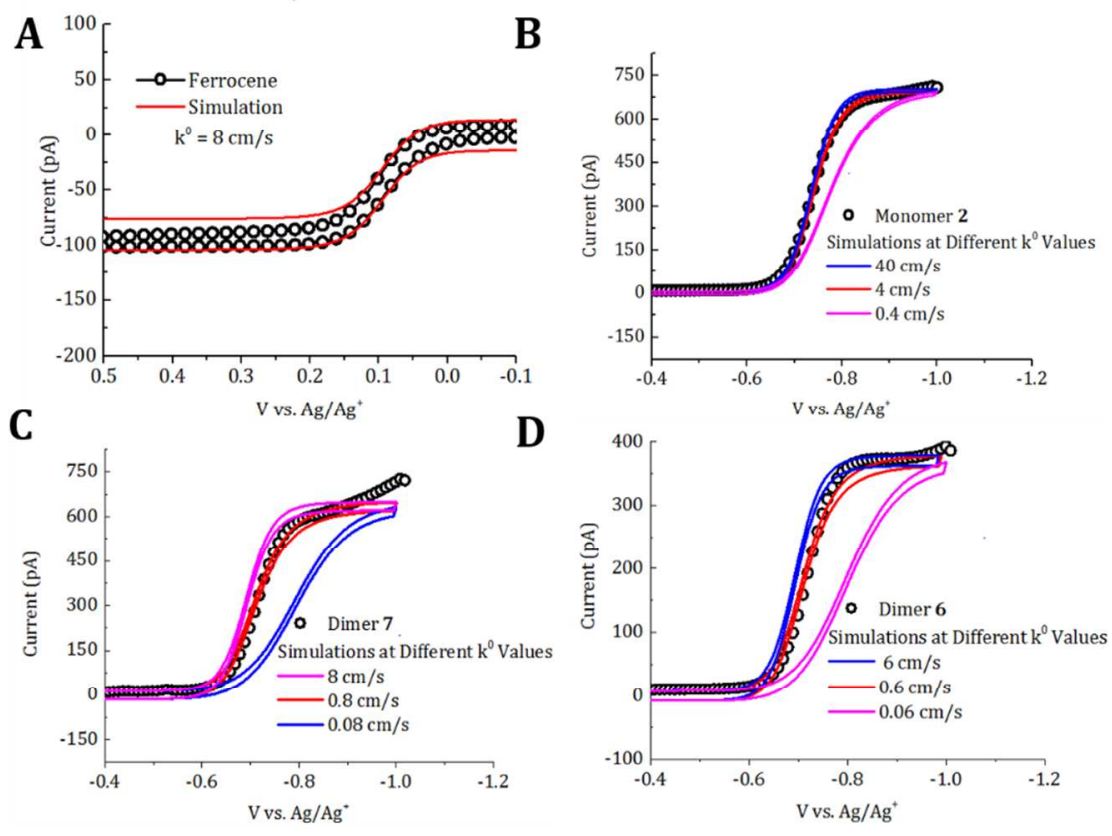

Figure S40: A. Simulation and experimental voltammetry of ferrocene using a $300 \mathrm{~nm}$ radius electrode in acetonitrile with $0.1 \mathrm{M}$ TBA.PF6 electrolyte with $0.5 \mathrm{mM}$ ferrocene at a scan rate of $20 \mathrm{mV} / \mathrm{s}$. B. Simulation and experimental voltammetry of viologen monomer 2 using a $300 \mathrm{~nm}$ radius electrode in acetonitrile with $0.1 \mathrm{M}$ TBA.PF6 electrolyte with $4 \mathrm{mM}$ viologen at a scan rate of $20 \mathrm{mV} / \mathrm{s}$. An order of magnitude of $\mathrm{k} 0$ higher and lower are shown to provide reference points. C. Simulation and experimental voltammetry of viologen dimer 7 using a $300 \mathrm{~nm}$ radius electrode in acetonitrile with $0.1 \mathrm{M}$ TBA.PF6 electrolyte with $4 \mathrm{mM}$ viologen at a scan rate of $20 \mathrm{mV} / \mathrm{s}$. An order of magnitude of $\mathrm{k} 0$ higher and lower are shown to provide reference points. D. Simulation and experimental voltammetry of viologen dimer 6 using a $300 \mathrm{~nm}$ radius electrode in acetonitrile with $0.1 \mathrm{M}$ TBA.PF6 electrolyte with $3 \mathrm{mM}$ viologen at a scan rate of $20 \mathrm{mV} / \mathrm{s}$. An order of magnitude of $\mathrm{k} 0$ higher and lower are shown to provide reference points. 

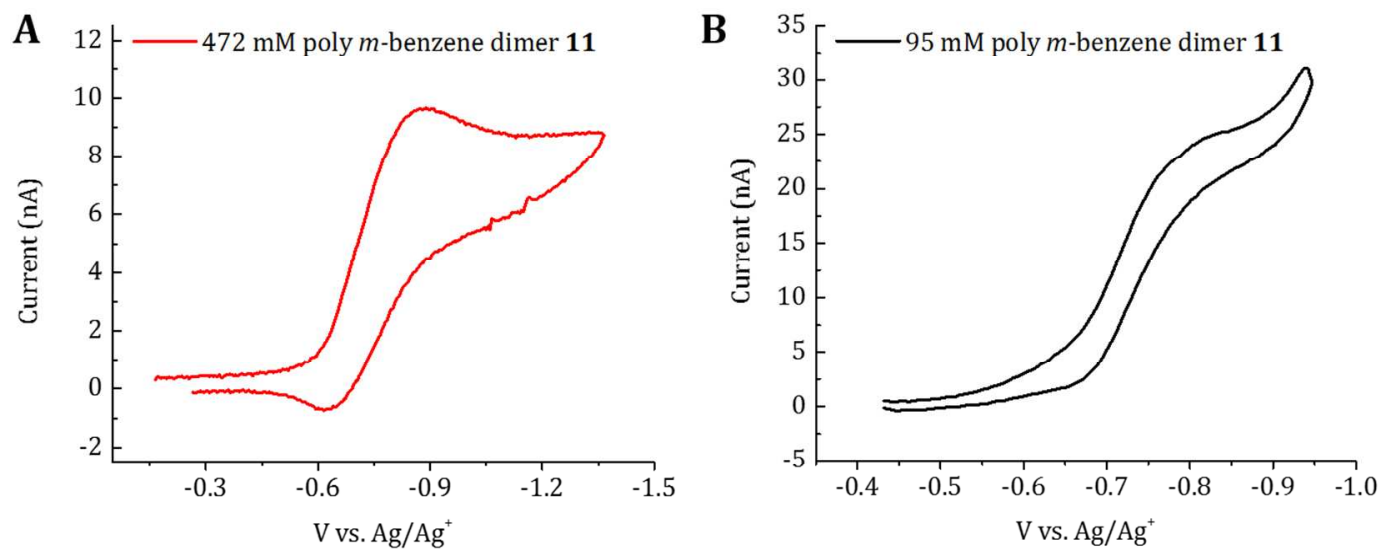

Figure S41. Resulting cyclic voltammograms for $m$-benzene polymer 11 in $\mathrm{LiBF}_{4} /$ acetonitrile for (A) $472 \mathrm{mM}$ of monomer with a resulting diffusion coefficient of $3.8 \times 10^{-8} \mathrm{~cm}^{2} / \mathrm{s}$ and (b) $95 \mathrm{mM}$ of monomer with a resulting diffusion coefficient of $6.5 \times 10^{-7} \mathrm{~cm}^{2} / \mathrm{s}$. The decreased current of the higher concentration RAP solution is primarily due to viscosity. We have measured the viscosity ratio of viologen RAP between $500 \mathrm{mM}$ and $100 \mathrm{mM}$ in $100 \mathrm{mM}$ supporting electrolyte to be $\sim 9$, which explains the order of magnitude difference in diffusion coefficients. To prevent any iR drop contributions all the measurements were done using a UME with a radius of $12.5 \mu \mathrm{m}$.

References

(1) Gottlieb, H. E.; Kotlyar, V.; Nudelman, A. J. Org. Chem. 1997, 62, 7512.

(2) Nagarjuna, G.; Hui, J.; Cheng, K. J.; Lichtenstein, T.; Shen, M.; Moore, J. S.; Rodríguez-López, J. J. Am. Chem. Soc. 2014, 136, 16309.

(3) Yus, M.; Foubelo, F.; García, D. Heterocycles 2009, 77, 991.

(4) Mannion, J. J.; Wang, T. S. Spectrochim Acta 1964, 20, 45.

(5) Katcka, M.; Urbanski, T. B. Acad. Pol. Sci. Biol. 1964, 12, 615.

(6) Ueno, Y.; Kawamura, A.; Takasu, K.; Komatsuzaki, S.; Kato, T.; Kuboe, S.; Kitamura, Y.; Kitade, Y. Org. Biomol. Chem. 2009, 7, 2761.

(7) Frisch, M. J.; Trucks, G. W.; Schlegel, H. B.; Scuseria, G. E.; Robb, M. A.; Cheeseman, J. R.; Scalmani, G.; Barone, V.; Mennucci, B.; Petersson, G. A.; Nakatsuji, H.; Caricato, M.; Li, X.; Hratchian, H. P.; Izmaylov, A. F.; Bloino, J.; Zheng, G.; Sonnenberg, J. L.; Hada, M.; Ehara, M.; Toyota, K.; Fukuda, R.; Hasegawa, J.; Ishida, M.; Nakajima, T.; Honda, Y.; Kitao, O.; Nakai, H.; Vreven, T.; Montgomery, J. A.; Peralta, J. E.; Ogliaro, F.; Bearpark, M.; Heyd, J. J.; Brothers, E.; Kudin, K. N.; Staroverov, V. N.; Kobayashi, R.; Normand, J.; Raghavachari, K.; Rendell, A.; Burant, J. C.; Iyengar, S. S.; Tomasi, J.; Cossi, M.; Rega, N.; Millam, J. M.; Klene, M.; Knox, J. E.; Cross, J. B.; Bakken, V.; Adamo, C.; Jaramillo, J.; Gomperts, R.; Stratmann, R. E.; Yazyev, O.; Austin, A. J.; Cammi, R.; Pomelli, C.; Ochterski, J. W.; Martin, R. L.; Morokuma, K.; Zakrzewski, V. G.; Voth, G. A.; Salvador, P.; Dannenberg, J. J.; Dapprich, S.; Daniels, A. D.; Farkas; Foresman, J. B.; Ortiz, J. V.; Cioslowski, J.; Fox, D. J. Wallingford CT, 2009.

(8) Zhao, Y.; Truhlar, D. G. Theor. Chem. Acc. 2008, 120, 215. 
(9) Marenich, A. V.; Cramer, C. J.; Truhlar, D. G. J. Phys. Chem. B 2009, 113, 6378.

(10) Kelly, C. P.; Cramer, C. J.; Truhlar, D. G. J. Phys. Chem. B 2006, 110, 16066.

(11) Bhattacharyya, S.; Stankovich, M. T.; Truhlar, D. G.; Gao, J. J. Phys. Chem. A 2007, 111, 5729 .

(12) Guerard, J. J.; Arey, J. S. J. Chem. Theory Comput. 2013, 9, 5046.

(13) Moens, J.; Geerlings, P.; Roos, G. Chem. Eur. J. 2007, 13, 8174.

(14) Borodin, O.; Behl, W.; Jow, T. R. J. Phys. Chem. C 2013, 117, 8661.

(15) Vollmer, J. M.; Curtiss, L. A.; Vissers, D. R.; Amine, K. J. Electrochem. Soc. 2004, 151, A178.

(16) Kelly, C. P.; Cramer, C. J.; Truhlar, D. G. J. Phys. Chem. B 2006, 111, 408. 